University of Tennessee Health Science Center

UTHSC Digital Commons

\title{
Characterizing Purkinje Cell Responses and Cerebellar Influence on Fluid Licking in the Mouse
}

Jeri Lonece Bryant

University of Tennessee Health Science Center

Follow this and additional works at: https://dc.uthsc.edu/dissertations

Part of the Medical Neurobiology Commons, and the Nervous System Commons

\section{Recommended Citation}

Bryant, Jeri Lonece, "Characterizing Purkinje Cell Responses and Cerebellar Influence on Fluid Licking in the Mouse" (2010). Theses and Dissertations (ETD). Paper 34. http://dx.doi.org/10.21007/ etd.cghs.2010.0038.

This Dissertation is brought to you for free and open access by the College of Graduate Health Sciences at UTHSC Digital Commons. It has been accepted for inclusion in Theses and Dissertations (ETD) by an authorized administrator of UTHSC Digital Commons. For more information, please contact jwelch30@uthsc.edu. 


\title{
Characterizing Purkinje Cell Responses and Cerebellar Influence on Fluid Licking in the Mouse
}

\begin{abstract}
Rodents consume water by performing stereotypical, rhythmic licking movements which are believed to be driven by central pattern generating circuits located in the brainstem. Temporal aspects of rhythmic licking behavior have been shown to be represented in the olivo-cerebellar system in the form of population complex spike activity. These findings suggest that the olivo-cerebellar system is involved in the generating circuitry responsible for licking rhythm in rodents. However, the representation of licking in the simple spike activity of Purkinje cells and the consequences of loss of cerebellar function on licking behavior has not been quantified. I investigated the influence of the cerebellum on the maintenance of rhythm in murine fluid-licking.
\end{abstract}

In one set of experiments, I characterized Purkinje cell activity in healthy mice during fluid licking. Use of a head-restrained preparation allowed recordings of well-isolated single units during repeated experimental sessions. Thus, a large number of neurons were tested for their relationship with behavior and detailed spatial maps of behavior related neuronal activity were generated as exemplified here with recordings from lick-related Purkinje cells in the cerebellum. The data show a multifaceted representation of licking behavior in the simple spike activity of a large population of Purkinje cells distributed across Crus I, Crus II, and lobus simplex of mouse cerebellar cortex. Lick related Purkinje cell simple spike activity was changed in a manner that was either rhythmic, in phase with the lick rhythm, or nonrhythmic with a decrease or increase in firing in relation to licks but not phasically. For rhythmically responsive units, signal modulation was marked by the introduction of a phasic variation in the frequency of spikes. A subpopulation of lick related Purkinje cells exhibited different activity patterns during short and long interlick intervals (ILIs).

I examined the role of the cerebellum in fluid-licking by using several models of cerebellar ataxia with distinct causes. First, I observed fluid-licking in animals over several days to determine how the microstructure of the behavior may also be altered. The first model involved animals that underwent cerebellectomies. Surgical removal of the cerebellum resulted in significant slowing of the lick rhythm but did not affect the mouse's ability to perform the gross licking movement. Thus, the cerebellum is involved in the modulation but not in the generation of the licking rhythm. Next, I observed changes to behavior in animals with a genetic cause to their ataxia, the Cerebellin1 (CBLN1) knockout and heterozygous mice (Morgan et al., 1988). The CBLN1 gene is a member of a family of proteins that have been found primarily in the Purkinje cell/parallel fiber synapse and is thought to stabilize the connection. Although removal of the gene does not alter the numbers of neurons or their spatial relations, the mutation results in moderate to severe ataxia. While these animals also varied significantly from their wild type counterparts in lick rate and microstructure, the changes were not all similar to the cerebellectomized model of ataxia. For example, cerebellectomized mice licked significantly slower with an average ILI of $135 \pm 8 \mathrm{~ms}$ (mean \pm S.D.) compared to $117 \pm 7 \mathrm{~ms}$ whereas in cbln1 $\mathrm{KO}$ had a faster lick rate $(110 \pm 4)$ than wild type counterparts $(121 \pm 6)$, with all of these values significant with $p<0.05$. These observations show that the removal of the normal functions of the cerebellum can alter fluid-licking resulting in bidirectional rate changes. An alternative possibility is that there may be compensatory process. Lastly, I used a chemically-induced model of cerebellar ataxia by injecting the GABA agonist muscimol in the medial and lateral deep cerebellar nuclei. This transient cerebellar ataxia resulted in a similar slowing of the licking rhythm as in the cerebellectomized mice with the eventual recovery of the fluid-licking behavior to normal as the effect of muscimol wore off.

My work to characterize the role of the cerebellum in the maintenance of fluid- licking rhythm and behavior microstructure has resulted in the development of experimental procedures for the recording of 
neuronal activity in awake and behaving mice. It is an important and necessary step towards neurophysiological investigation of normal and pathological mouse brain function. I have presented the first characterization of simple spike activity, the main cerebellar cortical output signal, during fluidlicking. Furthermore, my results show that the cerebellum is also involved in the control of fluid intake or homeostasis as the intervals between drinking events were abnormally long in mice with cerebellar ataxia. Electrophysiological recordings of individual Purkinje cells from the cerebellar cortex demonstrated variations in spike activity capable of influencing the rhythmicity of fluid licking. While licking still occurred with relative regularity in ataxic animals, the lick rates slowed significantly for mice with surgically induced ataxia and pharmalogically induced ataxia. For animals with a genetic origin to ataxia, lick rates increased. Regularity of licking remained evident despite the change in interlick interval duration. Any alteration of lick timing could ultimately affect the coordination of licking with other orofacial movements. Future investigations may benefit from this work by investigating if therapeutic interventions for cerebellar ataxias show a recovery of typical behavior or adapt the neurophysiological recordings to other behaviors in awake mice.

\section{Document Type}

Dissertation

Degree Name

Doctor of Philosophy (PhD)

\section{Program}

Biomedical Sciences

Research Advisor

Detlef H. Heck, Ph.D.

\section{Keywords}

cerebellum, fluid licking, mouse, oromotor behavior, Purkinje cell, rhythmicity

\section{Subject Categories}

Medical Neurobiology | Medicine and Health Sciences | Nervous System 


\title{
CHARACTERIZING PURKINJE CELL RESPONSES AND CEREBELLAR INFLUENCE ON FLUID LICKING IN THE MOUSE
}

\author{
A Dissertation \\ Presented for \\ The Graduate Studies Council \\ The University of Tennessee \\ Health Science Center
}

\author{
In Partial Fulfillment \\ Of the Requirements for the Degree \\ Doctor of Philosophy \\ From The University of Tennessee
}

By

Jeri Lonece Bryant

May 2010 
Portions of Chapter 1 and 3 (c) 2009 by Blackwell Publishing Ltd. Portions of Chapter 1, 2, and 4 (C) 2005 by Elsevier B.V.

Portions of Chapter 2 and 3 (C) 2005 by Elsevier B.V. All other material (c) 2010 by Jeri Lonece Bryant. 


\section{DEDICATION}

This dissertation is dedicated to my husband and son, David and Ari Wilcox, for their love and support in helping me to achieve a major goal. 


\section{ACKNOWLEDGEMENTS}

I would like to acknowledge everyone contributing to my completion of my dissertation. My research advisor, Dr. Detlef Heck, has truly been an important force in my perseverance through timely advice, patience, and his willingness to serve as a mentor in all aspects of my development as an independent researcher. I would like to thank Snigdha Roy for the ample assistance, numerous reviews of my texts, and friendship.

The University of Tennessee Health Science Center Department of Biomedical Instrumentation has provided helpful suggestions for the head-fixation assembly. I would like to thank the Tarnowski family for gift of the Edsel T. Bucovasz scholarship while I completed my studies. I would also like to thank American Psychological Association's Diversity Program in Neuroscience for the a year of funding through APA Fellowship R079008117 and the opportunity to receive neuroscience instruction at the Marine Biological Institute's summer SPINES program in 2007.

My graduate committee consisted of Dr. Hitoshi Kita, Dr. William Armstrong, Dr. Matthew Ennis, and Dr. Guy Mittleman. I thank them for guidance and commitment to my successful scientific progress. Your collective advice proved essential to the completion of my work. Lastly, I would like to acknowledge my family and friends for encouraging me to pursue my dreams. 


\begin{abstract}
Rodents consume water by performing stereotypical, rhythmic licking movements which are believed to be driven by central pattern generating circuits located in the brainstem. Temporal aspects of rhythmic licking behavior have been shown to be represented in the olivo-cerebellar system in the form of population complex spike activity. These findings suggest that the olivo-cerebellar system is involved in the generating circuitry responsible for licking rhythm in rodents. However, the representation of licking in the simple spike activity of Purkinje cells and the consequences of loss of cerebellar function on licking behavior has not been quantified. I investigated the influence of the cerebellum on the maintenance of rhythm in murine fluid-licking.
\end{abstract}

In one set of experiments, I characterized Purkinje cell activity in healthy mice during fluid licking. Use of a head-restrained preparation allowed recordings of wellisolated single units during repeated experimental sessions. Thus, a large number of neurons were tested for their relationship with behavior and detailed spatial maps of behavior related neuronal activity were generated as exemplified here with recordings from lick-related Purkinje cells in the cerebellum. The data show a multifaceted representation of licking behavior in the simple spike activity of a large population of Purkinje cells distributed across Crus I, Crus II, and lobus simplex of mouse cerebellar cortex. Lick related Purkinje cell simple spike activity was changed in a manner that was either rhythmic, in phase with the lick rhythm, or nonrhythmic with a decrease or increase in firing in relation to licks but not phasically. For rhythmically responsive units, signal modulation was marked by the introduction of a phasic variation in the frequency of spikes. A subpopulation of lick related Purkinje cells exhibited different activity patterns during short and long interlick intervals (ILIs).

I examined the role of the cerebellum in fluid-licking by using several models of cerebellar ataxia with distinct causes. First, I observed fluid-licking in animals over several days to determine how the microstructure of the behavior may also be altered. The first model involved animals that underwent cerebellectomies. Surgical removal of the cerebellum resulted in significant slowing of the lick rhythm but did not affect the mouse's ability to perform the gross licking movement. Thus, the cerebellum is involved in the modulation but not in the generation of the licking rhythm. Next, I observed changes to behavior in animals with a genetic cause to their ataxia, the Cerebellin1 (CBLN1) knockout and heterozygous mice (Morgan et al., 1988). The CBLN1 gene is a member of a family of proteins that have been found primarily in the Purkinje cell/parallel fiber synapse and is thought to stabilize the connection. Although removal of the gene does not alter the numbers of neurons or their spatial relations, the mutation results in moderate to severe ataxia. While these animals also varied significantly from their wild type counterparts in lick rate and microstructure, the changes were not all similar to the cerebellectomized model of ataxia. For example, cerebellectomized mice licked significantly slower with an average ILI of $135 \pm 8 \mathrm{~ms}$ (mean \pm S.D.) compared to $117 \pm 7 \mathrm{~ms}$ whereas in cbln1 $\mathrm{KO}$ had a faster lick rate (110 \pm 4$)$ than wild type counterparts $(121 \pm 6)$, with all of these values significant with $p<0.05$. These 
observations show that the removal of the normal functions of the cerebellum can alter fluid-licking resulting in bidirectional rate changes. An alternative possibility is that there may be compensatory process. Lastly, I used a chemically-induced model of cerebellar ataxia by injecting the GABA agonist muscimol in the medial and lateral deep cerebellar nuclei. This transient cerebellar ataxia resulted in a similar slowing of the licking rhythm as in the cerebellectomized mice with the eventual recovery of the fluid-licking behavior to normal as the effect of muscimol wore off.

My work to characterize the role of the cerebellum in the maintenance of fluidlicking rhythm and behavior microstructure has resulted in the development of experimental procedures for the recording of neuronal activity in awake and behaving mice. It is an important and necessary step towards neurophysiological investigation of normal and pathological mouse brain function. I have presented the first characterization of simple spike activity, the main cerebellar cortical output signal, during fluid-licking. Furthermore, my results show that the cerebellum is also involved in the control of fluid intake or homeostasis as the intervals between drinking events were abnormally long in mice with cerebellar ataxia. Electrophysiological recordings of individual Purkinje cells from the cerebellar cortex demonstrated variations in spike activity capable of influencing the rhythmicity of fluid licking. While licking still occurred with relative regularity in ataxic animals, the lick rates slowed significantly for mice with surgically induced ataxia and pharmalogically induced ataxia. For animals with a genetic origin to ataxia, lick rates increased. Regularity of licking remained evident despite the change in interlick interval duration. Any alteration of lick timing could ultimately affect the coordination of licking with other orofacial movements. Future investigations may benefit from this work by investigating if therapeutic interventions for cerebellar ataxias show a recovery of typical behavior or adapt the neurophysiological recordings to other behaviors in awake mice. 


\section{TABLE OF CONTENTS}

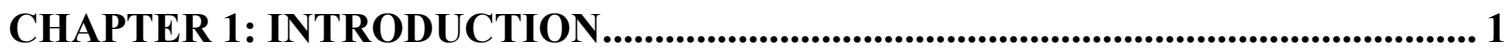

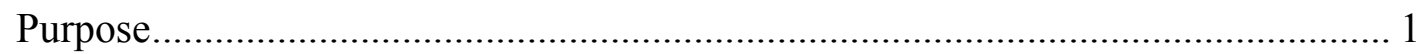

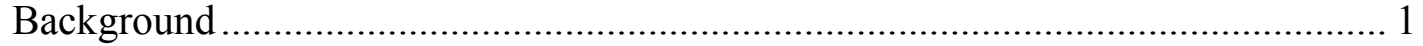

The Cerebellum and Movement.................................................................... 1

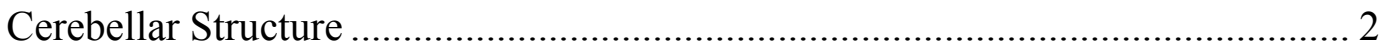

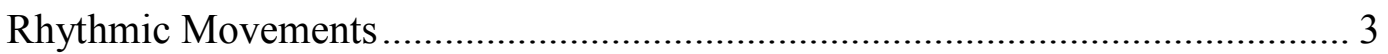

Research Objective and Specific Aims ............................................................ 6

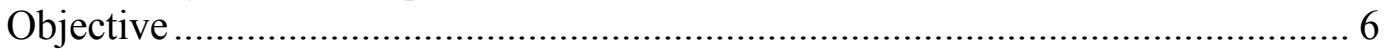

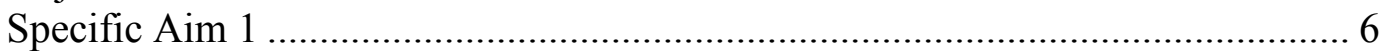

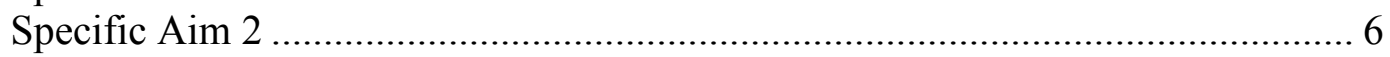

CHAPTER 2: EFFECTIVE METHODOLOGY........................................................... 7

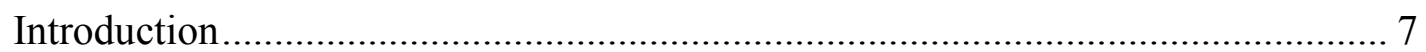

Necessity of an In Vivo Model..................................................................... 7

Adapting Primate Models to the Mouse ………….......................................... 7

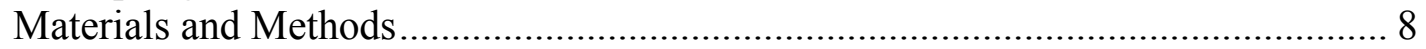

Surgical Procedure and Head-Fixation Assembly .............................................. 8

Training and Experimental Procedures........................................................... 12

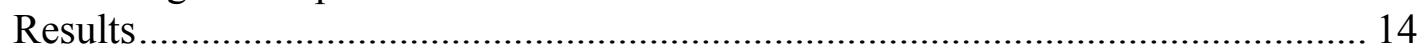

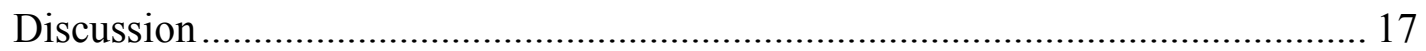

CHAPTER 3: PURKINJE CELL ACTIVITY DURING FLUID LICKING........... 21

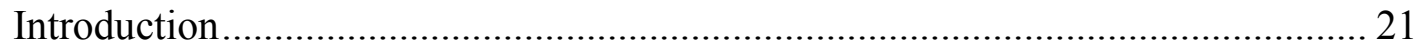

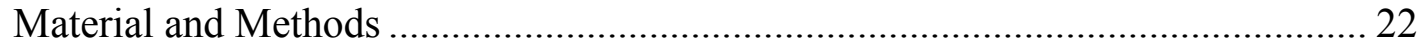

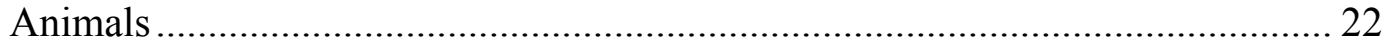

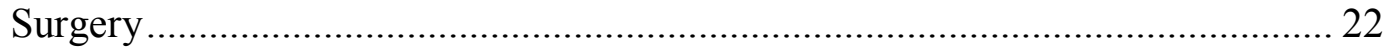

Electrophysiology and Behavior .................................................................. 23

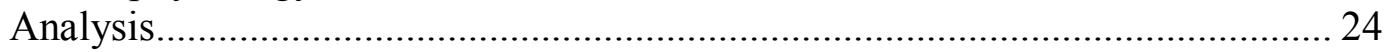

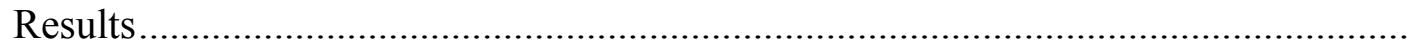

29

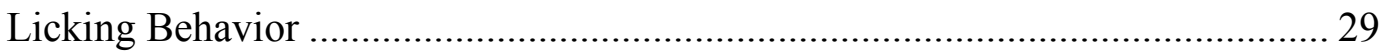

Spatial Distribution of Lick-Related Purkinje Cells ............................................... 29

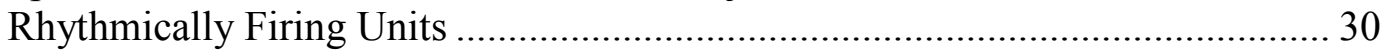

Spike Modulation at Lick Burst Onset............................................................. 32

Lick-Related, Nonrhythmically-Firing Units..................................................... 32

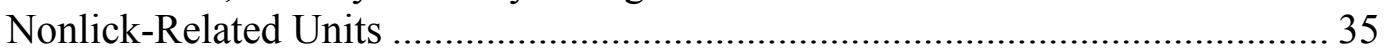

Spatial Distribution of Lick-Related Activity ....................................................... 35

Neuronal Representation of Interlick Interval Duration ........................................ 35

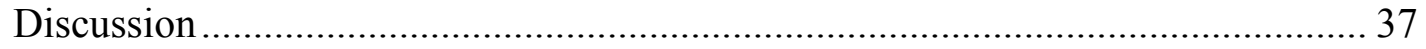




\section{CHAPTER 4: EFFECTS ON FLUID LICKING OF ALTERING THE}

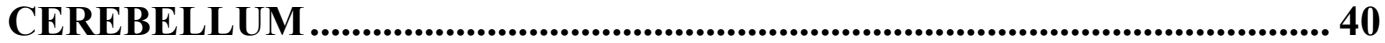

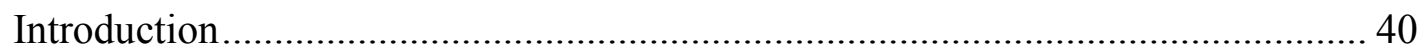

Materials and Methods................................................................................. 42

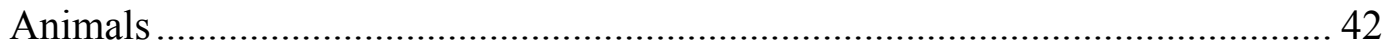

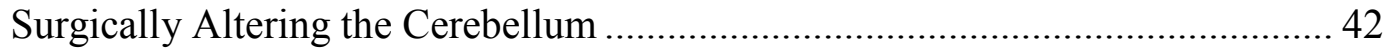

Genetically Altering the Cerebellum .............................................................. 44

Pharmacologically Altering the Cerebellum..................................................... 44

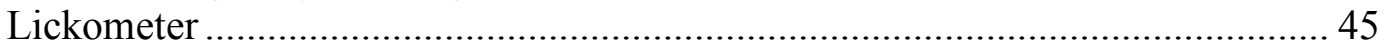

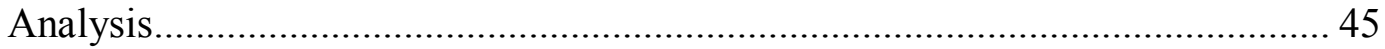

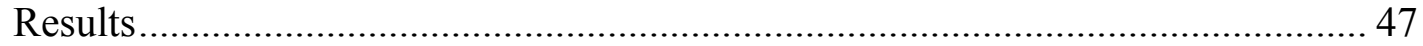

Licking Behavior in Cerebellectomized Mice ................................................... 47

Licking Behavior in Mice with a Genetic Origin to Cerebellar Ataxia................ 52

Licking Behavior in Mice with a Pharmacologically Altered Cerebellum........... 55

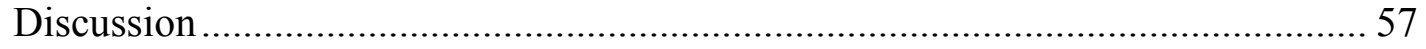

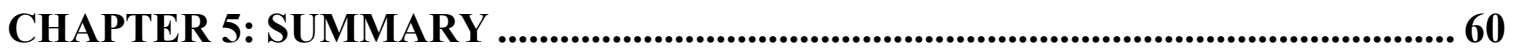

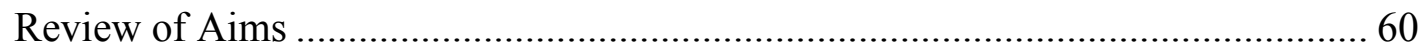

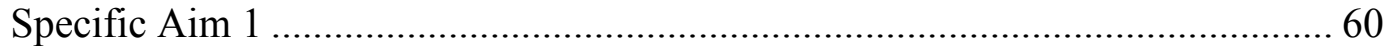

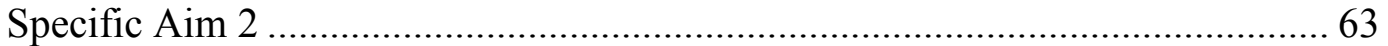

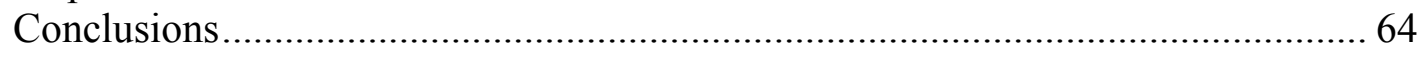

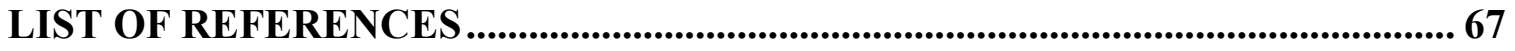

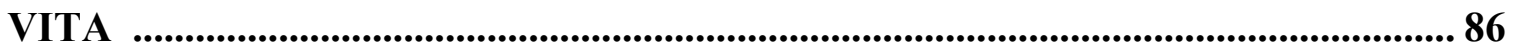




\section{LIST OF FIGURES}

Figure 2.1 Arrangement of headpost and recording chamber on the mouse's skull..... 10

Figure 2.2 Line drawing of the experimental setup................................................. 11

Figure 2.3 A train of licks simultaneously recorded with the junction potential method and with a commercial lickometer............................................... 15

Figure 2.4 Example of simultaneous recorded fluid licking and spike activity ............ 16

Figure 2.5 Correlations between spikes and licks ..................................................... 18

Figure 3.1 Temporal structure of licking behavior in mice.......................................... 25

Figure 3.2 Spike activity recorded during licking ................................................ 26

Figure 3.3 Summary of electrophysiological results................................................ 28

Figure 3.4 Scattergrams comparing the spike rates of single units before and

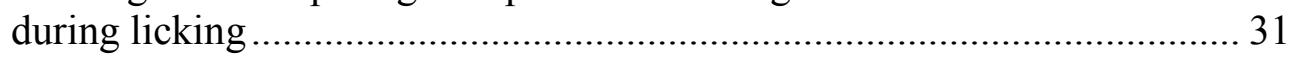

Figure 3.5 Lick-related, rhythmic single unit phase relationships to licking................ 33

Figure 3.6 Interlick interval duration is represented in Purkinje cell simple spike

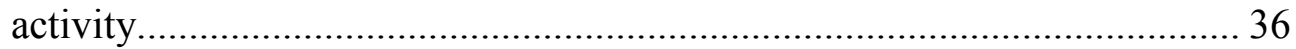

Figure 4.1 Whole brain images of the control and cerebellectomized mouse brain ..... 43

Figure 4.2 Experimental setup to measure lick events with a standard analog/digital (A/D) converter in the home cage....................................... 46

Figure 4.3 Transient inactivation of the interposed deep cerebellar nuclei and the removal of the cerebellum significantly slow licking rhythm ..................... 48

Figure 4.4 Mean volume of water consumed per lick decreases with an altered cerebellum

Figure 4.5 Intervisit intervals (IVI) distribution for cerebellectomized mice and age-matched controls. ........................................................................... 50

Figure 4.6 Microstructure of licking behavior in ataxic mice..................................... 51

Figure 4.7 Average ILIs in the mouse model of ataxia in a genetically altered

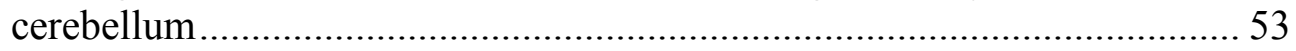

Figure 4.8 Purkinje cell electrophysiological response types ...................................... 54

Figure 4.9 Change in average ILI following microinjection........................................ 56 


\section{LIST OF ABBREVIATIONS}

\begin{tabular}{ll} 
CBLN1 & Cerebellin1 precursor/Precerebellin \\
CBX & Cerebellectomized \\
DCN & Deep cerebellar nuclei \\
GABA & $\gamma$-aminobutyric acid \\
HET & Heterozygous \\
ILI & Interlick interval \\
IVI & Intervisit interval \\
KO & Knockout (Cerebellin1 null mutant) \\
LFP & Local field potential \\
LPB & Licks per burst \\
LPV & Licks per visit \\
PC & Purkinje cell \\
RF & Reticular formation \\
SAL & Saline \\
WT & Wild type \\
\hline
\end{tabular}




\section{CHAPTER 1: INTRODUCTION}

\section{Purpose}

Background material describing the topics found within this dissertation is discussed within this chapter. The cerebellum influences movements through a network of connections to the brainstem and cerebral cortex. The focus of this work is to understand how the activity of Purkinje cells in the cerebellar cortex represents a rhythmic behavior known to originate from a brainstem central pattern generator, fluid licking; and how changes to the cerebellar circuitry affect this behavior.

\section{Background}

\section{The Cerebellum and Movement}

According the Principles of Neural Science (Kandel, Schwartz, \& Jessell, 2000a), the cerebellum is one of seven functionally distinct regions of the human brain and contains fifty percent of its neurons despite only being ten percent of its mass. The cerebellum is principally recognized for its role in motor learning and coordination (Marr, 1969; Albus, 1971; Mauk, Garcia, Medina, \& Steele, 1998), though other roles are attributed such as a contributor to the control of respiration (Cruz-Sanchez et al., 1997; Xu \& Frazier, 2002), integrator of spatiotemporal (Meek, 1992; Heck, 1996; Yarom \& Cohen, 2002) and sensorimotor information (Paulin, 1993). These roles allow the cerebellum to assist in error correction. Diseases that afflict the cerebellum are characterized by uncoordinated limb movement, aberrant changes in posture, hypotonia, or an abnormal gait (Diener \& Dichgans, 1988; Diener, Dichgans, Guschlbauer, Bacher, \& Langenbach, 1989; Dichgans \& Diener, 1989; Diener \& Dichgans, 1992; Thach, 1998). While problems with the extremities are a focus of cerebellar disorders, progression of disease may also lead to less common complaints like cognitive deficits, vision problems, problematic swallowing or dysphagia (Schmahmann, 2004; Gupta \& Marks, 2008). Although little research exists about the cerebellum and dysphagia, as evinced by a simple Pubmed search; national organizations that focus on treatment and coping with ataxia list problems swallowing as common concerns (Lederman \& Rosquist, 2004; Schut, 2008). A general diagnosis of cerebellar ataxia can also lead to dysfunctional movements, problems with balance, and aberrant speech patterns (Diener et al., 1992).

Historically, cerebellar function and structure have been elucidated through several insightful experiments. Luigi Rolando was the first to accurately describe the effect of cerebellar lesions on motor systems in 1809; though he wrongly deduced that movement originated from the cerebellum due to the profound effects he observed (Caputi, Spaziante, de Divitiis, and Nashold, 1995). Fifteen years later, Pierre Flourens clarified that cerebellar lesions did not paralyze animals but led to reduced coordination 
of movements and substantial recovery was possible after a lesion (Yildrim \&

Sarikcioglu, 2007). Several years later, Luigi Luciani would further classify the effects of cerebellar lesions (Morabito, 2000). The major symptoms were atonia, asthenia, and astasia which were seen in patients as a lack of muscle tone, weakness, and tremor. Gordon Holmes would apply these ideas to his clinical evaluations of soldiers with the pure cerebellar lesions (1917). Stimulation experiments in the motor cortex (Fritsch and Hitzig, 1870) led to increased interest in brain regions that could induce movement following stimulation (Lazar, 2009). Ferrier performed extensive studies in cerebellar stimulation and Lewandowsky used a method developed by Ewald (Clark, 1938) to stimulate the cerebellum of conscious, unrestrained dogs. More careful surgical techniques led to functional localization while better stains by Golgi and Ramon y Cajal led to a better understanding of the anatomy. Several case studies of cerebellar agenesis confounded beliefs about cerebellar function (Glickstein, Strata, \& Voogd, 2009). Szentágothai and Rajkovits used silver impregnation and stains to further knowledge of cerebellar anatomy (1958) while Eccles, Szentágothai, and Ito collected electrophysiological studies elucidating the inhibition and excitation within the cerebellar network and published a comprehensive book on cerebellar structure and function entitled The Cerebellum as a Neuronal Machine (1967). This knowledge of the cerebellum led to theoretical postulations by Marr that proposed that the cerebellum's primary purpose was learning (1969). Marr suggested that granule cell activity patterns could be altered to increase efficiency if they occurred with simultaneous climbing fiber input (1969). Albus (1971) suggested that long term depression was a more likely mechanism for inducing the learning thus setting the foundation to make plasticity a critical component to current understanding of cerebellar motor learning.

\section{Cerebellar Structure}

The mammalian cerebellar surface can be divided into two cerebellar hemispheres separated by the vermis. These regions can be further divided into lobes separated by fissures and differ in the types of afferents they receive. The highly-folded appearance of these regions is distinct to the cerebellum and the folds are called folia. The vermis primarily receives inputs pertaining to somatosensory information about the head, eyes, ears, and balance. The hemispheres, or cerebrocerebellum, receive input from the cerebral cortex. An additional lobule, the flocculonodular lobe, also known as the vestibulocerebellum, is considered the oldest region of the cerebellum and is responsible for balance and eye movement coordination.

The cerebellar cortex is a tri-layered structure with a five different neuron types organized in a distinct orthogonal arrangement. The first layer is the molecular layer. It is the most exterior and the only cell types that exist entirely within this layer are two types of inhibitory interneurons, the stellate and basket cells. This layer also houses the large dendritic arbors of Purkinje cells and axons of the granule cells. The excitatory axons are also known as parallel fibers due to their parallel arrangement with the folia. The inhibitory Purkinje cells have dendrites that are perpendicular to the parallel fibers. One of the two sources of inputs to the cerebellum, the climbing fibers of the inferior olives, 
terminates in this layer on the proximal dendrites of one to ten Purkinje cells. Below the parallel fibers is the Purkinje cell layer, and it consists of the cell bodies of Purkinje cells. These cells are GABAergic, inhibitory, and have somata that are approximately $65 \mu \mathrm{m}$ in diameter for humans. The axons are the only ones that leave the cerebellar cortex and they project through the underlying layer to the deep cerebellar nuclei. The most interior layer of the cerebellar cortex is the granule cell layer and this layer houses small granule cells and the occasional interneuron known as the Golgi cell. The afferents inputs from the pons, called the mossy fibers, end in this layer and climbing fiber inputs from the inferior olives traverse this layer to terminate on Purkinje cells. The deep cerebellar nuclei receive inputs from descending Purkinje cell axons. The hemispheres send their axons predominantly to the dentate nuclei of the cerebellum which is thought to be concerned with motor planning. While the most medial portion of the of the vermis projects to the fastigial nuclei. This nucleus along with the interposed nuclei, which receive inputs from the medial portions of the hemispheres, is responsible for the motor execution. The vestibular nuclei receive inputs from the flocullonodular lobe. This clearly defined structure, with known network connections, has made the cerebellum an often studied organ (Glickstein, Strata, and Voogd, 2009).

Investigating the prospect that the cerebellum is engaged during rhythmic behavior requires a focused approach. It is known that the cerebellum contains a homunculus (Thach, 1987; Rijntjes, Beuchel, Kiebel \& Weiller, 1999; Leergaard et al., 2000). Studies have used that homunculus to determine the region or regions that pertain to somatosensory responses. Previous research has shown that the crus I and crus II lobules of the right cerebellar hemisphere are of particular interest for neuronal activity association with orofacial stimulation (Tolbert, 1989; Rowland \& Jaeger, 2005), although these experiments are generally from the sensory aspect because they are performed in anesthetized rodents. While neuronal recordings from the cerebellar cortex could focus on any number of GABAergic interneurons, granule cells, or Purkinje cells; it is reasonable to focus on the Purkinje cell. First, Purkinje cells are the sole output neuron of the cerebellar cortex and therefore their activity is reflective of the result of signal processing in the cerebellar cortex. Secondly, the large cell bodies and distinctive firing patterns make them easily identifiable during extracellular recordings that require a blind approach of the neurons. That distinctive pattern consists of a high frequency baseline firing rate of simple spikes interrupted by the low-frequency complex spike (Thach \& Jones, 1979). Simple spikes are ultimately the result of mossy fiber inputs into the cerebellar cortex whereas the 1-5 Hz complex spike is spurred by the climbing fiber inputs from the inferior olive. The input of climbing fibers causes a temporary cessation in the firing of simple spikes which means that the complex spikes are usually followed by a pause in Purkinje cell firing for approximately $20 \mathrm{~ms}$.

\section{Rhythmic Movements}

Movements can be described as reflexive, voluntary, or rhythmic. The cerebellum and basal ganglia regulate the planning and execution of movement through direct inputs to projection neurons of the brainstem (Kandel, Schwartz, \& Jessell, 200b). Reflexive 
movements are considered involuntary and these do not require higher brain centers to occur. However, higher brain centers can affect the intensity of the movement. Voluntary movements are considered goal-oriented and can be improved through learning and repetition. The cerebellum is considered a brain center that contributes to this ability. Rhythmic movements have aspects of both voluntary and reflexive movements. They can be triggered by an external signal or a goal but typically involve the activation of underlying circuitry in the spinal cord or brainstem. For the rhythmic oromotor patterns of behavior, central pattern generators display oscillatory neuronal firing that stabilize motorneuron firing (Nistri, Ostroumov, Sharifullina, \& Taccola, 2006). Examples include chewing, swallowing, and scratching, and fluid licking.

Rhythmic oromotor behavior encompasses several different types of movements. Mastication, the sweep of whiskers, and licking are among the most prominent movements of orofacial origin in mouse. Kobayashi and colleagues made strides at a greater understanding of rhythmic jaw movements and found that the murine jaw opens and closes at an approximately $8 \mathrm{~Hz}$ cycle between two phases of incision and mastication during feeding (Kobayashi et al., 2002). This rate falls within the range of oromotor movement that occurs during fluid consumption in mouse. Rhythmic tongue movements must be carefully categorized. In humans, rhythmic tongue movement can be related to mastication, speaking, singing, and swallowing nutrients. These movements are considered critical to the survival of human infants because the rhythmic suckling that is reflexive to newborns allows them to seek nourishment from their mothers. The neonatal oral motor assessment scale has been in place for decades to provide a systematic method of evaluating how efficiently babies use their orofacial musculature (Case-Smith, Cooper, $\&$ Scala, 1989). The precision and speed with which humans engage in multiple orofacial movements are disrupted in many pathologies of a neurological origin which can greatly decrease the quality of life in patients (Sawczuk \& Mosier, 2001).

Licking behavior in animals must be further categorized because mice and rats use their tongues to self-groom, to participate in some social interactions, as well as to consume fluids. The work presented in this dissertation will focus on fluid licking although licking associated with grooming has been shown to be decreased in duration and bouts for Lurcher mice, animals with the deletion of the Delta 2 subunit of glutamate receptors, despite a relative preservation of the movements (Strazielle \& Lalonde, 1998). Fluid licking is a highly stereotyped behavior in rats, mice and many other mammals that involves the rhythmic co-ordination of muscle groups involved in tongue protrusion and retraction, jaw opening and closing and swallowing. The coordination of these oromotor movements is thought to be under the control of central pattern generators (CPGs), motor 'programs' extant among premotor neuron networks that send rhythmic inputs to motor neuron pools in cranial nerve nuclei V, VII and XII (for reviews see Nakamura \& Katakura, 1995; Travers et al. 1997). Current evidence suggests a substrate for rhythmic licking organized among premotor neurons in the medullary reticular formation (RF). Premotor neurons associated with intrinsic and extrinsic tongue muscles are located in a number of medullary and pontine RF cell groups (Kandel, Schwartz, \& Jessell, 2000b; Travers \& Rinaman, 2002). Neurons rhythmically active during licking are found in both the parvocellular and intermediate zones of the RF (e.g. Travers et al. 1997), and 
reversible lesion studies in awake rat preparations suggest a necessary role for the rostrolateral medullary RF (Chen \& Travers, 2003). However, the specific identity and physiological properties of the neurons and networks that underlie the CPG for licking are unknown.

Fluid-licking is used as a measure of taste preference (Belknap, Crabbe, \& Young, 1993; Smith, Volaufova, \& West, 2001) is well-studied, and has a known neuronal circuitry (Nakamura \& Katakura, 1995; Travers, DiNardo, \& Karimnamazi, 2000). The gustatory pathway includes peripheral inputs via several ganglia that terminate on the nucleus of the solitary tract, which in turn sends projections to the parabrachial nucleus, reticular formation, nucleus ambiguus, dorsal motor nucleus of the $\mathrm{X}$ cranial nerve, and the salivatory nuclei (Kandel et al., 2000b). The latter three focus on physiological reflexes while the reticular formation contacts the oromotor nuclei and can affect the onset of oromotor reflexes.

Typically, the behavior is most often studied in relation to the chemosensory properties of the tongue and taste cells. The fine-tuned taste discrimination in the taste cells have been used to train animals to produce certain tasks (Spector \& Travers, 2005; Spector \& Glendinning, 2009). The peripheral nervous system is not to be ignored as the nature of the fluid-licking experience for the animal may be affected by the ability of the animal to process the taste. Important factors include the ability to identify the stimulus, the motivation for ingestion, feed-forward physiological responses following fluid consumption, and other sensory experience such as olfaction and other nongustatory cues (Spector \& Glendinning, 2009). All of these factors can complicate interpretation of the behavior beyond the question of whether or not the behavior occurred. Regardless of the motivation, method of identifying the stimulus, and other contributing factors, once fluidlicking occurs, it followed a relatively stereotypical pattern of movement due to the motor pathway of the behavior having a central pattern generator (Travers, DiNardo, \& Karimnamazi, 1997; Smith, 2000).

The species of choice for investigating the physiological and anatomical substrates of licking has been the rat (Weijnen, 1998). Studies have also looked at pharmacologically induced changes to the behavior and striatal firing in rats. Cocaine was shown to not alter the overall lick rhythm but to lower the lick duration and while not changing the time to the next lick onset (Tang et al., 2008). Researchers have also shown that rat orolingual motor function have age-related components that trend towards a slowing down of lick rhythm and increased visit duration with age regardless of genetic backgrounds (Zhang \& Stanford, 2008). However, the study of strains of mice with different lick or ingestion rates holds substantial promise for genetic approaches to the study of oromotor CPGs (Okayasu, Yamada, Kohno, \& Yoshida, 2003; Tomiyama et al., 2004). Horowitz, Stephan, Smith, \& Whitney examined ad libitum fluid licking over a series of 20-h periods in nondeprived C57BL/6 (B6) and DBA/2 (D2) mice, and their F1 progeny, using an infrared-beam lickometer (1977). Local lick rate, as defined by interlick intervals less than $390 \mathrm{~ms}$ differed substantially between strains; B6 mice exhibited a slower lick rate (mean ILI - $124 \mathrm{~ms}$ ) than D2 mice (mean ILI - $97 \mathrm{~ms}$ ), and F1 mice expressed an intermediate rate (mean ILI $-109 \mathrm{~ms}$ ). These data indicated robust and 
genetically influenced differences in lick rate, and that the strain difference was stable over time and in response to different stimuli. Other strain differences in licking have been reported: Smith et al. (2001) showed a significant strain lick-rate difference between water-deprived inbred mice, with SWR/J mice possessing a shorter modal ILI (faster lick rate; $109 \mathrm{~ms})$ than $\mathrm{AKR} / \mathrm{J}$ mice $(129 \mathrm{~ms})$ in a short (30 s) trial. More recently, Dotson \& Spector (2005) assessed lick rate in four strains of mice (B6, D2, 129P3 and SWR) in a commercially available lickometer (Davis MS160). These strains differed significantly in terms of mean ILI when the analysis was limited to ILIs $50=200 \mathrm{~ms}$, with D2 and SWR mice licking significantly faster than the other strains.

\section{Research Objective and Specific Aims}

\section{Objective}

The experimental model used was fluid-licking in the mouse. The methods incorporated into this study allow for the extended monitoring of fluid-licking in a home cage environment in addition to simultaneous recording of licking behavior and neuronal activity (Hayar, Bryant, Boughter, \& Heck, 2006) in a head-fixed preparation. The consumption of fluid requires the coordination of the muscles involved in tongue and jaw movement (Weijnen, Wouters, \& van Hest, 1984). In the mouse, fluid-licking is an instinctually elicited behavior that is highly repetitive and easily quantified. The behavior can be observed in ataxic mice, as I will show. While the focus of the study was the elucidation of the cerebellum's influence on stereotypic behaviors, the choice of model provided insight into symptomatic complaints of the cerebellar ataxias involving problems with the coordination of orofacial musculature such as dysphagia or speech difficulties. This simple model thus provides a means of studying cerebellar function and dysfunction. I proposed the following specific aims to achieve a comprehensive understanding of the cerebellar cortex's influence on fluid licking behaviors:

\section{Specific Aim 1}

The first aim of this body of work was to test the hypothesis that the cerebellum modulates the rhythm observed during fluid licking and contains a neuronal representation of the behavior.

\section{Specific Aim 2}

The second aim of this body of work was to test the hypothesis that disruption of the cerebellar circuitry will significantly alter the observed temporal pattern of fluid licking in the mouse. 


\title{
CHAPTER 2: EFFECTIVE METHODOLOGY
}

\author{
Introduction
}

\section{Necessity of an In Vivo Model}

A central goal of brain research is to understand how the brain controls behavior and how the brain's ability to generate normal behavior is affected by brain disorders. Studies of behavior related neuronal activity in awake and behaving animals are necessary to accurately assess the complex interactions of neurons and their networks during the generation of behavior.

\section{Adapting Primate Models to the Mouse}

Although traditionally a domain of primate research, many fundamental questions about normal and pathological brain function can be successfully studied in small rodents. In fact, the development of genetic mouse models of human brain disorders now offers unparalleled opportunities to study the neuronal and behavioral defects associated with brain disorders. While the use of anesthesia alters the brain's mode of operation, sometimes producing results irrelevant for our understanding of the function of the conscious brain (Schonewille et al., 2006; Bengtsson \& Jorntell, 2007), recordings in awake, behaving mice avoid this issue.

Recordings of neuronal activity in awake mice (Mus musculus) have been successfully performed with permanently implanted electrodes to study hippocampal long term potentiation (LTP) based on local field potentials (LFPs) and multi-unit signals (Davis, Bliss, Dutrieux, Laroche, \& Errington, 1997; Errington, Bliss, Morris, Laroche, \& Davis, 1997; Jones et al., 2001; Schonewille et al., 2006). Advantages of this established technique are that it allows users to make long term observations of neuronal activity at one location and animals can behave more naturally as they move around freely. Limitations include that implanted electrode recordings are not suitable for mapping studies and that stable single unit recordings are more reliably and easily obtained in a head-restrained paradigm because of reduced tissue movements and because micromanipulators can be used for micrometer precise electrode placement. Furthermore, not all brain areas are as amenable to recordings with implanted electrodes as the neocortex and particularly the hippocampus. The cerebellum in particular seems to be able to move inside the skull, causing the stationary implanted electrodes to slice through and destroy the tissue as determined by the experience of my advisor. Using the headrestrained preparation described here overcomes the problems associated with tissue damage around permanent implants in regions subject to more motion, allows for multiple recordings from many neurons in the same animal, and could later be adapted to allow for the use of optical imaging methods and intracellular recording techniques in the awake mouse. Optical and physiological recordings from head-restrained mice have been 
performed by a small number of labs (Cheron et al., 2004; Goossens et al., 2004; Schonewille et al., 2006; Ferezou et al., 2007) and so far no comprehensive description of the experimental procedures involved is available in the literature. The experimental technique described here was initially developed to perform cerebellar recordings in awake behaving rats (Heck \& Sultan, 2002; Heck, Zhao, Roy, Ledoux, \& Reiter, 2008) and has been adapted for the performance of stereotaxic recordings from behaving mice during head fixation. The behavioral spectrum of head-restrained mice is limited, but the animals will perform spontaneous orofacial behaviors such as whisker movements (Ferezou et al., 2007) and rhythmic fluid licking (Hayar, Bryant, Boughter \& Heck, 2006). These behaviors also yield a large number of repetitions, which is an important prerequisite for electrophysiological investigations of the underlying neuronal processes. The method described in this chapter was the result of modifications to earlier applications and were applied to investigate the neuronal representation of rhythmic fluid licking behavior in the simple and complex spike activity of Purkinje cells in the mouse cerebellar cortex. Fluid licking has been studied in a variety of contexts, including studies of taste preference (Lewis et al., 2005), chronic or acute drug treatment (Hsiao \& Spencer, 1983; Genn, Higgs, \& Cooper, 2003), and to phenotype mouse models of autism spectrum disorders such as Angelman syndrome (Heck et al., 2008).

The rhythm or inter-lick-interval (ILI) of fluid licking in mice is strain-specific (Horowitz et al., 1977; Boughter et al., 2007). The experimental paradigm described here can therefore be useful for the investigation of strain differences in the neuronal mechanisms controlling the licking rhythm. This approach can be readily adapted for recordings from other brain areas of the mouse while monitoring either licking or other behaviors, like movements of the mystacial whiskers.

\section{Materials and Methods}

\section{Surgical Procedure and Head-Fixation Assembly}

All experiments adhered to procedural guidelines approved by the University of Tennessee Health Science Center Animal Care and Use Committee. Principles of laboratory animal care established by the Guide for the Care and Uses of Laboratory Animal (National Research Council, 1996) were followed.

The following procedures were successfully performed with adult mice from four different strains (C57BL/6J, DBA/2J, Cbln1 $1^{-/}$and Lurcher mice). Here we present data examples obtained from C57BL/6J mice. Prior to surgery, mice were weighed and then anesthetized with isoflurane or tribromoethanol (Avertin). Tribromoethanol was used for anesthesia in Lurcher mice because this strain had a very low survival rate with isoflurane. With Tribromoethanol as anesthetic $(250 \mathrm{mg} / \mathrm{kg}$, IP), survival rates for Lurcher mice went up to around $90 \%$. For all other strains, that tolerated it well, isoflurane was used because duration and depth of the anesthesia could be more accurately controlled with a vaporizer. Isoflurane anesthesia was induced in a chamber 
filled with a mixture of 3\% isoflurane in oxygen (isoflurane from Baxter Pharmaceutical Products, Deerfield IL) and maintained during surgery (via nose-cone) at 1.0-2.5\%. Isoflurane concentration was controlled with a vaporizer (Ohio Isoflurane vaporizer, Highland Medical Equipment, CA). Survival rates dropped markedly if the surgeries lasted significantly longer than $1 \mathrm{~h}$. Thus, considerable effort was made to reduce the time in surgery through careful preparation and practice of all critical steps. Also, during the last 10-15 min of the surgery, i.e. application of the acrylic cement and injections of fluid supplement and analgesic, isoflurane concentration was always lowered to $1 \%$. This measure reduced the time it took the mice to wake up from anesthesia.

The anesthetized mouse was mounted in a stereotaxic instrument with non-rupture ear bars (Zygoma ear cups, David Kopf Instruments, Tujunga, CA). Body temperature was monitored with an electronic rectal thermometer and maintained at $37-38.0{ }^{\circ} \mathrm{C}$ using a feedback controlled heating pad (FHC Inc., Bowdoinham, ME). The scalp hair at the surgical site was removed with a depilatory and the skin was treated with iodine solution (Xenodine, Veterinary Products Laboratory; Phoenix, AZ). A scalpel was used to make a $1-1.5 \mathrm{~cm}$ long midline incision in the scalp. The skin was retracted to expose the skull bone which was then cleaned of all tissue with a dental scraper and sterile cotton swaps. Three holes were drilled in the parietal and interparietal bones at the approximate positions indicated by the arrowheads in Fig. 2.1, using a $0.7 \mathrm{~mm}$ spherical stainless steel burr (SS White, Lakewood, NJ). Small machine screws (1/8' dome head, $0.8 \mathrm{~mm}$ diameter, 2 mm long, part number: MX-000120-01B, Small Parts, Inc., Florida, USA) were carefully fastened about $1 \mathrm{~mm}$ deep into the holes. To provide access to the brain area of interest, a circular opening of $34 \mathrm{~mm}$ diameter was drilled into the lateral interparietal bone, exposing part of the cerebellar hemisphere. The same size drill bit was used to drill the screw holes and the skull opening. If bleeding occurred, it was immediately stopped with either an electric cauterizer (Aaron medical, St. Petersburg, FL) or Gelfoam (Pfizer Inc., NY, NY). Great care was taken to leave the dura intact. Immediately after removing the bone the dura was covered with Triple Antibiotic Ointment (Walgreens, US) to prevent drying and infections. A cylindrical plastic recording chamber $(0.45 \mathrm{~cm}$ diameter and $8 \mathrm{~mm}$ height $)$ was fashioned from a drinking straw. Small curved scissors were used to shape the bottom of the chamber to fit the curvature of the bone. The chamber was treated with $100 \% \mathrm{ETOH}$, dried, and placed over the skull opening. A few drops of Vetbond tissue adhesive (3M St. Paul, MN) were applied to where the bottom rim of the chamber touched the skull bone. This served to hold the chamber in place until it would eventually be embedded in acrylic cement. The chamber was then filled with Triple Antibiotic Ointment, which would seal the chamber, keep the dura moist and prevent infections. The Triple Antibiotic Ointment had to be removed for each recording session and was replaced with new ointment upon the end of each session.

A stereotaxic manipulator was used to place a custom-made aluminum headpost (Fig. 2.1A and Fig. 2.2) in a stereotaxically defined position, relative to bregma. The right caudal corner of the post was placed at bregma as shown in Fig. 2.1D. Thus, the corresponding corner on the upper end of the headpost served as a stereotaxic reference for electrode placements during awake recordings. Finally, the chamber and headpost 

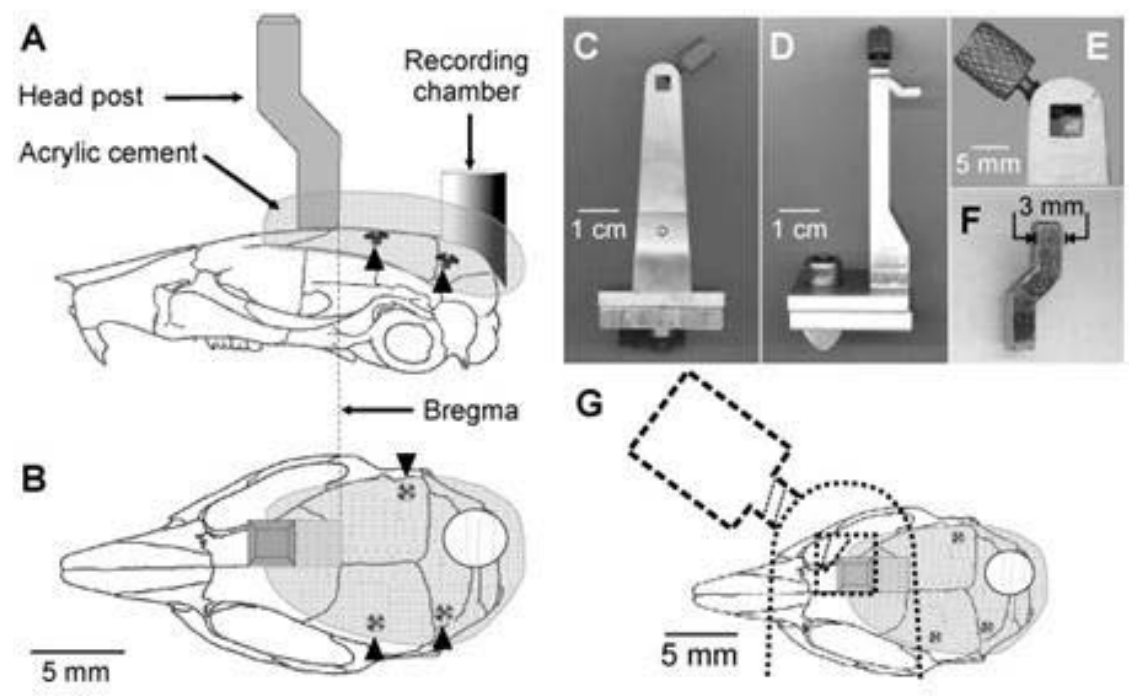

Figure 2.1 Arrangement of headpost and recording chamber on the mouse's skull.

All drawings are true to scale. (A) Side view of the skull with mountings. The headpost and recording chamber are embedded in acrylic cement, which is anchored to the skull with three screws, two of which are visible in this side view (black arrowheads). A stereotaxic micromanipulator was used to position the caudo-medial corner of the headpost on top of bregma. The vertical dashed line indicates the anterior-posterior coordinates of bregma. The recording chamber was fashioned from a drinking straw and the bottom was shaped with scissors to match skull bone curvature. The bend in the post increased the space between the recording chamber and the headpost clamp to allow unhindered access with recording equipment. (B) Top view of the skull showing the location of all three skull screws in relation to the headpost and chamber. This view illustrates that the headpost is optimally positioned in reference to the chamber. A craniotomy granted access to the underlying brain area (cerebellum shown here) through the intact dura. (C) Bottom view and (D) side view of the headpost clamp. In (D) the headpost is inserted into the opening as it would be during an experiment. The bend serves as a mechanical stop and determines how deep the post can be inserted. This allows the reliable reproduction of z-axis coordinates across experiments. (E) Enlarged top view of the headpost clamp with headpost (post contour marked with dotted line) held in the lower right corner by the set screw. (F) Enlarged view of the headpost, which was cut from a $3 \mathrm{~mm}$ thick aluminum sheet. The bend added three millimeters of distance between the headpost clamp and the recording chamber and determined how deep the post could insert into the clamping fixture. (G) A true-to-scale drawing of the headpost clamp and set screw (dashed outlines) and a mouse's skull with headpost and chamber. The 5-7 $\mathrm{mm}$ distance between the posterior edge of the clamping fixture and the recording chamber were sufficient for electrode access to the chamber. Reprinted with permission from Elsevier B.V. Bryant, J. L., Roy, S., \& Heck, D. H. (2009). A technique for stereotaxic recordings of neuronal activity in awake, head-restrained mice. J.Neurosci.Methods, 178, 75-79. 


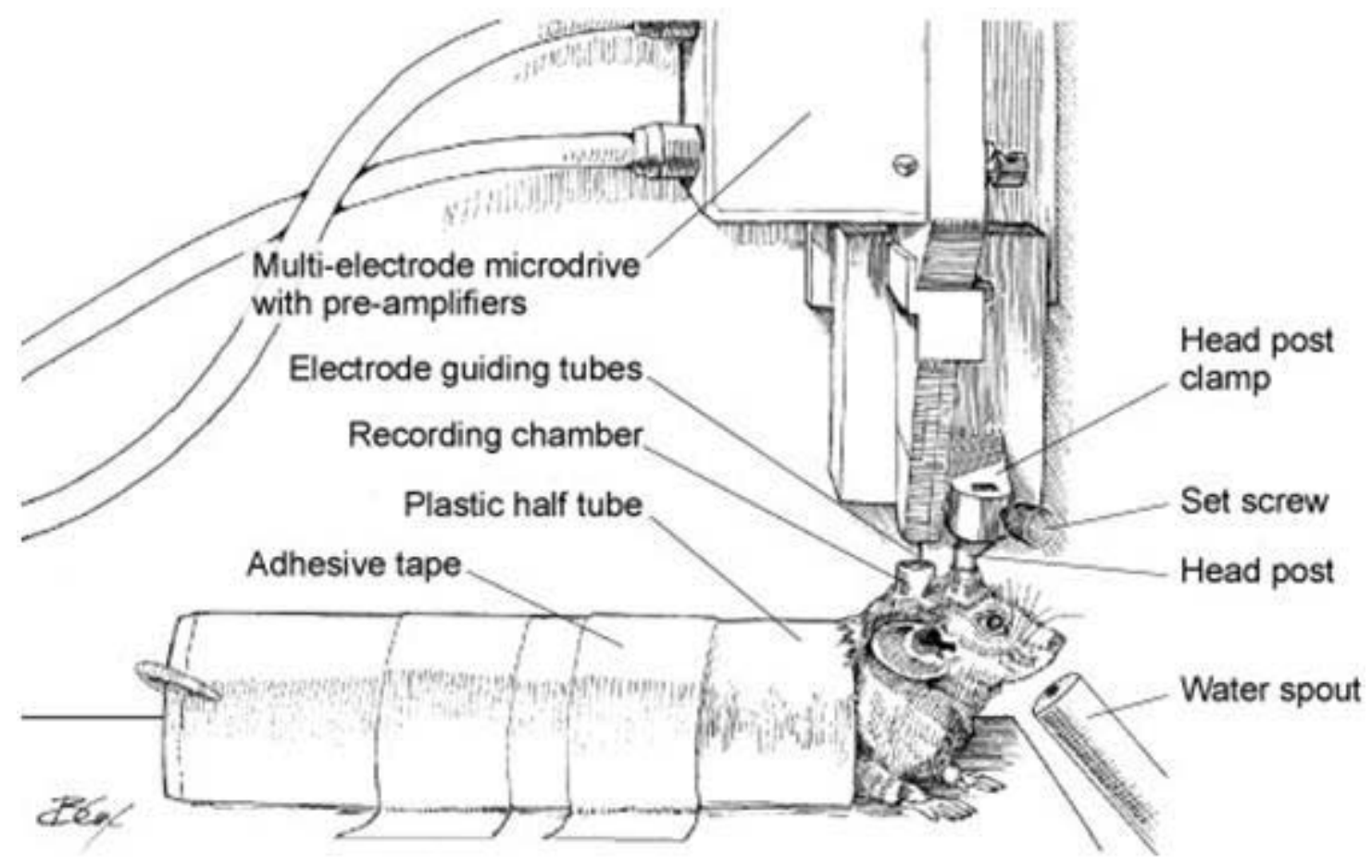

Figure 2.2 Line drawing of the experimental setup.

The recording chamber and headpost are embedded in acrylic cement and are firmly attached to the mouse's skull. The top of the headpost is inserted into the headpost clamp and held in place by a set screw. The mouse's body is covered with a loose fitting plastic half-tube ( $5 \mathrm{~cm}$ diameter, $10 \mathrm{~cm}$ long) to limit body movements. The half-tube is held in place with adhesive tape. A water spout is placed within tongue-reach $(4-6 \mathrm{~mm})$ in front of the mouse's mouth. A multiple-electrode microdrive with integrated pre-amplifiers is shown with the electrode guiding tubes inserted into the recording chamber. Reprinted with permission from Elsevier B.V. Bryant, J. L., Roy, S., \& Heck, D. H. (2009). A technique for stereotaxic recordings of neuronal activity in awake, head-restrained mice. J.Neurosci.Methods, 178, 75-79. 
were secured into place with dental acrylic (Teets methyl methacrylate denture material; CoOral-Lite Mfg. Co., Diamond Springs, CA, USA). At the end of surgery, mice were subcutaneously injected with $8 \mathrm{mg} / \mathrm{g}$ of the analgesic butorphanol tartrate (Torbugesic, Fort Dodge, USA) to alleviate pain. Body fluid was also supplemented towards the end of the surgery with subcutaneous injections of $0.5 \mathrm{ml}$ of lactated Ringer's solution. For the first hour after surgery mice were kept underneath a $250 \mathrm{~W}$ infrared heating lamp (at a distance of $50 \mathrm{~cm}$ ) to prevent a drop in body temperature during the recovery period. Butorphanol tartrate injections were repeated the next morning. Following surgery, mice were individually housed. After several days of recovery, animals were allowed to aclimate to the experimental conditions by being placed on the platform in the headfixed position shown in Fig. 2.2.

\section{Training and Experimental Procedures}

After a 3-4-day recovery period mice were adapted to the head-restrained experimental situation during 2 sessions of head fixation of 15 and 30 min duration performed on the same day at 8 a.m. (15 min session) and 4 p.m. (30 min session). During these sessions the head was held fixed and the body was covered with a loose fitting plastic half-tube ( $5 \mathrm{~cm}$ diameter, $10 \mathrm{~cm}$ long) to limit body movements (Fig. 2.2). Mice typically adapted to the head fixation within 2-3 sessions as judged from observations of markedly reduced walking and running movements during the third session compared to the first or second. After completing the adaptation procedure, access to water in the home cages was restricted until the next day, when the first experiment was performed. Controlling access to water was necessary in this paradigm to ensure that the mice would lick water during the experimental sessions. Mice consumed water during the experiments and during an hour of free access to water after each experiment. During the 5 days of the week water access was thus controlled. Over the weekend, animals had ad libitum access to water. Access to food was not restricted at any time. Body weight was constantly monitored to ensure that no weight loss greater than $10 \%$ of the initial body weight occurred.

During experiments the mouse's head was immobilized by affixing the headpost to a custom-made aluminum headpost clamp (Fig. 2.2), which was attached to a metal stand. The metal stand was attached to the surface of a vibration isolation table with 4 machine screws. Fig. 2.1 shows photomicrographs of the headpost clamp from underside (Fig. 2.1A); from the side (Fig. 2.1B) and of the headpost in the headpost clamp held in place by the diagonally arranged screw (Fig. 2.1C). The curved or bent aluminum headpost was cut out of a $3 \mathrm{~mm}$ thick aluminum sheet (Fig. 2.1D). The bend in the post served two purposes. First, it increased the distance between the headpost clamp and the recording chamber to provide sufficient room to access the chamber with a multielectrode drive. Secondly, it served as a mechanical stop when inserting the post into the headpost clamp, thus keeping the $z$-axis coordinate constant between experiments. All components of the head-fixation assembly were custom built by the machine shop of the Department for Biomedical Engineering at the University of Tennessee Health Science Center. Inserting the headpost of a mouse could be performed by hand for a mouse that 
was accustomed to the experimental sessions, which occurred after several sessions. Initially, the use of forceps greatly aids the process. These mice generally adapted to the experimental session within 1 day. We judged the improved adaptation or reduced stress level by the duration and amount of "escape attempts" in form or running movements performed while under head fixation. These occurrences of such movements are greatly reduced after 1 day of adaptation and decreases more during subsequent experimental sessions.

After the headpost was fixed, the mouse's body was covered with a plastic halftube ( $5 \mathrm{~cm}$ diameter, $10 \mathrm{~cm}$ long). The triple antibiotic filling was removed from the recording chamber. Then, the chamber was rinsed and filled with Ringer's solution. Recording electrodes (glass insulated tungsten/platinum, $80 \mu \mathrm{m}$ OD, impedance: $2-$ $12 \mathrm{M} \Omega$ ) were advanced through the intact dura into the brain using a computer controlled microdrive (MiniMatrix, Thomas Recording, Germany). Purkinje cells were identified based on their location and firing characteristics such as the presence of complex spikes as well as sustained high frequency simple spike firing rates (Thach, 1972). The raw spike signals were high-pass filtered $(300 \mathrm{~Hz}$ to $8 \mathrm{kHz})$ and amplified $230 \times$ (FA32 filteramplifier, Multichannel Systems, Germany). Filtered and amplified spike signals were digitized and stored on a computer hard disk (16 bit A/D converter, sampling rate $25 \mathrm{kHz}$ ) using a CED power1401 and the Spike2 software (both Cambridge Electronic Design, UK). Licking behavior was monitored using a junction potential based measuring device (Hayar, Bryant, Boughter, \& Heck, 2006c). Licking signals were neither amplified nor filtered, digitized at $2 \mathrm{kHz}$ and stored in the same file as the spike signals.

After a sufficient number of licks were performed $(n>50)$, the water spout was manually removed to interrupt the licking behavior before satiation. Then a new unit was sought by either advancing the electrode or by retracting it from the tissue and moving to a different site on the cerebellar hemisphere. Upon completion of each recording session, the Ringer's solution was removed and the recording chamber was again filled with triple antibiotic. To remove the mouse from the head-restrained position, the screw that held the headpost firmly in place was loosened. Usually the mouse would remove the post from the holder by lowering its head but the process could be aided by using forceps to push the headpost out of the holder. Mice were then returned to their home cages. Each animal typically participated in experiments for 3-6 weeks, reliably performing licking behavior during each recording session. Within this time-frame, triple antibiotic maintained the accessibility of the tissue by keeping the dura soft and free of infection.

Primary analysis of the electrophysiology involved identification of single units and the correlation of neuronal activity to the behavior. Software integrated algorithms in Spike2 (Cambridge Electronic Device, UK) could be used to identify spike signals and licks from the digitized data. We also performed a cross correlation of this baseline spike activity to time-shifted licks to provide a shuffling of spike activity and to yield the variability of the spike intervals during a period without licking. Average spike activity during licking was obtained from 10-30 s periods of an uninterrupted burst of licking. Correlation analysis was performed to determine if Purkinje cell spike activity was modulated during licking (Spike2 software, CED, UK). Baseline correlations were 
obtained by shifting the lick-event triggers in time to a period of the data that occurred when the animal was not licking and calculating correlations with spontaneous simple spike activity recorded during rest. This process takes the one of the two dynamically changing sets of data that may or may not be correlated in real-time and shifts it to allow for a correlation that is subtractable from correlated real time data. Basically, the time shifted correlation shows how the data sets compare to one another when there is no real correlation. This is similar to a shuffle-corrected cross correlation. Another benefit of this analysis is that is gives the researcher a measure of the chance occurrence of a correlation based on the activity of the neuron.

During the last experimental session, two or three small electrolytic lesions were set with a negative current injection $(-10 \mu \mathrm{A}, 10 \mathrm{~s})$ to stereotaxically defined locations using the headpost as a reference. The lesion sites were later used as reference points for mapping of the recording site coordinates onto the cerebellar cortex. Mice were euthanized with $2.5 \mathrm{~g} / \mathrm{kg}$ urethane and perfused with $3.7 \%$ formaldehyde. Following fixation, the brain was cut into $40 \mu \mathrm{m}$ coronal sections using a Vibratome Series 3000 Plus (Vibratome, St. Louis, MO), which were mounted and stained with cresyl violet.

\section{Results}

Junction potentials occur wherever dissimilar conductors are in contact. The voltage generated by the contact of the mouse tongue with the spout is due to the metalwater junction potential. Connecting the BNC core and shield directly with each other i.e. short-circuiting the input to ground - reduced the $60 \mathrm{~Hz}$ cycle noise in the acquired signal but produced no voltage change (Fig. 2.3). Also, connecting both poles of the BNC via a resistor of $1.5 \mathrm{M} \Omega$ produced no voltage change. However, a voltage change (100 $\mathrm{mV}-1000 \mathrm{mV}$ ) was produced when the core and shield of the BNC cable were connected to 2 stainless steel probes immersed in fluids capable of conduction. The duration of the voltage step corresponded to the duration of contact between the two probes. This occurrence can be extended to the mouse on a conductive surface connected to one probe that licks a water spout housing the other probe. Hence, the junction potential signal can be used to measure both the timing of licking activity as well as the duration of spout contact for each individual lick.

A threshold algorithm was used to detect and mark the ascending slope of the lick junction potentials (vertical lines in trace of Fig. 2.3B), which were used as temporal markers for time occurrence of licks. These lick onsets were correlated to the other licks so that the resultant autocorrelations could be used to determine the temporal regularity of the licking behavior. The intervals between adjacent lick onsets were considered an interlick interval (ILI). Stable recordings of isolated Purkinje cells during behavior were possible as seen in Fig. 2.4. This method supplied millisecond discrimination for the occurrence of spikes and lick onset. I also recorded the local field potential (LFP) to provide data on the synaptic activity of the neurons surrounding the targeted Purkinje cells during behavior were possible as seen in Fig. 2.4. This method supplied millisecond discrimination for the occurrence of spikes and lick onset. I also recorded the local field 


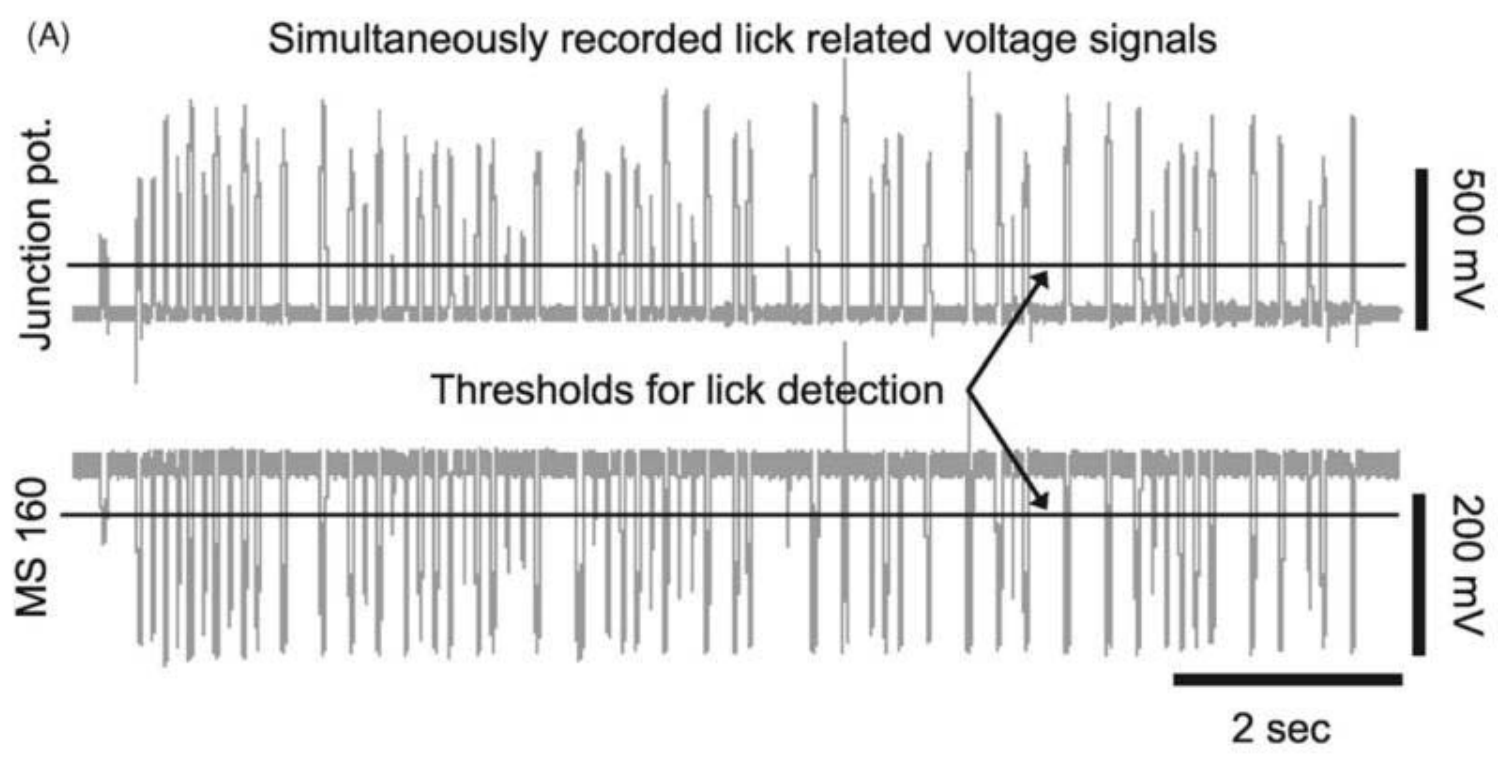

(B) Junction pot. Threshold detected lick events

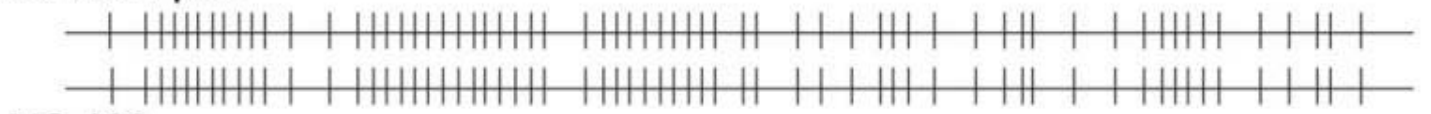
MS 160

\section{Figure 2.3 A train of licks simultaneously recorded with the junction potential method and with a commercial lickometer.}

The input of an A/D converter was connected to the water bottle spout and the ground to the metal cage wall of the MS-160 rig (DiLog Instruments, FL). The BNC output of the MS-160 was connected to a different channel of the same A/D converter and both voltage signals were simultaneously recorded while a mouse (BALB/cByJ female) licked water. (A) The junction potential method produced a positive voltage deflection, whereas the MS-160 produced a drop in voltage from $3 \mathrm{~V}$ dc signal. Fluctuations in amplitude are most likely due to differences in surface area of contact between the spout and the tongue. In control experiments using finger contact signal amplitude increased with increasing skin area contacting the spout. Connecting the A/D converter to the MS-160 considerably increased noise and amplitude fluctuations in licking related voltage signals. Signal-to-noise ratios for each method used by alone are significantly better. Licking events were detected using fixed voltage thresholds indicated by the solid lines. (B) Licking events detected by threshold crossings in the MS-160 and the junction potential signals are identical in timing and number. 


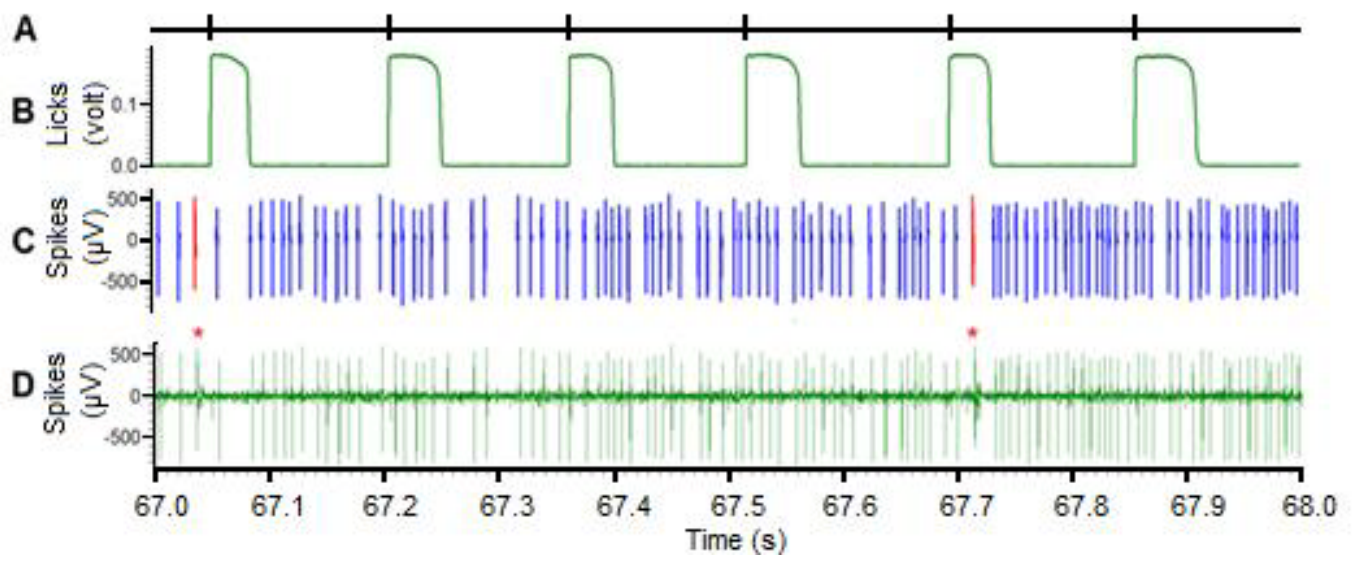

Figure 2.4 Example of simultaneous recorded fluid licking and spike activity.

One second of data showing a Purkinje cell spike train. (A) Individual lick onsets as defined by the junction potential rising through 0.08 volts. (B) Raw signal from the junction potential changes during water spout contact with the mouse's tongue. (C) Individual spikes as determined by a post process analysis of the raw signal as seen in D. The simple spikes are shown in blue while complex spikes are shown in red. (D) The raw spike signal isolated from a single Purkinje cell in the Crus I region of the right cerebellar hemisphere. The red asterisk marks above the signal show complex spikes. 
potentials (LFP) to provide data on the synaptic activity of the neurons surrounding the targetted Purkinje cell. LFP recordings yielded evidence of decreases in signal voltage that coincides with the time the tongue is touching the waterspout. At the end of each lick, LFP signal returned to a representative basal level. I was unable to determine if this change in signal was an artifact or a legitimate neuronal phenomenon although I resolved to treat the change as an artifact due to the inconsistency of the changes in multiple sessions.

An example of how this recording method was successfully combined with in vivo electrophysiological recording is shown in Fig. 2.4. It is important to note that the junction potential method described here either did not produce any detectable electrical artifacts in the spike signal recordings, or produced small artifacts that did not interfere with spike detection. The size of the artifact could be reduced to zero by improving the mouse-metal grid contact. Fig. 2.4 shows the spike activity of a Purkinje cell in Crus I of the right cerebellar hemisphere of a C57BL/6J mouse recorded during licking. This neuron did not show oscillatory spike activity during rest (data not shown) but clearly modulated its spontaneous firing rate in phase with the licking movement as shown by cross-correlation analysis in Fig. 2.5. Other cells recorded in the same area showed similar behavior $(n=4)$ but had different phase relationships between the rhythmic licking movement and spike rate modulation. These results indicate that the method described here is an accurate, yet inexpensive solution for electrophysiological investigation of the neuronal mechanisms underlying licking behavior.

\section{Discussion}

Lick sensors are valuable tools to study licking and drinking behavior (Weijnen, 1989). Commercially available lickometers come at a cost of a few to several hundred dollars (e.g., TSE systems, model 2.07, Midland, MI; Columbus Instruments drinkometer, Columbus, OH; Stoelting, model 57450, Wood Dale, IL; Med Associates Inc, model ENV-250, St. Albans, VT; Coulbourn Instruments, model H24-01, Allentown, PA; MS-160 Lickometer, DiLog Instruments, Tallahassee, FL). There are three different types of sensors in use: electrical, optical, and force sensors. They differ in the exact time of activation during the tongue protrusion/retraction cycle and precautions in the use of each type of sensor need to be taken. Weijnen (Weijnen, 1977; Weijnen and Mendelson, 1977; Weijnen, 1989; Weijnen, 1998) has published several excellent articles and reviews outlining the advantages and disadvantages of each type of lickometer. One method involves incorporating a miniature strain gauge in the drinking spout so that the pressure of each lick can be recorded (Vrtunski and Wolin, 1974). Movements of the tongue can also be detected when it crosses a light beam mounted in front of the drinking spout (Smith et al., 1992; Schoenbaum, 2001).

By far the most common method now in use involves passing an undetectable current $(<1 \mu \mathrm{A})$ through the drinking spout. When the animal drinks it becomes part of a circuit from the spout to the cage floor, which is grounded, and this change in conductivity is amplified, shaped, and recorded by a computer (Vajnerova et al., 2003). 

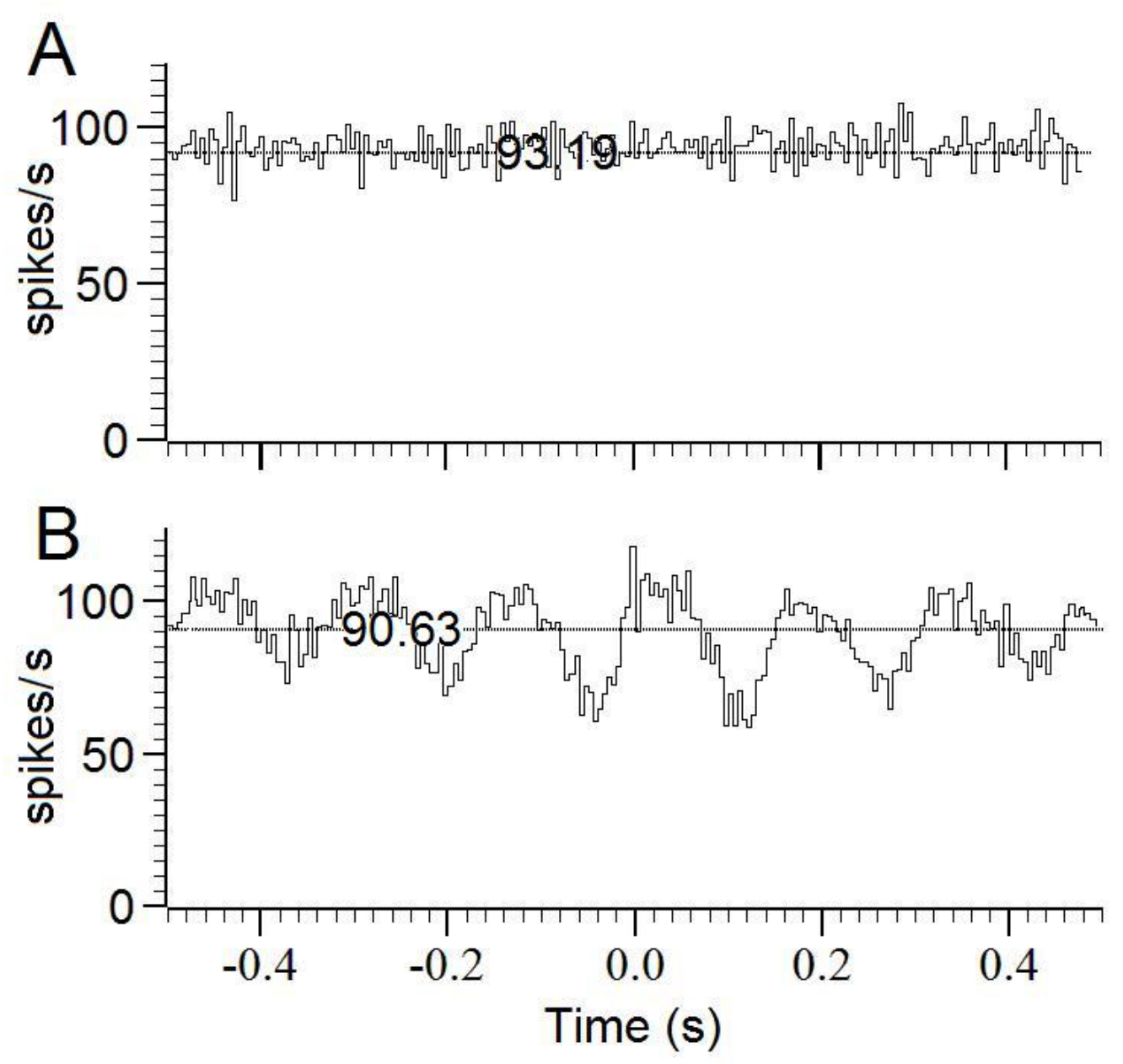

Figure 2.5 Correlations between spikes and licks.

(A) The correlation between spikes and time-shifted licks is shown for the neuron displayed in Fig. 2.4C. This correlation shows the firing activity and the variance that is typical of the neuron when the animal is at rest because spike activity is correlated to licks that have been shifted to a period in the data with no licks before the spikes, recorded in real time, were correlated to the licks. (B) The same simple spike unit is correlated to licking behavior as both occurred in real time. Certain characteristics of the real time correlation distinct from the correlation shown in A would allow this neuron to be classified as rhythmically correlated to fluid licking. While the mean spike frequency of the bins within the two correlations overlap the same range with a mean $\pm \mathrm{SD}$ of $93 \pm$ $10 \mathrm{~Hz}$ for $\mathrm{A}$ and $91 \pm 12 \mathrm{~Hz}$ for $\mathrm{B}$, the latter correlation meets specific criteria to be classified as rhythmic in that within the $500 \mathrm{~ms}$ around tongue contact, this correlation demonstrates multiple peak to trough transitions that extend beyond one standard deviation of the average frequency of the correlation. For these rhythmic units, the peak to peak distance was typical similar in value to the average interlick interval. Bin size is 5 ms in both correlation histograms. 
In this method, the animal tongue contact with the fluid or the fluid delivery device causes a change in voltage or capacitance (Hill and Stellar, 1951; Mundl and Malmo, 1979; Field and Slotnick, 1987; Weijnen 1989; Spector et al., 1990). Rats and mice appear to be unable to detect direct current in the sub- $\mu \mathrm{A}$ range (Weijnen, 1989; Gannon et al., 1992), so this approach is useful for behavioral experiments. However, even these very low currents may cause large noise artifacts in brain recordings, and thus, these methods alone are not suitable for neurophysiological studies (unpublished observations). Although a modification involving alterations in capacitance and the use of AC currents has been reported to work without causing noise artifacts, this method requires a relatively complex circuit (Mundl and Malmo, 1979). In order to overcome the disadvantages of the using electric sensors, Schoenbaum et al. (2001) recently developed an optical method for detecting licking behavior during recording of electrophysiological signals from the brain. This method, however, requires custom preparation of a drinking well and the purchase and adaptation of optical sensor equipment.

The method described here requires only a standard A/D converter, needs no additional equipment and performs as reliably as commercially available lickometers (Fig. 2.3). We suggest that our method mostly measures the metal-to-liquid junction potential which occurs between the water and the metal sipper tube (Fig. 2.1). The sipper tube is made of stainless steel, which contains in large part iron that can exist in solution as a doubly positively charged ("ferrous") ion or a triply positively charged ("ferric") ion. Such a system is often called a "redox couple", such as the "ferrous/ferric" couple. In addition to iron, stainless steel contains a minimum of $12 \%$ chromium, which makes it rust-resistant. Nevertheless, the chromium in the steel is also oxidized in water to form a thin, invisible layer of chrome-containing oxide, called the passive film. However, the exact nature of the redox reactions generating the metal-to-liquid junction potentials is unknown in our conditions. An additional junction potential most likely occurs at the junction between the animal and the ground. Replacing the aluminum foil with a stainless steel reference electrode inserted in the animal brain resulted in a reduced amplitude of lick related junction potentials $(50-150 \mathrm{mV})$. It is therefore possible that many factors affect the amplitude of the recorded junction potentials such as the area of contact, the humidity of the tongue, the conductivity of the mouse body, and the composition of the metallic probes. Investigation of these factors is beyond the scope of this study, but in subsequent recordings with a nonconducting sipper tube with an stainless steel wire inserted within the tube and the connection for the input provided similar results as a completely steel sipper tube but minimized the false licks that occurred by junction potentials created when the mouse's paw touched the tube.

The mouse closes the electrical circuit whenever the tongue touches the sipper tube or the water, thus creating a detectable junction potential at this interface. The junction potential is in the order of few hundred millivolts and can be digitized and analyzed without additional amplification. A fixed voltage threshold can be used to reliably detect lick onsets (Fig. 2.3). This method can be ideally combined with electrophysiological measurement of neuronal spike activity during the licking behavior (Fig. 2.2) because it produces no or only minor electrical artifacts and can be collected in the same data acquisition software as the neuronal signals. 
In summary, I adapted neurophysiological techniques readily applied to rats and primates to study behavior to the mouse. This adaptation also required that the behavior of interest be readily quantified. The use of the A/D converter for both the electrophysiological recordings and the lickometer proved advantageous in that I was able to optimize the space and resources to collect stable recordings. The lickometer performed in a manner consistent with the standards of established commercial devices. This method for acute stereotaxic recordings of neuronal activity from awake mice in a head-restrained paradigm is a critical step for ability to address the question posed in first specific aim of this work. The ability to maintain stable single unit recordings of neuronal activity of Purkinje cells in the mouse cerebellum during rhythmic fluid licking behavior was shown. Fluid licking, which is a natural and spontaneous behavior in rodents and is for several reasons ideally suited for neurophysiological investigations. It requires no training, can be readily quantified and mice generate large numbers of licks per experiment. Several aspects of fluid licking are under genetic control (Boughter et al., 2007) and fluid licking can be a sensitive phenotyping tool for the detection of subtle genetic differences (Heck, Zhao, Roy, LeDoux, \& Reiter, 2008). An important feature of acute stereotaxic recordings in head-restrained mice is that large numbers of different neurons can be tested and spatial maps of behavior related neuronal activity can be generated. The described technique can readily be adapted for recordings from other brain areas.

Genetically altered mice have become an important animal model for the investigation of genetic brain disorders. The development of techniques to record neuronal activity from awake and behaving mice, as described here, is a significant methodological advancement. It provides unique new opportunities for the investigation of normal and diseased brain function in animal models of human heritable brain disorder, currently not available in any other animal species. 


\section{CHAPTER 3: PURKINJE CELL ACTIVITY DURING FLUID LICKING}

\section{Introduction}

Licking constitutes an ideal behavioral paradigm for the study of motor control as it is a readily quantifiable and natural behavior in rodents. Evidence from physiological and anatomical studies suggests that licking movements are controlled by central pattern generator (CPG) circuits located in the brainstem (Brozek, Zhuravin, Megirian, \& Bures, 1996; Nakamura, Katakura, \& Nakajima, 1999). These rhythmically active circuits drive hypoglossal motor neurons that innervate orofacial musculature and are believed to be under modulatory control from supramedullary structures (Travers, DiNardo, \& Karimnamazi, 1997). Evidence for supramedullary control of licking was first seen in experiments involving intracortical microstimulation of the frontal cortex which initiated licking-like movements in anesthetized rabbits (Liu et al., 1993), and in lesion studies with rats which demonstrated impaired licking behavior after lesions in the frontal cortex (Whishaw \& Kolb, 1983). Electrophysiological recordings in freely moving rats also revealed an extended representation of licking in the lateral striatum (Mittler, Cho, Peoples, \& West, 1994). Later, a neuronal representation of the lick rhythm was found in the population complex spike activity of Purkinje cells in Crus II of the rat cerebellum (Welsh, Lang, Sugihara, \& Llinás, 1995; Lang, Sugihara, Welsh, \& Llinás, 1999). These last studies showed that distributed populations of Purkinje cells occasionally fired synchronized complex spikes during specific phases of the licking movement, with different populations synchronizing during different phases. Complex spikes are characteristic of Purkinje cell activity (Thach, 1968) and result from the inputs Purkinje cells receive from the inferior olive via climbing fibers (Palay \& Chan-Palay, 1974). The lick-related population complex spike activity suggests a role for the inferior olive cerebellar system in controlling licking behavior. According to influential theory of cerebellar function (Marr, 1969; Albus, 1971; and Ito, 1972) complex spikes are believed to deliver precisely timed "teaching signals" to the cerebellum which shape the high frequency simple spike output of Purkinje cells in cerebellar dependent forms of motor learning (Raymond, Lisberger, \& Mauk, 1996; Mauk \& Buonomano, 2004; Catz, Dicke, \& Thier, 2005). Here we asked how fluid licking is represented in Purkinje cell simple spike activity and how loss of cerebellar function affects licking behavior.

We used extracellular recording techniques in awake, head-restrained mice to record Purkinje cell simple and complex spike activity during fluid licking behavior in mice of the common strain C57BL/6J (B6) (Hayar et al., 2006). Based on the cross correlations of their simple spike activity to fluid licking, we identified two major classes of lick-related Purkinje cells, nonrhythmic and rhythmic firing cells. Simple spike activity in the rhythmically firing group was phase-locked to the lick rhythm on a cycleby-cycle basis. Both classes of lick-related cells were widely distributed across cerebellar lobules Crus I/II and lobus simplex and intermingled with Non lick-related cells. Interestingly, a subpopulation of rhythmic cells showed different activity patterns for short and long inter-lick interval durations, suggesting an involvement of these cells in cycle-by-cycle control lick timing. Fluid licking in rats has been shown to be tightly 
coordinated with swallowing and respiratory movements (Welzl \& Bures, 1977; Weijnen et al., 1984). Swallowing occurred during inter-lick intervals (ILIs) which were slightly longer than the average ILI, suggesting that the coordination of licking with swallowing is achieved by controlling the timing of licks to allow completion of swallowing during slightly longer ILIs. Here I propose that the cerebellum modulates the duration of lick intervals in order to coordinate licking with associated orofacial movements such as swallowing and breathing. Support for this possible new function of the cerebellum comes from clinical studies which have implicated the cerebellum in the modulation of respiratory behavior, orobuccolingual and pharyngeal motor control (Suzuki et al., 2003; Ramio-Torrentia, Gomez, \& Genis, 2006).

\section{Material and Methods}

\section{Animals}

Five adult male C57BL/6J (B6) mice (Jackson Laboratories, Bar Harbor, ME) were used as subjects in electrophysiological experiments. ( 8 weeks). Animals were housed in a temperature controlled vivarium under a 12:12 h light/dark cycle and had ad libitum access to food on all days. 12 hours prior to the first of 5 consecutive days of recording sessions, water access was granted on a restrictive schedule. During the 5 experimental days, all daily water was consumed during the experiments and during a 15 minute period with free access to water following the completion of recordings. If the body weight of a mouse fell to less than $90 \%$ of body weight measured before restricted access, its water intake was supplemented with additional access to water following recording sessions. All experiments adhered to procedural guidelines approved by the University of Tennessee Health Science Center Animal Care and Use Committee.

\section{Surgery}

Anesthesia was induced with 3\% Isoflurane (Baxter Pharmaceutical Products, Deerfield IL) and maintained with $0.5 \%-1.5 \%$ during surgery using an Ohio Isoflurane vaporizer (Highland Medical Equipment, CA). Body temperature was maintained between 36.5 and $38.0^{\circ} \mathrm{C}$ with a feedback controlled heating pad (FHC Inc, Bowdoinham, $\mathrm{ME}$ ). Once the mouse was positioned in a stereotaxic head mount and the anesthesia was applied (via nose cone), standard surgical techniques were used to secure 4 small machine screws in the skull (1/8' dome head, $0.8 \mathrm{~mm}$ diameter, $2 \mathrm{~mm}$ long, Small Parts, Inc, Miami Lakes, FL) and to perform a craniotomy exposing Crus I/Crus II of the right cerebellar hemisphere. The exposed dura was covered with Triple Antibiotic (Walgreens, US $)$ to keep the dura moist. A cylindrical plastic chamber $(0.45 \mathrm{~cm}$ diameter and $8 \mathrm{~mm}$ height) was fashioned from a drinking straw, treated with $100 \% \mathrm{ETOH}$, and placed over the skull opening. The chamber was filled with Triple Antibiotic to help keep the dura moist and to prevent infection. A stereotaxic manipulator was used to place a custommade square head post $(3.15 \times 3.15 \mathrm{~mm}, 16 \mathrm{~mm}$ high $)$ in a stereotaxically defined 
position relative to bregma. The chamber and head post were secured into place with dental acrylic (Teets methyl methacrylate denture material; CoOral-Lite Mfg. Co., Diamond Springs, CA, USA). Following surgery the mice were injected with $8 \mathrm{mg} / \mathrm{kg}$ Torbugesic (Fort Dodge, USA) to alleviate pain and with $0.5 \mathrm{ml}$ of lactated ringer solution (subcutaneously.) to supplement fluid. The triple antibiotic within the chamber was also regularly removed and replaced to ensure that the tissue was healthy. Mice were given 4-5 days of recovery.

\section{Electrophysiology and Behavior}

Mice were weighed each day prior to experiments. All recordings occurred during the light cycle. For the recording sessions the heads were immobilized by affixing the head posts with a machine screw to a custom-made stationary metal brace, which was mounted on the table. The mouse's body was covered with a plastic half-tube $(5 \mathrm{~cm}$ diameter, $10 \mathrm{~cm}$ long) to restrain body movements. The recording chamber was cleaned and filled with Ringer's solution. Recording electrodes (glass insulated tungsten/platinum, $80 \mu \mathrm{m}$ O.D., impedance: $2-12 \mathrm{M} \Omega$ ) were advanced into the brain using a computer controlled micro drive (MiniMatrix, Thomas Recording, Germany). Purkinje cells were identified based on their location and firing characteristics such as the presence of complex spikes as well as sustained high frequency simple spike firing rates between 20 and $200 \mathrm{~Hz}$. The raw signals were high-pass filtered $(300 \mathrm{~Hz}-8 \mathrm{kHz})$ and amplified (total: 230x) using a filter-amplifier (FA32, Multichannel Systems, Germany). Filtered and amplified voltage signals were digitized and stored on a computer hard disk (16 bit $\mathrm{A} / \mathrm{D}$ converter, sampling rate $>20 \mathrm{kHz}$ ) using a CED power 1401 and Spike 2 software (both Cambridge Electronic Design, UK). After recording 1.5-5 minutes of spontaneous neuronal activity while the animal was alert but at rest, the metal water spout of the lickometer was manually positioned in front of the mouse's mouth so that the mouse could easily reach the orifice with its tongue to lick water (a distance of $\sim 2-4 \mathrm{~mm}$ ). Licks were recorded in form of junction potentials created when the mouse touched the water spout with its tongue (Hayar, Bryant, Boughter, \& Heck, 2006). Water flow from the spout was controlled by applying positive pressure to the inside of the sealed water bottle using a $20 \mathrm{cc}$ syringe, connected to the bottle via a silicone tube.

The water spout was presented for approximately 100 seconds or until an adequate number of licks ( $\sim 60-80$ licks) was performed. In order to maintain the mouse's motivation to lick during an entire experimental session, the licks allowed in the 100second spout presentation were stopped after licks were in excess of 60 to prevent the mouse from achieving satiety before the completion of the experimental session. Licking behavior and Purkinje cell spike activity were recorded simultaneously and stored in the same data file. After a sufficient number of licks were performed, the water spout was manually removed or the water flow was interrupted to stop licking behavior. Recording of spontaneous spiking activity was continued for one to five minutes. Then a new unit was sought by either advancing the electrode or by retracting it from the tissue and moving to a different site on the cerebellar hemisphere. 
After completion of the recording session, the Ringer's solution was removed and the recording chamber was again filled with triple antibiotic. Mice were then weighed and returned to their home cages. Animals participated in experiments for 2 to 6 weeks. Anatomical verification of recording sites began with the injection of a negative current into $(-10 \mu \mathrm{A}, 10 \mathrm{~s})$ into stereotaxically defined locations using the bregma-centered head post as a reference. The lesion sites were used as reference points to map recording sites onto the cerebellar cortex. Mice were euthanized with $2.5 \mathrm{~g} / \mathrm{kg}$ urethane and perfused with a $3.7 \%$ formaldehyde fix. Following fixation, the brain was cut into $40 \mu \mathrm{m}$ coronal sections using a Vibratome Series 3000 Plus (Vibratome, USA), which were mounted and stained with cresyl violet.

\section{Analysis}

\section{Licking behavior}

The times of licks were marked when the ascending junction potential crossed a threshold of $0.08 \mathrm{~V}$. The tick marks in the upper trace of Fig. 3.1A each mark a lick onset. Enlarged in the trace below is a short piece of raw signal showing two brief lick clusters. Licking behavior was characterized by the mean and standard deviation of the inter-lick interval (ILI) distribution. A lick cluster may consist of a few to over one hundred licks. Clusters were defined as a train of licks with no ILI longer than $500 \mathrm{~ms}$. In order to determine whether changes in Purkinje cell activity precede or follow licks, the first licks of all clusters were marked so that a correlation analysis of "first licks" with Purkinje cell spike activity could be performed. To verify that licking behavior was not altered by the head-fixed experimental conditions, the licking behaviors of two animals were measured before surgery and compared with their performance during experiments. The mean inter-lick interval durations were the same under experimental and pre-surgery control conditions (Fig. 3.1B). Mean lick interval values of control and cerebellectomized mice were compared and tested for statistical significance using the paired t-test, where appropriate.

\section{Neuronal activity}

Single-unit simple and complex spikes of Purkinje cells were identified based on spike shapes using the Spike2 software (CED, Cambridge, UK) (Fig. 3.2B,C). The correlations of simple and complex spikes with licking behavior were analyzed separately using cross-correlation analysis (Spike2 and NeuroExplorer software from Nex Technologies, Littleton, MA) (Fig. 3.2D,E). Single-unit spike activity was characterized by 1) simple-spike amplitudes exceeding 6 standard deviations (SD) of the baseline signal voltage distribution measured during brief epochs without spikes and 2) by the presence of a refractory period of at least $2 \mathrm{~ms}$ as determined from the inter-spike interval distribution. If either of these criteria were not met, data were categorized as multi-unit activity. Occasionally movement artifacts occurred which compromised the careful analysis of spike activity, resulting in the exclusion of the data from further analysis. 

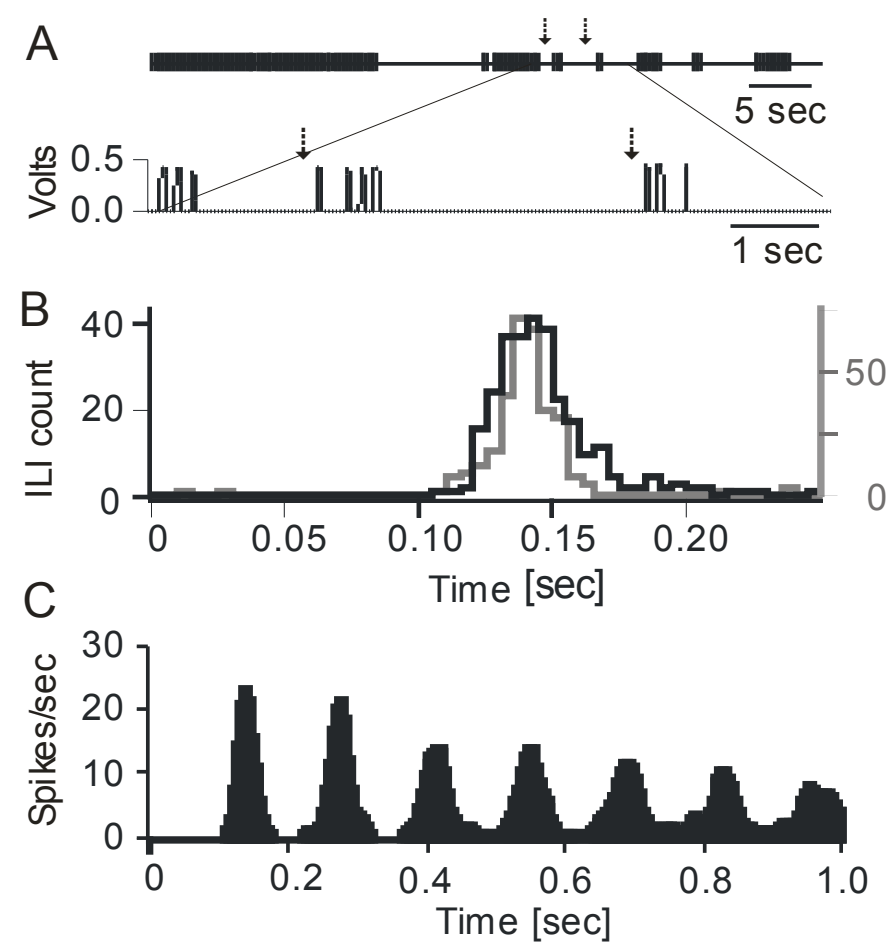

\section{Figure 3.1 Temporal structure of licking behavior in mice.}

(A) A typical raw data example of mouse licking behavior recorded during head-fixation. Each vertical line in the upper trace represents one lick. The lower trace shows the raw lick voltage signals corresponding to the area in the upper trace indicated by the lines. Lick times were marked at the ascending slope of the voltage step, i.e. at the beginning of the tongue to waterspout contact. Typically mice licked in bursts of licks with the number of licks per cluster being highly variable. The upper row shows 7 lick clusters. The lower row shows on an expanded time scale the last few licks of the second cluster and the very short clusters 3 and 4. (B) Inter-lick interval distributions of licking behavior recorded prior to surgery (black) and during a typical experimental session involving head fixation and recording of neuronal activity. The two distributions are nearly identical, indicating that head fixation did not affect licking behavior. (C) The autocorrelation analysis of the licking behavior shown in A shows multiple equidistant side peaks, indicative of a highly regular lick rhythm. 


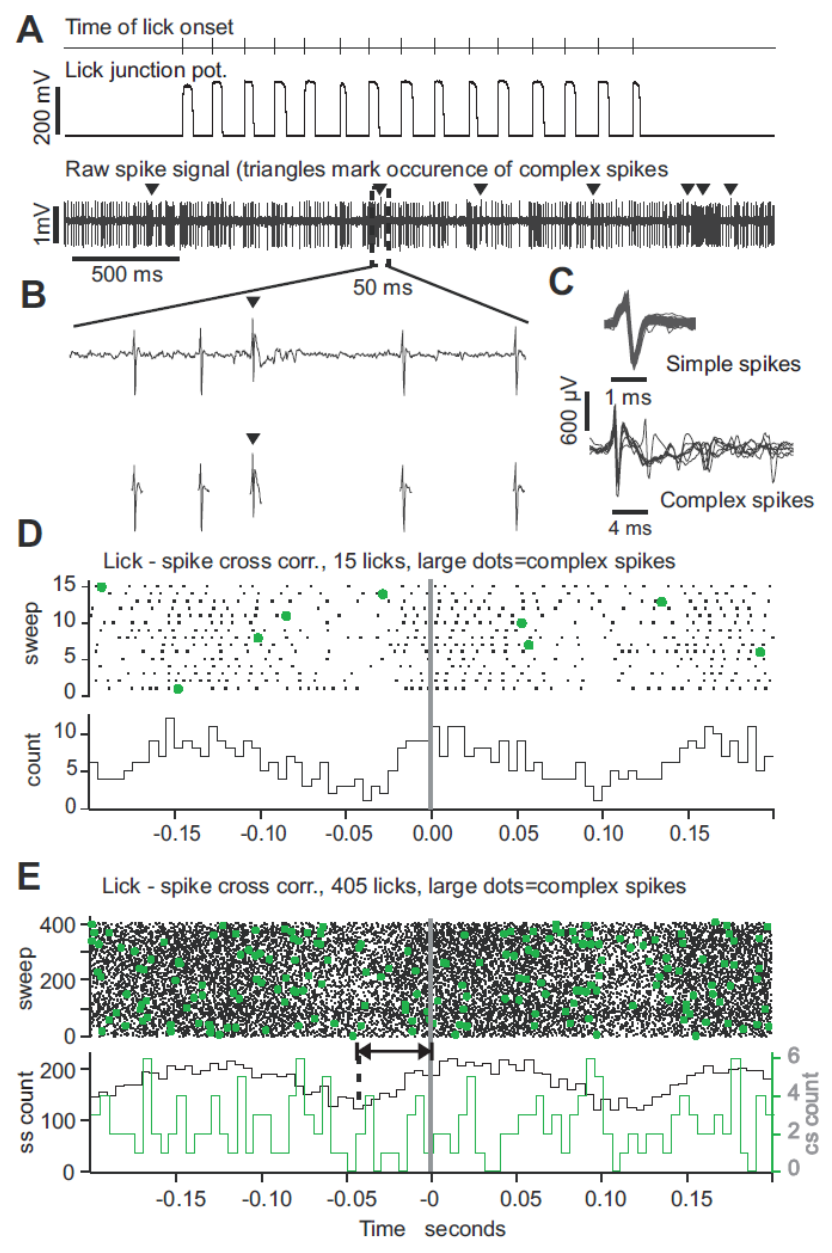

\section{Figure 3.2 Spike activity recorded during licking.}

(A) The tick-marks in the top row show the times of lick onset, i.e. when the tongue touched the water spout. The middle row demonstrates the raw junction potential signals generated by 15 licks. The lower row shows the simple and complex spike activity of a Purkinje cell recorded simultaneously with the licks. Arrows mark the occurrence of complex spikes. (B) Expansion of spike signal showing examples of simple and complex spikes in the top row. Second row: separation of simple and complex spikes based on differences in spike shapes. (C) Ten superimposed simple spikes (top) and ten superimposed complex spikes (bottom) from the data in A and B. Arrows point a difference between the two spike shapes. (D) Lick-spike cross correlation calculated during the cluster of 15 licks shown in A. Zero marks lick onset time. The green circles in the raster plots represent the complex spikes. (E) Cross correlation analysis of spiking activity of the same neuron but for $>400$ licks. All cross correlation histograms show the frequency for spikes in $5 \mathrm{~ms}$ bins. 
For each recording site the baseline spike rate (mean +/- SD) was obtained from the $100 \mathrm{~s}$ period preceding the animal's access to the water spout. From observations of spike activity changes made during rhythmic licking behavior it is impossible to determine whether activity changes follow or precede licking movements. We therefore performed a separate analysis in which we correlated Purkinje cell simple spike activity exclusively with the "first licks" of lick clusters.

Finally, we determined if the duration of inter lick intervals was represented in the simple spike firing rates of Purkinje cells. For this analysis we converted the spike trains to continuous rate functions by calculating the number of spikes around each sampling point $(+/-20 \mathrm{~ms}$ ) weighted by a Gaussian with a standard deviation of $3 \mathrm{~ms}$. The parameters of the function were optimized for the choice in sampling point intervals and the smaller variation among ILIs used for the rate comparisons. The 20-30 shortest and longest inter-lick intervals within the ILI distribution were identified and the interval onsets (i.e. tongue to water spout contact time of the first lick) were used for the temporal alignment in the calculation of the average rate trajectories. Average rate trajectories were calculated for a 40 millisecond time window starting 10 milliseconds prior to interval onset.

\section{Classification of Purkinje cell firing patterns}

We identified three major types of Purkinje cells based on their firing patterns during licking behavior. These types were defined as follows: 1) lick-related rhythmically firing, 2) lick-related nonrhythmically firing and 3) non lick-related cells. To be classified as lick-related, the real time cross-correlation had to reveal either a peak or a trough that extended beyond $1 \mathrm{SD}$ of the mean firing frequency in the correlation histogram. Units that met this first criterion could be further divided. The first class, rhythmically firing units, were classified as strongly lick-related if the real time cross correlation demonstrated multiple peak to trough transitions where the peak and the troughs were at least one standard deviation away from the mean firing frequency of the unit in the lickspike cross correlation histogram (expressed in spikes/sec) (Fig. 3.3A, B). Some units demonstrated the multiple and phasic peak to trough transitions but this variation in the spike frequency did not extend beyond $1 \mathrm{SD}$. The units were labeled as weakly-correlated rhythmic units. At least 3 peaks with inter-peak intervals matching the mean inter-lick interval (Fig. 3.3D) were typical of these rhythmic units. For the lick-related, nonrhythmic units, the neurons did have a peak or trough with a value that had an absolute value greater than $1 \mathrm{SD}$ away from the mean firing rate of the unit during activity. While a unit may have had more than one peak or trough with values more than $1 \mathrm{SD}$ away from the mean, these variations were not consistently spaced and usually these changes were found with $10 \mathrm{~ms}$ of lick onset. Units which had neither correlation peaks nor troughs exceeding 1 SD nor fitted the classification for "weakly modulated" were classified as non lick-related (Fig. 3.3C). As a quantitative measure for the phase relationship between rhythmic simple spike rate modulations and rhythmic licking behavior, delays between the lick onsets and the peaks or troughs of the spike-lick crosscorrelations were measured. We determined the delays between the temporal align (time zero $=$ lick onset $)$ and the nearest minimum and maximum in the cross correlation 

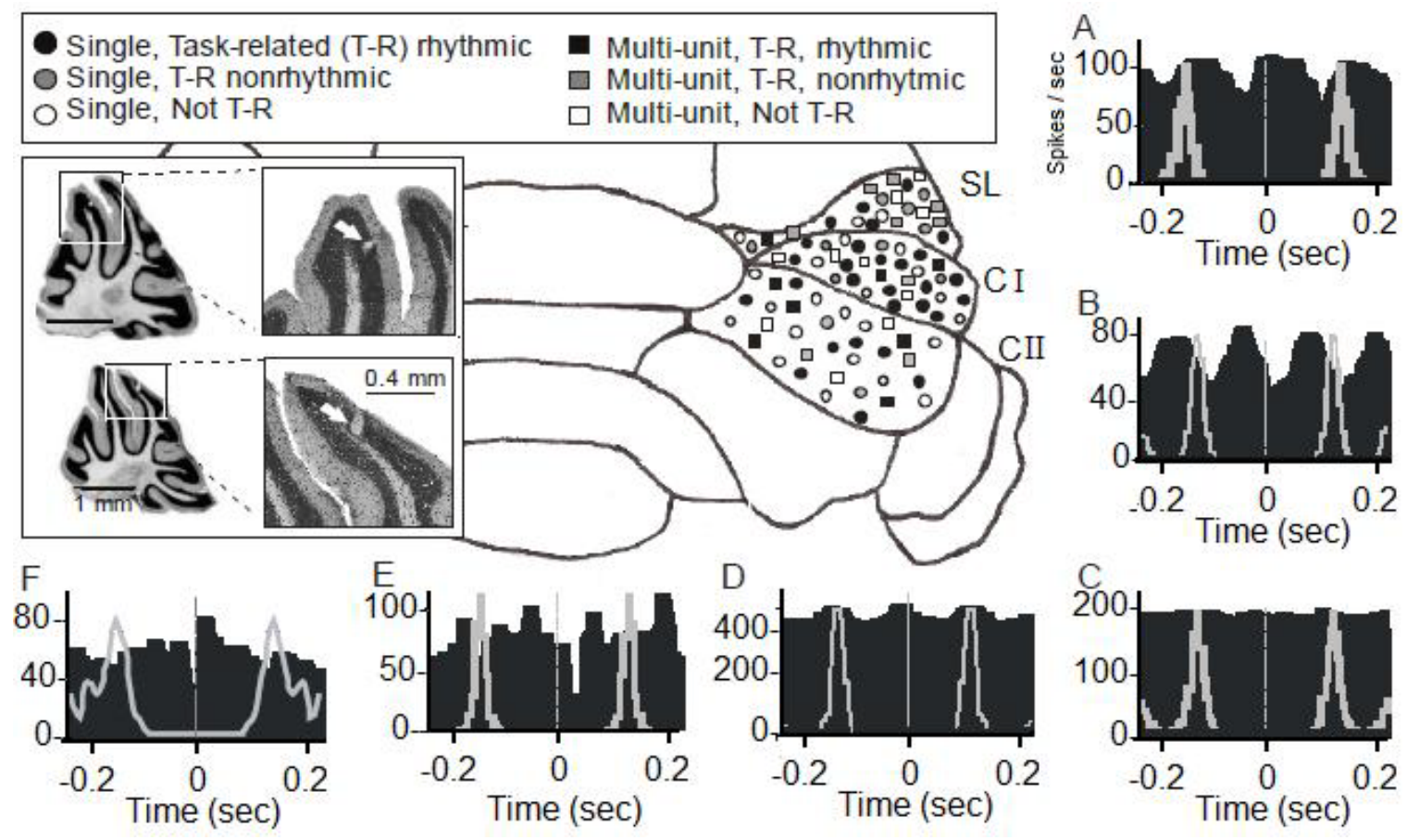

\section{Figure 3.3 Summary of electrophysiological results.}

The types and locations of recorded Purkinje cells are shown here. (A-F) Crosscorrelation histograms (black) of simple spike and licking behavior illustrate typical examples of the different types of neuronal activity encountered in experiments. The $\mathrm{x}$ axis is time in seconds and the y axis displays the frequency of firing. Grey overlays in each histogram are the skyline traces of autocorrelations for the licks used in the cross correlation analysis. The examples shown illustrate different types of responses observed: (A) Lick-related, rhythmically correlated single unit; (B) Lick-related, rhythmically correlated multi-unit recording; (C) Not lick-related, Multi-unit; (D) Lick-related, mildly rhythmic multi-unit; (E), Nonrhythmic, lick-related multi-unit; and (F) Nonrhythmic, lick-related single-unit. Note that the inter-peak interval within the cross correlations occur relative to the inter-lick intervals. The symbols in the schematic map of the cerebellar cortex indicate the approximate location of recording sites. Different symbols represent different response types as described in the legend. The inset displays photomicrographs of Nissl stained $50 \mu \mathrm{m}$ sagittal slices with electrolytic lesions marking recording sites. Lesions were the result of a $10 \mu \mathrm{A}$ negative current injection for 10 seconds. White arrows mark the lesions. Top left shows a simple lobule lesion and bottom left shows a Crus I lesion. Bin width in all histograms is $5 \mathrm{~ms}$. Histograms were smoothed with a 3-point Gaussian. SL = Simple Lobule, CI = Crus I lobule, CII = Crus II lobule. Please see methods for a detailed description of the criteria used for response classification. 
histogram. Minima and maxima occurring before or after lick onset were assigned negative and positive delays respectively. The probability distribution of maxima and minima was plotted in histogram form.

\section{Results}

\section{Licking Behavior}

Different strains of mice have different strain specific lick frequencies which vary little with environmental conditions (Horowitz, Stephan, Smith, \& Whitney, 1977; Smith, Voluaufova, \& West, 2001; Boughter, Baird, Bryant, St. John, \& Heck, 2007). In our study, adult B6 mice licked at an average inter-lick interval of $125.2 \pm 12 \mathrm{~ms}$, corresponding to an average rate of $8.0 \pm 0.6 \mathrm{~Hz}($ mean $\pm \mathrm{SD}$ ) (Fig. 3.1). The lick rates observed in this study were concordant with previously published lick rates for B6 mice $(8.0$ +/- 0.4 Hz, mean +/- SD) (Horowitz, Stephan, Smith, \& Whitney, 1977; Boughter, Baird, Bryant, St. John, \& Heck, 2007).

Fig. 3.1B shows the inter-lick intervals of the same mouse before surgical placement of head post and recording chamber (black histogram, mean ILI $139 \mathrm{~ms}$ ) and under head fixed experimental conditions (gray histogram, mean ILI $146 \mathrm{~ms}$ ). When averaging across all mice $(n=5)$ we calculated a mean lick rate of $8.0 \pm 0.3 \mathrm{~Hz}$ (mean \pm SD) before surgery and of $7.4 \pm 0.6 \mathrm{~Hz}$ during electrophysiological recording sessions. This difference was not statistically significant $\left(\mathrm{t}_{4}=2.0, P=0.12\right.$, paired Student $\mathrm{t}$-test).

We used extracellular recording techniques to monitor Purkinje cell spiking activity in the cerebellar cortex of five B6 mice during fluid licking (Fig. 3.2). Mice started to lick as soon as the water spout was brought within licking-distance $(2-4 \mathrm{~mm})$ and licked several hundred times during a single recording session. If a Purkinje cell had lick-related simple spike activity, the correlation between spike activity and licking was evident even for as few as 15 licks (Fig 3.2D). No correlation was found between single unit complex spikes and licking behavior throughout the whole course of the recording for this example unit (Large dots in Fig. 3.2D, E).

\section{Spatial Distribution of Lick-Related Purkinje Cells}

Purkinje cell activity was recorded from 72 different recording sites, all located within crus I, crus II and lobus simplex of the right cerebellar hemisphere (Fig. 3.3). The Purkinje cell layer was identified first by the presence of high frequency spiking activity after moving the electrode tip through the "quiet" molecular or granule layer and second by the occurrence of complex spikes. Single unit Purkinje cells were isolated whenever possible. The location of recordings sites was mapped relative to bregma (Fig. 3.3, inset) and verified through electrolytic lesion. Mapping the recording locations of all cells onto a schematic drawing of the cerebellar cortex revealed that neurons of all categories were 
widely distributed and intermingled with non lick-related cells (Fig. 3.3). There was no apparent topographical organization of behavior related response patterns.

A total of 52 single-units were isolated and the remaining spike trains $(\mathrm{N}=27)$ were analyzed as multi-unit signals. Multi-unit responses were used to map the representation of licks in the cerebellar cortex but were not analyzed further. Purkinje cell responses were divided into three different categories based on behavior related changes in simple spike activity: 1) lick-related rhythmically firing (single unit: $\mathrm{N}=24$, Fig. 3.3A and multi unit: $\mathrm{N}=8$, Fig. 3.3B), 2) lick-related nonrhythmically-firing units (single unit: $\mathrm{N}=8$, Fig. 3.3F and multi unit: $\mathrm{N}=9$, Fig. 3.3E) and 3) nonlick-related (single unit: $\mathrm{N}=$ 20 Fig. 3.3C, multi unit: $N=10$ ). Of the lick-related rhythmically firing single units, 6 were classified as weakly modulated, based on the fact that their rhythmic rate modulation was within 1 SD of the baseline correlation. Five of 8 multiunit recordings were weakly modulated with lick-related, rhythmic firing (Fig. 3.3D). To illustrate the individual phase relationship between rhythmic simple spike modulation and licking behavior, the autocorrelation histograms of the licking behavior were calculated and plotted as gray line graphs on top of the corresponding lick-spike cross correlations in Fig. 3.3. The photomicrographs in Fig. 3.3 show examples of cresyl violet-stained cerebellar sections with stereotaxically identified lesions set at recording sites (white arrows).

To investigate whether Purkinje cells changed their average level of spike activity during licking behavior or whether spike rates were instead modulated around a stable mean firing rate, we compared the average firing rates of single-unit Purkinje cells before and during licking. Purkinje cells were either grouped by their location in one of the three lobules (Fig. 3.4A-C) or by their type of lick related spike activity (Fig. 3.4D-F). There were no significant changes in the mean firing rates between rest and licking behavioral conditions differences between pre- and during- behavior baseline firing rates in any of the groups (Student's t-test). Location within the simple lobule $\left(P_{14}=0.40\right)$, crus I $\left(P_{21}=\right.$ $0.52)$, nor crus II $\left(P_{19}=0.47\right)$ resulted in a distinguishable difference between lick rates before and during licking. The average firing rates of nonrhythmic lick-related units did slightly decrease during licking behavior as compared to pre-licking activity (Fig. 3.4E), but this difference was not statistically significant $\left(P_{8}=0.31\right)$. The other two other classifications of Purkinje cell response types had similar average firing rates before and during licking $\left(P_{20}=0.87\right.$ for the nontask-related and $P_{24}=0.66$ for the rhythmically task-related units). I also determined whether the intrinsic rhythmicity of simple spike firing patterns changed between rest and licking behavior. A comparison of autocorrelation results calculated from Purkinje cell simple spikes before and during licking showed no difference (data not shown).

\section{Rhythmically Firing Units}

The fact that the lick-spike cross-correlations of lick-related rhythmically firing units had multiple peaks at delays, which were multiples of the mean inter-lick interval, indicates that rate modulations were phase locked with the lick rhythm. To evaluate 


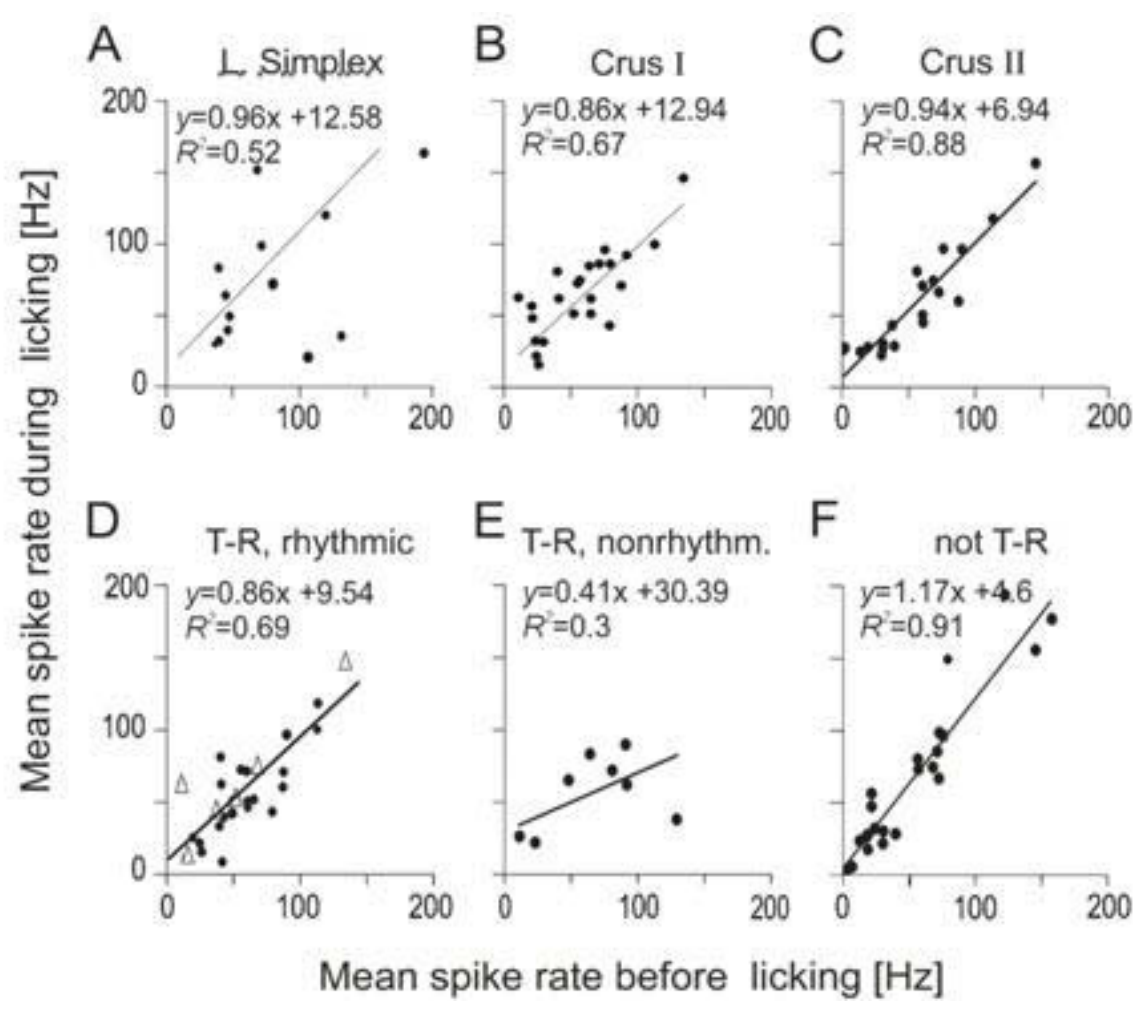

Figure 3.4 Scattergrams comparing the spike rates of single units before and during licking.

Comparison by region. The top row of scatterplots display a comparison of spike rates before and during licking for single units segregated by the lobule in which each unit was recorded (A-C). The equation from the linear regression analysis and the coefficient of determination is shown for each data set. While no region displayed a significant difference between firing rates before and during licking, single units obtained from Crus II displayed the least variance among units. Comparison by response type. The lower row displays single unit firing rates for different response types (D-F): (D) Lick-related, rhythmic single units showed no change in firing rates among those with a strong rhythmic firing pattern (black dots) and those that were mildly correlated (white triangles). (E) Lick-related, nonrhythmic single units displayed the most variance between firing rates before and during licking. (F) Non lick-related units showed no change to firing rates before and during licking. Regression line slopes close to one reflect that groups displayed no difference between spike frequencies before licking and during licking with the coefficient of determination reflecting the strength of the relationship for those data points. 
whether there were preferred phase relationships between the lick rhythm and the rhythmic correlations of Purkinje cell spike activity, we determined the temporal relationships between spike rate minima and maxima and lick onset times for all rhythmically firing single units. The resulting histograms in Fig. 3.5A-B show that spike rate minima (Fig. 3.5A) and maxima (Fig. 3.5B) typically occur near lick onset, with no bias of occurrence before or after lick onsets. Each Purkinje cell had its own individual, but stable phase relationship with the licking rhythm (see also Fig. 3.3A-B). To determine the temporal relationship between lick related changes in Purkinje cells simple spike activity and an individual lick we performed the lick-spike cross correlation analysis using only the occasionally occurring single licks and the first licks of all lick burst (Fig. 3.5C, D) as temporal aligners. In about 50\% of Purkinje cells rate minima occurred before the tongue to spout contact and in the other $50 \%$ rate minima occurred afterwards (Fig. 3.5C). For rate maxima, however, we found a larger number of cells with maxima occurring after the tongue to spout contact (Fig. 3.5D).

Weakly-correlated units showed rhythmic lick-related simple spike rate modulations similar to those observed in rhythmic, strongly modulated units, except for the fact that the rate modulations did not exceed $1 \mathrm{SD}$ of the baseline rate variability. As with strongly modulated units, the mean firing rates of weakly modulated units did not significantly change during licking behavior compared to rest (Fig. 3.4D, white triangles). As was the case for rhythmically firing units, there was no preferred phase relationship for weakly modulated units with licking behavior.

\section{Spike Modulation at Lick Burst Onset}

Analysis of the simple spike rate changes at the first licks of lick clusters showed that about an equal number of Purkinje cells had rate minima before and after lick burst onset (Fig. 3.5C). There were, however, a larger number of cells with rate maxima occurring after lick burst onset (Fig. 3.5D). The distribution of these cells' responses to first licks still occur both before and after these initial licks and therefore it does not provide irrefutable evidence that the cerebellum has a strictly motor or sensory role in fluid licking.

\section{Lick-Related, Nonrhythmically-Firing Units}

Analysis shows that 8 out of 52 single units (15\%) and 9 out of 27 multi unit signals $(33 \%)$ were nonrhythmically lick-related. The lick-spike cross-correlation analysis showed lick-related reductions in simple spike rate in 4 single units, rate increases in 2 single units and triphasic rate modulation in 2 single units. The increases or decreases in firing rate generally occurred within $10 \mathrm{~ms}$ of the time of tongue contact to the spout. Triphasic rate modulation consisted of a rate increase followed by a decrease and then another increase. One unit completed this pattern of activity change within the $30 \mathrm{~ms}$ prior to tongue to waterspout contact while the other began an increase in firing rate $15 \mathrm{~ms}$ prior the tongue to waterspout contact and completed the triphasic pattern 
Figure 3.5 Lick-related, rhythmic single unit phase relationships to licking.

The delays of closest immediate minimum and maximum occurring relative to lick onset in cross correlations were compiled into the histograms seen here. (A) The cross correlation for all spikes to licks in an example file is shown at the top. The mouse licked 403 times with an average spike firing rate of $90.25 \pm 12.03 \mathrm{~Hz}$. The value of the minimum in firing rate that occurs closest to zero is $66 \mathrm{~Hz}$ (marked with arrow) and occurs at $0.045 \mathrm{~s}$ before lick onset. For each file, this minimum was determined and compiled into the histogram shown. (B) The value of the maximum firing rate that occurs closest to zero is $105 \mathrm{~Hz}$ for the example file. This maximum (marked by an arrow at the top of B) occurs $0.018 \mathrm{~s}$ after lick onset and is entered among the values for maxima shown in the histogram. While the bins closest to the time of tongue contact to the spout $(\mathrm{t}=0.0)$ contain more of both maximum and minimum offsets, the values generally fall within one average inter-lick interval before or after lick onset. To determine if the changes in neuron responses occurred before or after lick onset, spikes were correlated to all solitary licks and the first licks of each burst. (C) For the example file used in A, $34 / 403$ licks were deemed as first or individual licks. Then correlation analysis was performed for spikes with these select licks. The result of the correlation analysis is shown here. The average firing rate in this analysis is $102 \pm 18.98 \mathrm{~Hz}$. The minimum closest to zero is $83.4 \mathrm{~Hz}$, marked with an arrow, and occurs at 0.025 seconds before lick onset. This value is included with other files in C. (D) Similarly, the maximum of $117 \mathrm{~Hz}$ that occurs at 0.037 seconds after lick onset is marked with an arrow at the top of $\mathrm{D}$. The maximum offset relative to zero for the average response to all licks is displayed. With first licks, some neurons had yet to display a change in firing pattern strong enough to demarcate clear minimums and maximums as seen in the averaged responses for all licks, therefore some neurons' offset measurements were excluded. The histograms have $10 \mathrm{~ms}$ bins. 
A
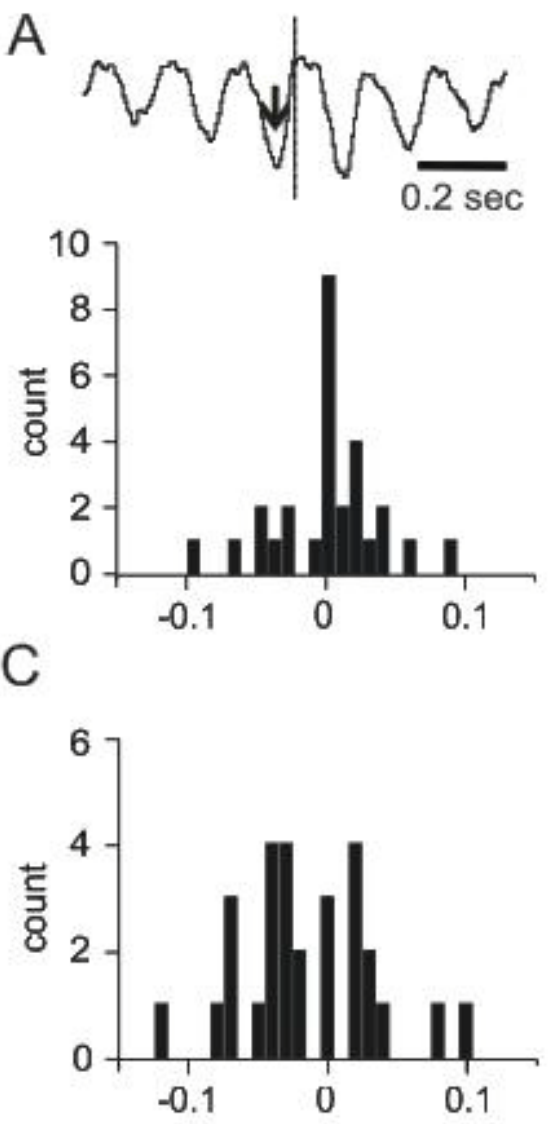

B
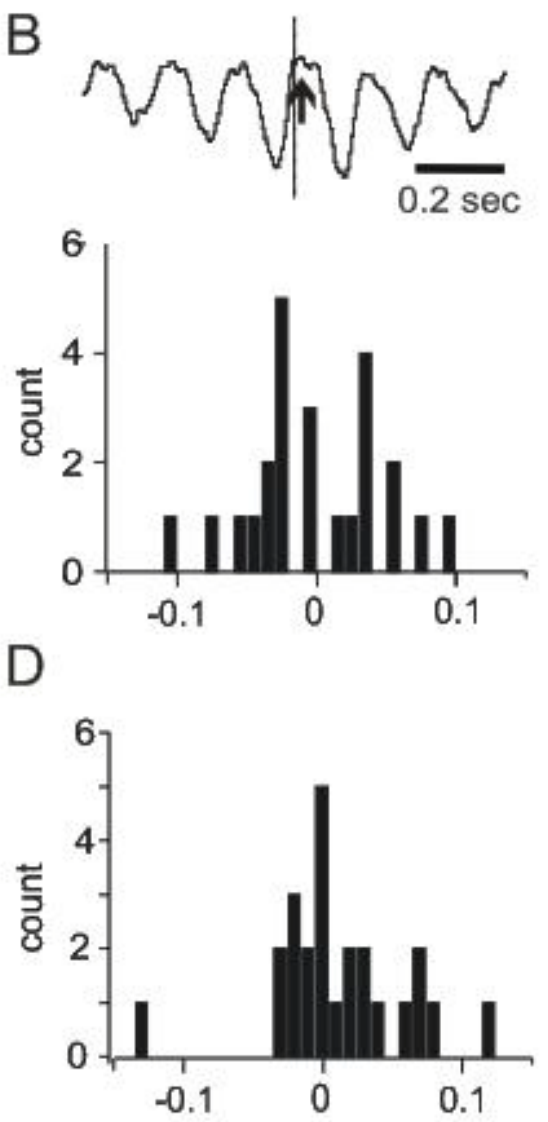

Time (s) 
within $10 \mathrm{~ms}$ after the tongue to water spout contact or lick onset.

\section{Nonlick-Related Units}

Out of 52 recorded single units 20 were classified as not lick-related (38\%). Nonlick-related units were found interspersed between lick-related cells in all regions of the cerebellar cortex from which neurons were recorded.

\section{Spatial Distribution of Lick-Related Activity}

Lick-related and non lick-related cells were spatially distributed in an apparently random manner (Fig. 3.3). There was no indication of a spatial clustering or somatotopical organization of different types of lick related Purkinje cells comparable to the fractured representation of orofacial sensory inputs previously described for the rat (Shambes, Gibson, \& Welker, 1978).

\section{Neuronal Representation of Interlick Interval Duration}

Although the mean ILI is very stable for individual animals, closer examinations have revealed that systematic variations in the duration of individual ILIs are behaviorally highly relevant. For example, swallowing movements have been shown to occur during longer than average ILIs (Weijnen et al., 1984). Presumably, this provides the additional time needed to complete the swallowing movement before the next lick occurs. In order to determine whether the cerebellum might be involved in controlling this temporal aspect of the licking behavior we asked if lick related Purkinje cell simple spike activity represented ILI duration. We separated and compared the average simple spike responses of rhythmically firing units during the longest and shortest inter-lick intervals performed during a recording session (see methods). In 13 out of 28 rhythmically firing Purkinje cells information about interval duration was represented in the simple spike rate changes based on differences between their average rate trajectories for long and short ILIs. These duration-encoding units typically showed a rapid increase in simple spike rate at the beginning of a lick interval followed by a slower decrease. The time course of the rate decrease differed between short and long ILIs. During short ILIs the rate decreased faster and reached a rate minimum earlier than during long ILIs (Fig. 3.6A,B).

A second group ( 8 of 24) of rhythmically firing cells showed long lasting rate modulations which were identical for long and short ILIs (Fig. 3.6C). A third group (7 out of 24) generated brief increases in simple spike activity around the time of contact between the tongue and the water spout $(25 \%)$. Those rate increases were the same for long and short intervals (Fig. 3.6D). The analysis shows that while neurons may become rhythmically tuned to the licking behavior, the manner in which the modulate their firing rates has significant variations. 

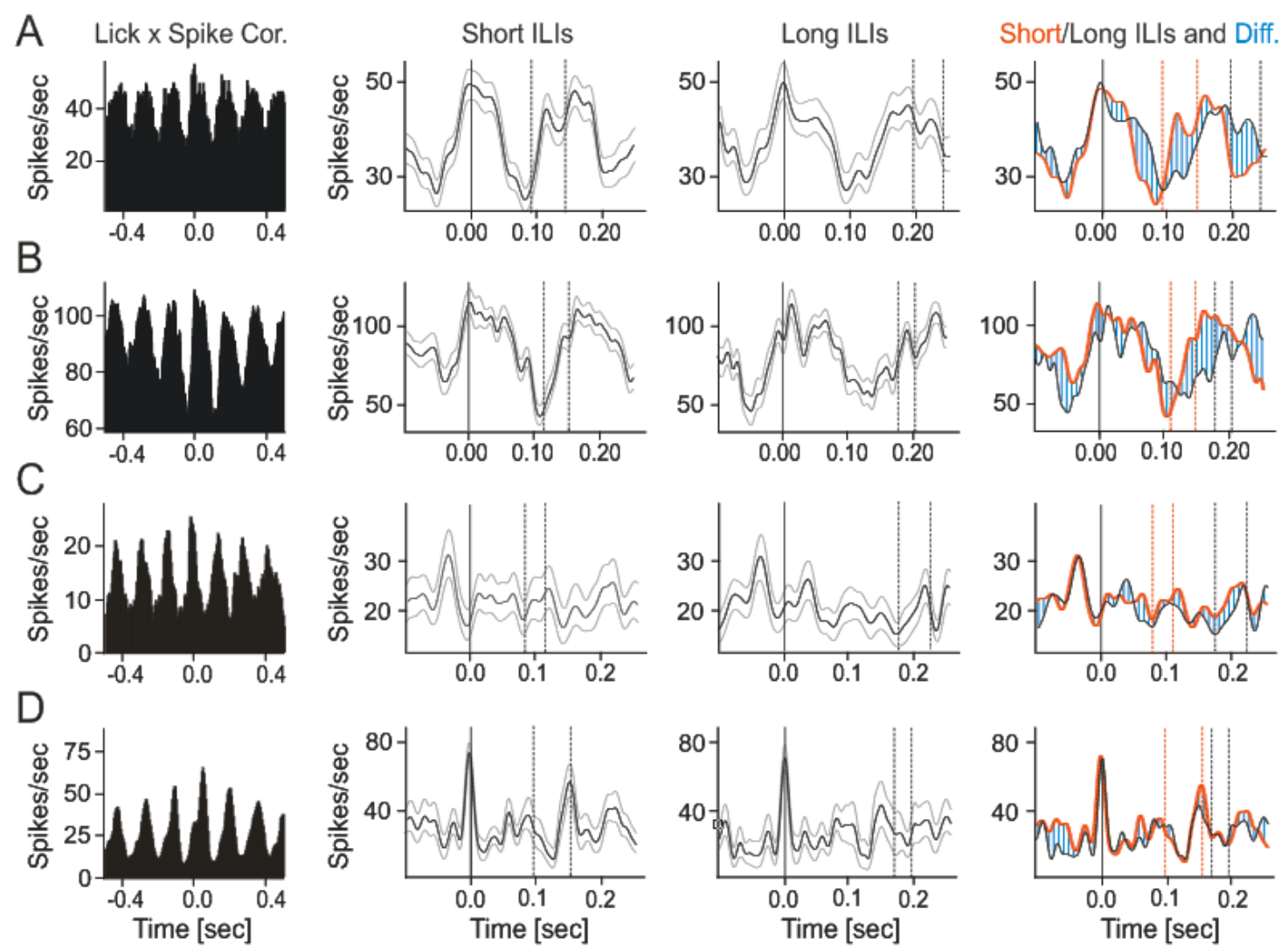

Figure 3.6 Interlick interval duration is represented in Purkinje cell simple spike activity.

The average firing rates of four rhythmically modulated lick-related Purkinje cells (A-D) were calculated separately for the 30 shortest and 30 longest inter-lick intervals (ILIs) in the data set. The histograms in the left column show the lick-spike correlations (all licks included) for the four units. The center two columns show average spike rate trajectories (black curves) recorded during short (center left) and long (center right) ILIs. Gray curves mark $+/$ - one standard deviation. Solid vertical lines in each histogram mark the times of tongue to water spout contact, dashed vertical lines delimit the time intervals within which the next tongue contact occurred. The right-most column shows an overlay of the data in the two center columns with responses during short ILIs shown in red, responses during long ILIs shown in black and the difference hatched in blue. The time course of the spikes rates of units (A) and (B) were different during long and short ILIs. Spike rate minima and maxima occurring earlier during short ILIs than during long ILIs. Units (C) and (D) generated similar spike rate patterns during long and short ILIs. All of the cross correlations contained $5 \mathrm{~ms}$ bins that were smoothed with a 3-point Gaussian function. 


\section{Discussion}

In a series of multi-electrode experiments in awake and behaving rats, Welsh and colleagues (1995) showed that population complex spike activity in the cerebellum was phase-locked to the rhythm of fluid licking behavior. Even though complex spikes reflect an input signal arriving from the inferior olive and contribute little to the cerebellar spike output, these findings clearly showed a cerebellar involvement in licking behavior. Welsh and colleagues suggested that the olivo-cerebellar system was crucially involved in the generation of the lick-motor rhythm. Although lick timing is usually treated as a characteristic originating from the brainstem alone, this proposed role that was consistent with the longstanding view of the cerebellum as a timing and motor control device (Braitenberg, 1967; Ivry, Keele, \& Diener, 1988) but was never experimentally tested. Here we investigated the role of the cerebellum in rhythmic fluid licking by addressing two key questions: 1) How is fluid licking behavior represented in neuronal output signals of the cerebellar cortex, i.e. the high frequency simple spike activity of Purkinje cells? 2) How does loss of cerebellar function affect fluid licking behavior?

Electrophysiological recordings of cerebellar cortical output activity, Purkinje cell spikes, in awake and behaving mice revealed a dynamic representation of fluid licking behavior by a large and widely distributed population of Purkinje cells. A subset of these lickrelated Purkinje cells differentially represented the duration of inter-lick intervals, consistent with a cerebellar involvement in controlling the licking rhythm. Loss of cerebellar function, either permanent or temporary, significantly slowed, but did not eliminate the licking rhythm. Moreover, the gross licking movement seemed unaffected in ataxic mice.

Welsh et al. (1995) had shown that climbing fiber inputs to the cerebellar cortex originating in the inferior olive generated widely distributed patterns of correlated complex spike activity that was phase locked with the fluid licking rhythm in rats. Complex spikes occur at low frequencies $(\sim 1 \mathrm{~Hz})$ they contribute very little to the main spike output from the cerebellar cortex, which consists of Purkinje cell simple spikes with average firing rates (in our experiments) ranging from around 10 to $200 \mathrm{~Hz}$.

Instantaneous control of behavioral outcome, particularly of a fast rhythmic movement such as licking, is more likely to depend on the modulation of simple spike rather than complex spike activity. Complex spikes have been implicated in cerebellar dependent forms of motor learning by shaping behavior related simple spike activity through long term depression of the excitatory inputs to Purkinje cells (Boyden, Katoh, \& Raymond, 2004). It is thus possible that the phase locked lick related modulation of simple spike activity is at least partially caused by phase locked population climbing fiber inputs. In fact, Llinas (2009) argues that morphological and electrophysiological characteristics of the inferior olive, such as gap junction, meaning gap junctions and 1-10 $\mathrm{Hz}$ oscillations, are a likely means of mitigating error correction in on-going movements. This same group has also shown evidence of large scale oscillation within the inferior olive neurons with voltage-dependent dye imaging (Leznik, Makarenko, \& Llinas, 2002). The climbing fibers just provide a means of communicating the potential changes in pace and reset of movements to the cerebellum. The fact that we did not observe a correlation 
between complex spikes and licking does not contradict this view, since it requires the observation of a larger population of cells to measure the phase locked population activity (see Welsh et al. 1995).

Mapping of all recording sites onto the cerebellar surface showed that licking behavior was represented in the simple spike activity of a large and widely distributed population of Purkinje cells in crus I, crus II and lobus simplex (Fig. 3.3). There was no obvious topographical organization or clustering of lick-related Purkinje cells in general, or of the two functionally distinct lick-related groups of rhythmic and nonrhythmic cells. Instead, spatial distribution of rhythmic, non-rhythmic and non task-related Purkinje cells seemed random. This lack of topographical correlation also extends to the phase relationships of rhythmically responding units. The behavior-related neuronal output was dispersed widely and while rhythmic changes were observed in many of these neurons, no dominate phase relationship emerged. This finding does not contradict the basic idea of the cerebellum as a coordinator of orofacial movements because somatopic representation is not discretely organized within the cerebellum nor is the cerebellum particularly focused on one aspect of one movement in the awake, behaving animal.

It is unclear to what extent the neuronal representation of licking behavior in the cerebellum is related to sensory feedback, motor commands, or a combination of both. In an initial attempt at addressing this question, we measured the timing of simple spike rate changes relative to the timing of tongue-to-waterspout contacts. The assumption was that a purely sensory driven neuronal signal would coincide with the movement, particularly with the sensory event of tongue-to-waterspout contact, whereas motor command related changes in neuronal activity would preferentially occur before the movement. The results of this analysis showed no general preference for simple spike rate changes to occur before or after tongue-to-waterspout contact (Fig. 3.5). Instead simple spike rate maxima and minima were about normally distributed around the moment of tongue-to-waterspout contact within a time window of $\sim 240 \mathrm{~ms}( \pm 120 \mathrm{~ms})$, with the possible exception of rate maxima when analyzing only the first licks in a burst (Fig. 3.5D). The distribution of the maximum and minimum changes in spike firing activity, at least for rhythmically responding units, is not surprising if the cerebellum has a role in the coordination

The separate analysis of rate changes during short and long inter-lick-intervals revealed firing patterns in some Purkinje cells that consisted of very brief increases in firing rates coinciding with the time of tongue-to-waterspout contact (Fig. 3.6D). This form of lick-related activity is most consistent with a purely sensory representation of the tongue. Other cells had more complex spike rate patterns suggesting that they represented timing related aspects of the behavior. Particularly interesting were Purkinje cells with simple spike rate changes that differentiated between short and long inter-lick intervals. These cells could play an important role in modulating the lick rhythm and the loss of their function might explain the reduced lick frequency we observed in ataxic mice. We also investigated whether Purkinje cells showed a static change in baseline simple spike activity during licking behavior. By comparing average firing rates during rest and during licking we determined that baseline simple spike rates did not change during licking behavior. Regression line slopes of the scatter plots for firing rates during rest vs. 
behavior (Fig. 3.4) were close to one, with the exception of Lick-related, nonrhythmic single units which displayed the most variability in their firing rates but there was no clear trend towards increased or decreased rates during licking. Thus, the neuronal representation of licking behavior in Purkinje cells consisted of dynamic modulations of simple spike firing without changes in baseline firing rates. Cerebellar output activity in crus I, II, and lobus simplex thus seems to be concerned with licking behavior on the time scale of individual licks and not in the general behavioral state of licking or fluid consumption.

While it is plausible to assume that rhythmically firing lick related cells were concerned with the behavior on a lick by lick basis, it is less clear what the function of non-rhythmic lick-related Purkinje cells (Fig. 3.3E,F) might be. These cells seem to be involved in nonrhythmic events that occur during fluid licking and we propose that their activity is related to swallowing movements. Swallowing movements are known to be highly coordinated with fluid licking movements in rats. During licking fluid is accumulated in the oral cavity and swallowing occurs at irregular intervals every $6^{\text {th }}$ to $8^{\text {th }}$ lick (Weijnen et al., 1984). The nonrhythmic cross-correlations between simple spike activity and licking could reflect the activity of swallowing related Purkinje cells. Related to this might be the subset of Purkinje cells encoding ILI durations. These cells provide a potential neuronal substrate for a coordination of licking with swallowing or respiratory movements as their activity might be involved in delaying or accelerating the onset of the next pattern generator cycle. Nonrhythmic lick related Purkinje cells may thus be involved in controlling the timing of swallowing movements and/or of the respiratory pattern generator to prevent asphyxiation during swallowing. Considering that the parts of the cerebellum linked to respiration are generally located more medially in the vermis and paravermis (Xu, Taylor, Lee, \& Frazier, 1993; Xu \& Frazier, 2002) and that our recordings were restricted to the cerebellar hemispheres, it is more likely that we observed neuronal activity related to swallowing rather than breathing. Ultimately the work presented in this chapter of the dissertation addresses specific aim 1 while also showing the usefulness of the technique and its potential adaptability to other studies. Neurophysiological recordings of the Purkinje cells during behavior in these awake, behaving mice demonstrate the representation of fluid-licking in the activity patterns of the sole output neurons of the cerebellum and set the foundation to studies that alter the normal function of the cerebellum in the same behavior. With evidence of behavior correlated neuronal spiking and changes in the spike rate correlated to difference in ILI duration, an inevitable question is if this neuronal activity contributes to the completion of the typical behavior as previously observed. Thus, the results of experiments within this chapter supply the foundation for the experiments to follow. 


\section{CHAPTER 4: EFFECTS ON FLUID LICKING OF ALTERING THE CEREBELLUM}

\section{Introduction}

The cerebellum is a region of the brain most usually indicated in movement, including those of an orofacial origin (Vajnerova, Zhuravin, \& Brozek, 2000). This region of the brain can be subjected to many injuries. Oxygen deprivation, alcoholism, tumor formation, and neurological degenerative disease are just a few means of significantly altering cerebellar function, all of which lead to noticeable difference in behaviors (Schmahmann, et al., 2007). While changes to verbal fluency, abstract reasoning, working memory, and many cognitive tasks have been shown (Schmahmann et al., 2007), ataxia is one of the more obvious results of cerebellar damage. The portion of the study uses the behavior of interest and the lesion-deficit correlation assessments that are characteristic of behavioral neurology. We assess several means of altering cerebellar function to understand exactly how a behavior changes without the typically functioning organ. Three means of changing the cerebellum are presented including the removal of the structure, gene mutations that result in ataxia, and pharmacologically reducing the output of the cerebellar cortex. The cerebellectomy, or complete removal of the cerebellum, is a surgical procedure used clinically as a treatment option in cancer but it has been used in research to show the necessity of the cerebellum in learning. Motor tasks such as trained eye movements in goldfish (Pastor, de la Cruz, \& Baker, 1994) and swimming in trout (Roberts, Van Rossem, \& de Jager, 1992), have been shown to be aberrant in the cerebellectomized animal. Other studies have also shown spatial orientation deficits among cerebellectomized rodent like a problem with the completion of the Morris water maze in rodents (Hilber, Jouen, Haye-Bouchaud, Mariani, \& Caston, 1998) or changes to open field behavior and impaired memory (D’Agata, Drago, Serapide, \& Cicirata, 1993). Many mouse mutants are derived from spontaneous mutations resulting in motor disorders of a cerebellar nature. Much work has been done to identify the genes and physiological deficits that result from these mutations.

The mouse model of a genetically induced form of cerebellar ataxia involves the mutation of the Precerebellin gene (CBLN1). This gene was initially thought to be a cerebellum-specific hexadecaptide found in the perikarya and dendrites of cerebellar Purkinje cells (Slemmon, Danho, Hempstead, \& Morgan, 1985). The gene was later found to be expressed in the dorsal cochlear nucleus (Mugnaini, Dahl, \& Morgan, 1988). Further investigation elucidated a probable role for the heavy presence of the protein and its metabolites in the cerebellum as a transneuronal regulator of synaptic activity (Morgan et al., 1988; Slemmon, Goldowitz, Blacher, \& Morgan, 1988). While more specific details of the role of Cerebellin protein and similar proteins such as CBLN2, CBLN3, and CBLN4 have yet to be discovered, knockout mice demonstrate varying degrees of ataxia. While Purkinje cell number remains high, mouse with aberrant expression levels of CBLN1, show motor coordination deficits and have even been linked to multiple olivopontocerebellar atrophy and Shy-Drager syndrome (Mizuno et al., 1995). 
While several other knockout mouse models offer ataxia of a cerebellar nature such as the lurcher, staggerer, and weaver mice (Furuya et al., 1994; Lalonde \& Strazielle, 2007), these animals all show neurodegeneration of PCs or loss of granule cells. The CBLN1 null mice still have a cerebellum of relatively similar structure but with obvious functional deficits. One caveat to $t$ he interpretation of data is that some studies have found expression of Precerebellin and Cerebellin-like proteins in other regions of the body, such as the dorsal cochlear nucleus or even the adrenal gland (Mugnaini, Berribi, Dahl, \& Morgan, 1987; Mugnaini \& Morgan, 1987; Tocris Bioscience, 2009; Rucinski, Ziolkowska, Szyszka, \& Malendowicz, 2009). The heterozygous condition also offered the benefit of presenting an animal whose potential alterations in function were possibly mitigated by the reduced presence of the protein.

The last method involves using muscimol, a $\gamma$-Aminobutyric acid type A (GABA) receptor agonist that is a natural product of the fungus Amanita muscaria. Muscimol has an LD50 of $4 \backslash 2500 \mu \mathrm{g} / \mathrm{kg}$ for an intraperitoneal injection or $22 \mathrm{mg} / \mathrm{kg}$ when administered orally in mouse (Tocris Bioscience, 2009). Muscimol is a strong selective agonist of $\mathrm{GABA}_{\mathrm{A}}$ receptors, which have been shown through techniques like autoradiography (Saito et al., 1974; Rotter \& Frostholm, 1988), monoclonal antibody immunoreactivity (Saito et al., 1974; Meinecke, Tallman, \& Rakic, 1989; Somogyi, Takagi, Richards, \& Mohler, 1989), pharmacological ablation of function (Sakamoto \& Endo, 2008; Parker, Zbarska, Carrel, \& Bracha, 2009) to be vital to the composition and the function of the deep cerebellar nuclei. Muscimol is a structurally similar molecule to GABA and will eventually be metabolized and excreted through urine in mice (Ott, Wheaton, \& Chilton, 1975). In humans, consumption of muscimol-containing mushrooms of the Amanita, lead to hallucinations, ataxia, and general depression of the central nervous system after 2 hours (Satora, Pach, Ciszowski, \& Winnik, 2006). The effects of this molecule can extend to many regions of the brain with some behavioral deficits being linked to regions of high affinity binding of the molecule (Chandra et al., 2009). For example, muscimol infusions to brainstem caused the cessation of ingestive behavior in rats (Chen, Travers, \& Travers, 2001) while injections into primate deep cerebellar nuclei resulted in dysmetria of eye movements (Straube, Helmchen, Robinson, Fuchs, \& Buttner, 1994; Chen et al., 2001). The results of both these studies were combined into the hypothesis that introduction of muscimol into the deep cerebellar nuclei of mice would alter ingestive behavior, specifically fluid-licking.

Here, I used the method established in Chapter 2 and adapted it to an alternate arrangement so that animals could be monitored for extended periods of time. A sipper tube constructed of a nonconducting plastic was attached to a small drinking bottle with a conducting wire within the bottle, thus minimally changing the typical home cage environment for all mice used. This setup was also placed within a setting at allowed for the consistent occurrence of the light dark cycles for these animals. This long-term licking paradigm minimizes the influence of human discrepancies between the measurement of licking behavior in the shorter exposure used for the head-fixed recordings. 


\section{Materials and Methods}

\section{Animals}

Adult male and female mice ( $>60$ days old) from the common inbred strain C57BL/6J were individually housed in plastic shoebox cages in a temperature and humidity-controlled vivarium on a 12:12 h light-dark cycle. Animals were treated according to a protocol approved by the University of Tennessee Health Science Institutional Center Animal Care and Use Committee. Ad libitum water was granted through bottle containing capable of measuring a potential change made when a mouse stood on a grid on the floor of its home cage and licked the sipper tube. During testing mice received all their daily fluid in the lickometer. All mice were weighed prior to the start of licking experiments and after the completion of experiments.

\section{Surgically Altering the Cerebellum}

Mice $(\mathrm{N}=13)$ underwent a craniotomy on postnatal day 14 to allow for the surgical removal of the cerebellum through suction. This age maximized the survival rate obtained for the nature of the surgery. Following anesthetization with intraperitoneal injections of ketamine-xylazine $(90-150 \mathrm{mg} / \mathrm{kg})$, the cerebellum was removed by subpial suction through a suboccipital craniectomy (Ledoux, Lorden, \& Ervin, 1993). The intracranial space was filled with Avitene, a microfibrillar collagen hemostat (Davol Inc, Cranston, Rhode Island). For recovery, unweaned pups were returned to their mothers and any pups that were newly weaned were given a special diet with moistened chow and peanut butter. Their fluid was supplemented with injections of lactated Ringer's solution for several days until recovery was complete. Cerebellectomized pups were then housed together with other surviving pups from their litters until they reached maturity and could undergo behavioral testing as mature animals at 6-12 weeks after the surgery.

For cerebellectomized mice and an equal number of age-matched control C57BL/6J mice (13 pairs of animals), licking behavior was monitored by custom lickometer modified from Hayar et al., (2006) while the mice were in their home cages. Mice were monitored for 72 hours. In addition to the total number of licks, the lick intervals, number of visits to the water spout, number of lick clusters, and temporal pattern of these details were carefully observed. After behavioral testing, all lesioned animals were deeply anesthetized with tribromoethanol $(0.7 \mathrm{mg} / \mathrm{g})$ and perfused intracardially with saline followed by $10 \%$ buffered formalin. The scope of the cerebellectomy was then evaluated first by examining the brain, Fig 4.1. Then the brain cut into $40 \mu \mathrm{m}$-thick sections and Nissl-stained. Although several surgeries resulted in only partial ablation of the floccular complex due to bony structures blocking complete removal, animals were still included as the structures were not functional without the deep cerebellar nuclei (DCN) or cerebellar peduncles. Although ataxic, animals found to retain portions of the DCN or cerebellar cortex were excluded from analysis (4 of 13 animals that underwent surgery and their 4 age-matched controls were not analyzed). 


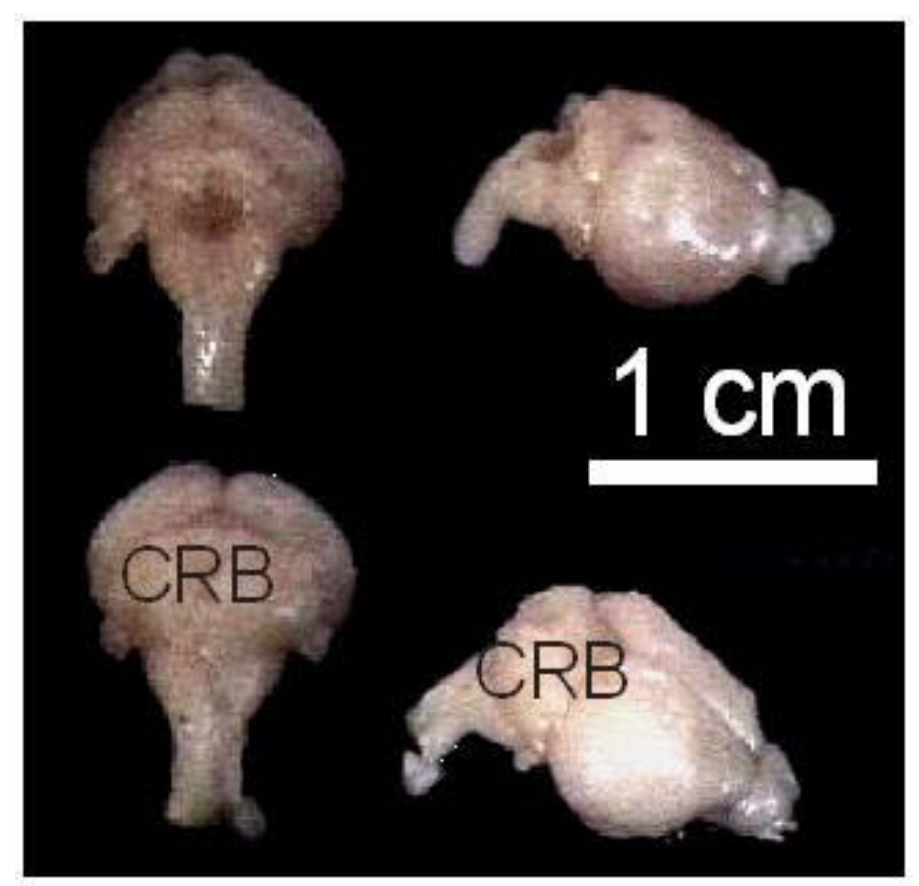

Figure 4.1 Whole brain images of the control and cerebellectomized mouse brain.

Top row: The view from a posterior perspective (left) and side view of a cerebellectomized mouse brain (right). Bottom row: The posterior perspective (left) and side view of a typical mouse brain (right). 


\section{Genetically Altering the Cerebellum}

Adult mice that are null for the Precerebellin (CBLN1) gene, of a heterozygous genotype, and wild type littermates all were monitored for an extended period of time (48h) in their individual home cages for licking behavior in a method similar to the above experiments. While the ataxic state of the knockout mice were useful for discriminating the genotype, the lab supplying the animals did independent testing to determine the genotype of all animals used. CBLN1 is a regulatory peptide important to development of a normal cerebellum in that it stabilizes parallel fiber-Purkinje cell synapses (Slemmon et al., 1988). Whereas many other ataxic strains of mice fail to develop normal neurons, this knockout mouse was chosen due to the potential to collect electrophysiological and behavioral data, which was done in a small group of these animals with the same method described in Chapter 3.

\section{Pharmacologically Altering the Cerebellum}

Adult mice were used and undergo home cage observations of licking rates prior to surgery. Muscimol was not added to the fluid for consumption with these animals because the molecule could have widespread affects on the central nervous system and confound interpretation of the results. Therefore, microinjections of the molecule into the deep cerebellar nuclei provided a suitable alternative means of delivering the GABA receptor agonist specifically to the deep cerebellar nuclei. The mice then undergo two craniotomies, each granting access to the lateral deep cerebellar nuclei. The openings were approximately $2 \mathrm{~mm}$ in diameter and centered on a point that was $-6.1 \mathrm{~mm}$ from bregma and $\pm 2.1 \mathrm{~mm}$ lateral from midline. The chamber placed above each opening was hollow, cylindrical plastic tubing, $3 \mathrm{~mm}$ in diameter and $4 \mathrm{~mm}$ in height. Three small screws were also placed in the skull above the cerebral cortex. A headpost was situated above bregma, and then dental cement was used to fix the positions of the chamber and headpost to the skull. After 4 days of recovery, the mice were head-fixed and a glass pipette tipped injector needle (thin-walled, $1 \mathrm{~mm}$ O.D.) was lowered into the cerebellum. As the electrode was lowered into the brain, placement of the electrode tip in the cerebellar nuclei was guided neuronal signals recorded with the same tip. The correct location of injection sites was also verified anatomically by injecting a nontoxic dye (India ink, Salis International Inc, USA) at the site. This data was collected in Spike2 (CED, UK). Once the pipette tip was lowered to the level of the deep cerebellar nuclei at about $-2 \mathrm{~mm}$ below the surface, $0.250 \mu \mathrm{l}$ of muscimol $(0.5 \mu \mathrm{g} / \mu \mathrm{l})$ in saline or just the vehicle of physiological saline $(0.9 \% \mathrm{NaCl})$ was injected into the tissue at a rate of 0.01 $\mu \mathrm{l} / \mathrm{min}$. We continued monitoring neuronal spike signals to track and confirm the inhibitory effect of muscimol on spiking activity, although upon completing the injection mice were transferred to their home cages where fluid licking behavior was continuously monitored for several hours post injection. This data was collected in Spike2 (CED, UK). Once the pipette tip was lowered to the level of the deep cerebellar nuclei at about $-2 \mathrm{~mm}$ below the surface, $0.250 \mu \mathrm{l}$ of muscimol $(0.5 \mathrm{mg} / \mu \mathrm{l})$ in saline or just the vehicle of physiological saline $(0.9 \% \mathrm{NaCl})$ was injected into the tissue at a rate of $0.01 \mu \mathrm{l} / \mathrm{min}$. We continued monitoring the signals and changes to signal following muscimol injections for 
5 minutes to verify that the muscimol affected the signal. The animals were observed to make some movements such as a contortion of the forepaw during muscimol injections. Upon completing the injection, mice were transferred to their home cages where licking behavior was monitored overnight.

\section{Lickometer}

During a recording session, mice were placed individually in a shoebox cage. Within each cage was a sipper tube with a connection to a BNC input to a CED $1401 \mathrm{~A} / \mathrm{D}$ converter. The grounded housing of the BNC was connected to a metal grid that was placed on the bottom of the home cage underneath the sipper tube. The volume of fluid consumed in a given period of time was also obtained by measuring the total volume of water given to mice upon placement into the home cage testing apparatus and measuring the volume of the bottle following the completion of the observation period. This measurement could also be taken at various times throughout the long-term observation period.

Throughout the recording of licking behavior, the chamber bottom was covered with a metal grid over wood chips and the water spout was connected to an $\mathrm{A} / \mathrm{D}$ converter. A positive voltage step of $100-800 \mathrm{mV}$ with rise times $<1 \mathrm{~ms}$ could be measured whenever the mouse stood on the metal grid and protruded its tongue to touch the sipper tube (Fig. 4.2). The voltage signal did not need amplification but could be directly acquired using standard A/D interfaces. We have used the powerCED 1401 (Cambridge Electronic Design, Cambridge, UK) with an input range of $\pm 5 \mathrm{~V}$, and the Digidata 1322A (Axon Instruments, Foster City, CA) with an input range of $\pm 10 \mathrm{~V}$. Both interfaces have input resistances of $1 \mathrm{M} \Omega$ and were equipped with 16 bit $\mathrm{A} / \mathrm{D}$ converters resulting in a voltage resolution of $0.15 \mathrm{mV}$ (CED) and $0.3 \mathrm{mV}$ (Digidata). Experiments were ran on groups of animals so that experimental animal and the respective controls had behavior monitored over the same span of time except in the case of pharmacological studies, which an animal was subject to multiple treatments and would later serve as its own control.

\section{Analysis}

While t-tests were sufficient for pair-wise comparisons of the experimental groups to their controls, care was taken to prevent a misinterpretation of data by evaluating the averages per animal. An alternative analysis used all data points collected which introduce thousands of licks and would lead to many degrees of freedom in the analysis of the statistical significance. Thus results would be highly significant while not reflecting the variation typical of biological systems. Analysis of licking microstructure was performed through the univariate procedure or a general linear model using SAS software, (SAS Institute Inc, USA) and through the analysis of log transformed data for parameters with large variation in value. This method could still detect significant differences between the experimental groups. 


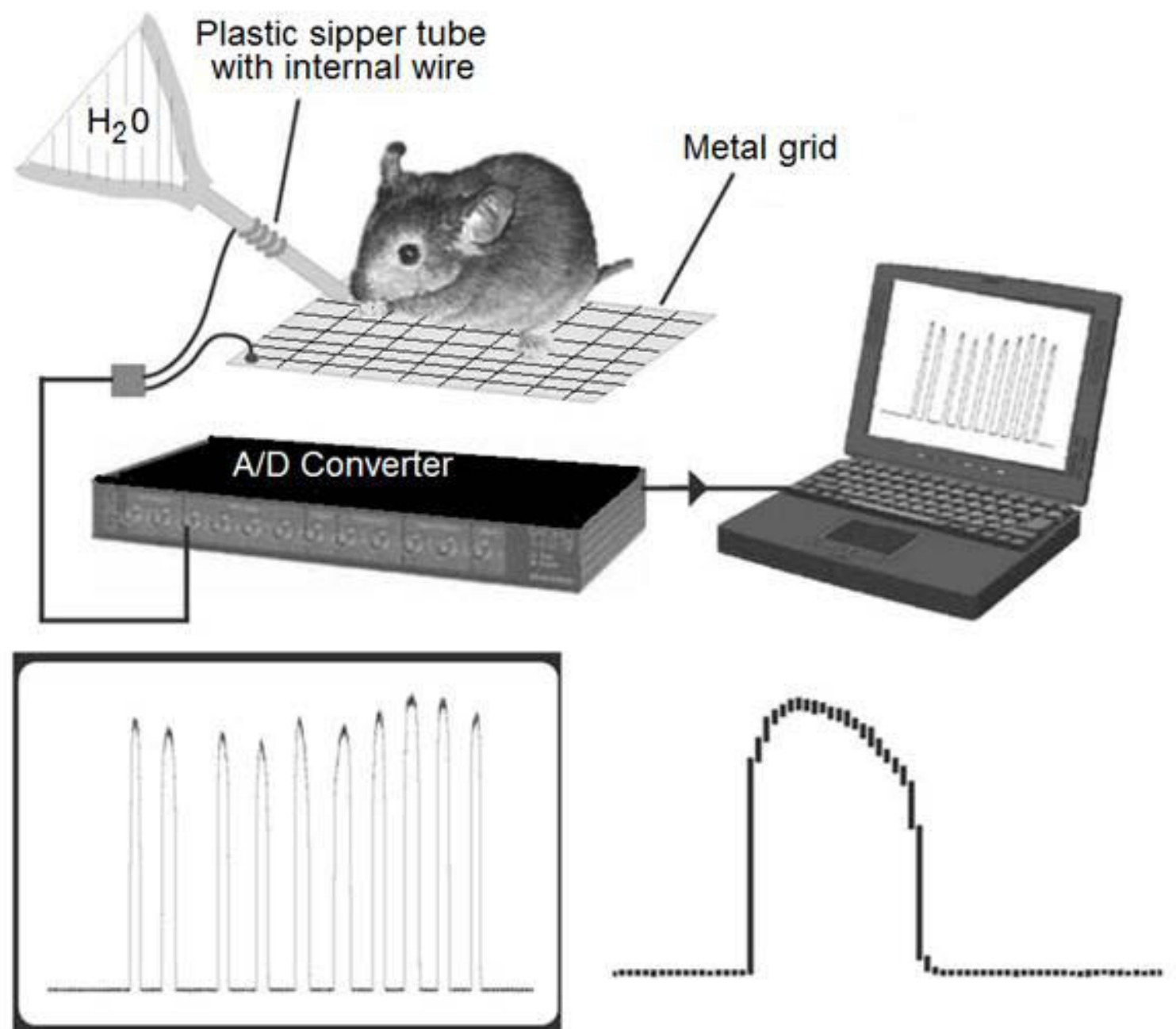

Recorded licking events

Figure 4.2 Experimental setup to measure lick events with a standard analog/digital (A/D) converter in the home cage.

Water was delivered through a sipper tube that had bare wire within it and contacting the water. The bottom of the mouse cage contained a metal grid below the sipper tube that was conductive. The input of the A/D converter was connected to the wire within the sipper tube and the ground was connected to the metal grid. Each lick closed the electrical circuit for the duration of the tongue-sipper tube contact and the junction potential between the metal wire water interface and the mouse's saliva could be recorded. Junction potentials could reach amplitudes of $1 \mathrm{~V}$. Baseline noise was typically $<5 \mathrm{mV}$. Lower right panel illustrates one typical licking event. Note that the rise-time is much faster than the fall-time. 


\section{Results}

\section{Licking Behavior in Cerebellectomized Mice}

We surgically removed the cerebella of 13 adult mice in an effort to determine what influence the loss of cerebellar function would have on fluid licking behavior. The spontaneous licking behavior (i.e. without prior water deprivation) of the cerebellectomized mice and age-matched controls was observed over a 72 hour period. The weights of all animals did not change significantly during testing though the CBX mice did weigh less as a group. Weights were with $26.6 \pm 1.1 \mathrm{~g}$ for CBX and $28.1 \pm 1.3$ controls $(P=0.018$, Student's T-test). After verifying the complete cerebellectomy (Fig. 4.1), 4 mice that underwent surgery and their controls were eliminated due to an incomplete cerebellectomy. The data showed that cerebellectomized mice had a significantly slower lick rate than the control animals with an average inter-lick interval in cerebellectomized mice of $135 \pm 8 \mathrm{~ms}$ (mean \pm SD) and in wild-type mice of $117 \pm$ 7ms (Fig. 4.3B). This difference was significant at a level of $\mathrm{p}<0.001$ (paired T-test). There were no gender specific differences in lick rate as determined by a two way analysis of variance with gender and treatment used as factors.

A more comprehensive analysis of the fluid consumption reveals other changes to the microstructure of fluid-licking. The volume of fluid consumed per lick is reduced in the cerebellectomized mice $(0.95 \mu \mathrm{L} /$ lick $)$ compared to $(1.41 \mu \mathrm{L} /$ lick in the control animals) as seen in Fig. 4.4A. This was determined by measuring the change in volume over a given period and dividing by the total number of licks that occurred during the same time frame. It was also shown that while CBX mice drank on average $3.7 \pm 2.6 \mathrm{~mL}$ of water per day, their age-matched counterparts had a similar intake of water with $3.3 \pm$ $2.2 \mathrm{~mL}(P=0.76$, $\mathrm{t}$-test). Evaluation of the microstructure of the cerebellectomized mouse's licking behavior led to the discovery of several significant changes as well. Licking microstructure includes several other aspects of the behavior besides the rate of tongue protrusion and retraction. During fluid-licking, the first approach of the water spout is termed a visit. During a visit, the animal will lick, typically in bursts of 2 or more individual licks. A lick burst ends when a period greater than 6 standard deviations of the average ILI has occurred with no licks. A visit ends after more than one second has past at the completion of a burst. Overall fluid licking behavior can be examined for the interval between these visits. These visits can be further characterized by the burst composition and the bursts can be examined for licking. During the night cycle both the $\mathrm{CBX}$ mice tended to have multiple visits to the waterspout resulting in many interval that were under 5 hours and this was reflected in the overall distribution of inter-visit intervals (IVIs) shown in Fig. 4.5. This figure shows cerebellectomized mice tended to have longer inter-visit intervals as seen in the larger area under the curve for periods that extend beyond one day or night cycle (12 hours). The comparison of the mean values for IVIs (Fig. 4.6D) between the CBX mice ( 23 hours) and their controls (18hours) shows that the CBX mice had significantly more time between visits. At least two of these mice had intervisit intervals greater than 36 hours (not shown). While the CBX mice did not have more licks per bursts, 15.6, than the control animals, 16.1; they had more bursts per visit, 

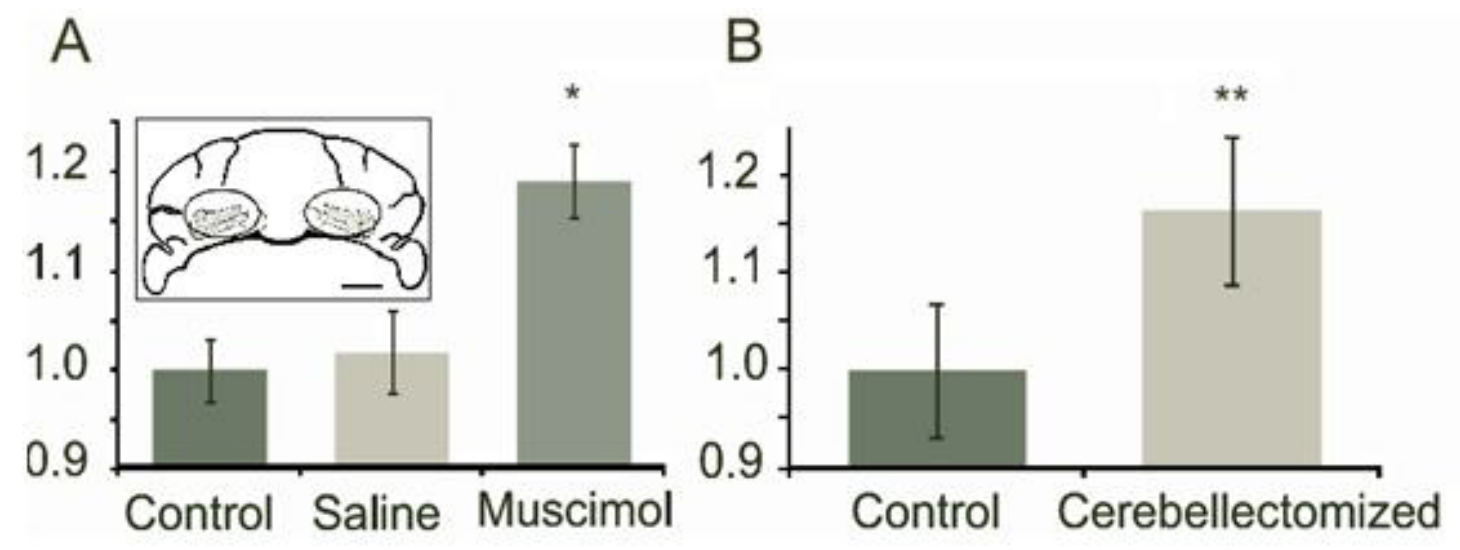

Figure 4.3 Transient inactivation of the interposed deep cerebellar nuclei and the removal of the cerebellum significantly slow licking rhythm.

(A) Pharmacological alteration of cerebellar function. This graphic is the shows the mean interlick intervals as obtained from all ILIs in the first 3 hours following a treatment only. Average lick interval durations increase significantly following bilateral microinjections of muscimol into the cerebellar nuclei compared to pre-treatment values and to control conditions involving bilateral injections of saline into the cerebellar nuclei $(\mathrm{N}=9)$. ILI values are normalized to the pre-treatment values. The inset shows the approximate region affected by the bilateral injections of muscimol approximately $6 \mathrm{~mm}$ posterior to Bregma and $2 \mathrm{~mm}$ lateral of midline. * refers to a $\mathrm{P}$ value $=0.017$ for the muscimol treated group compared to control. (B) Average interlick interval duration of mice that were cerebellectomized at postnatal day $14(\mathrm{~N}=7)$ and of healthy litter mates $(\mathrm{N}=7)$ (ILI values normalized to average ILI of healthy mice). Cerebellectomized mice had longer interlick intervals and thus a slower lick rhythm than normal mice (** refers to a $\mathrm{P}$ value that is less than 0.01 , Student's t-test). Statistical analysis of the animals involved a paired t-test for experimental treatment groups compared to spontaneous licking for the control setting. Error bars depict standard error. 

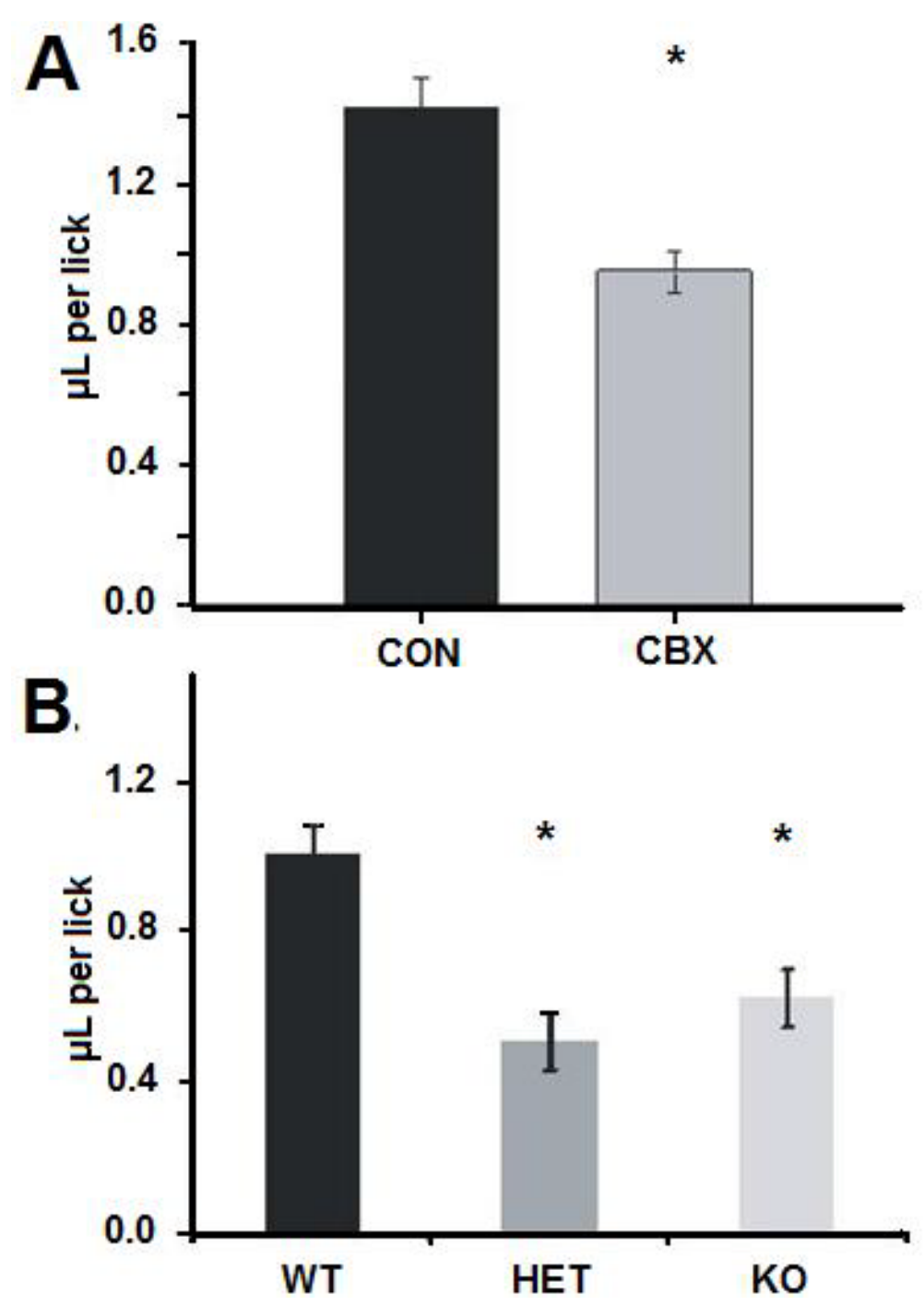

Figure 4.4 Mean volume of water consumed per lick decreases with an altered cerebellum.

Animals from each group were monitored for the total number of licks that occurred in a 48 hour period as well as the total volume of water consumed by the animals during the time frame. The volume consumed was divided by the total number of licks to yield a volume/lick value for an individual mouse. All the values were grouped for an average depending on which experimental group the mouse belonged. (A) Average volume/lick for age-matched control (left) and cerebellectomized (right) mice ( $\mathrm{N}=9$ per group). (B) Volume/lick is shown for the wild type (left), heterozygous (center), and CBLN1 knockout (right) mice ( $\mathrm{N}=6$ per group). For both (A) and (B), ${ }^{*}=\mathrm{P}<0.05$ as determined by Student's T-test and the error bars are shown. 

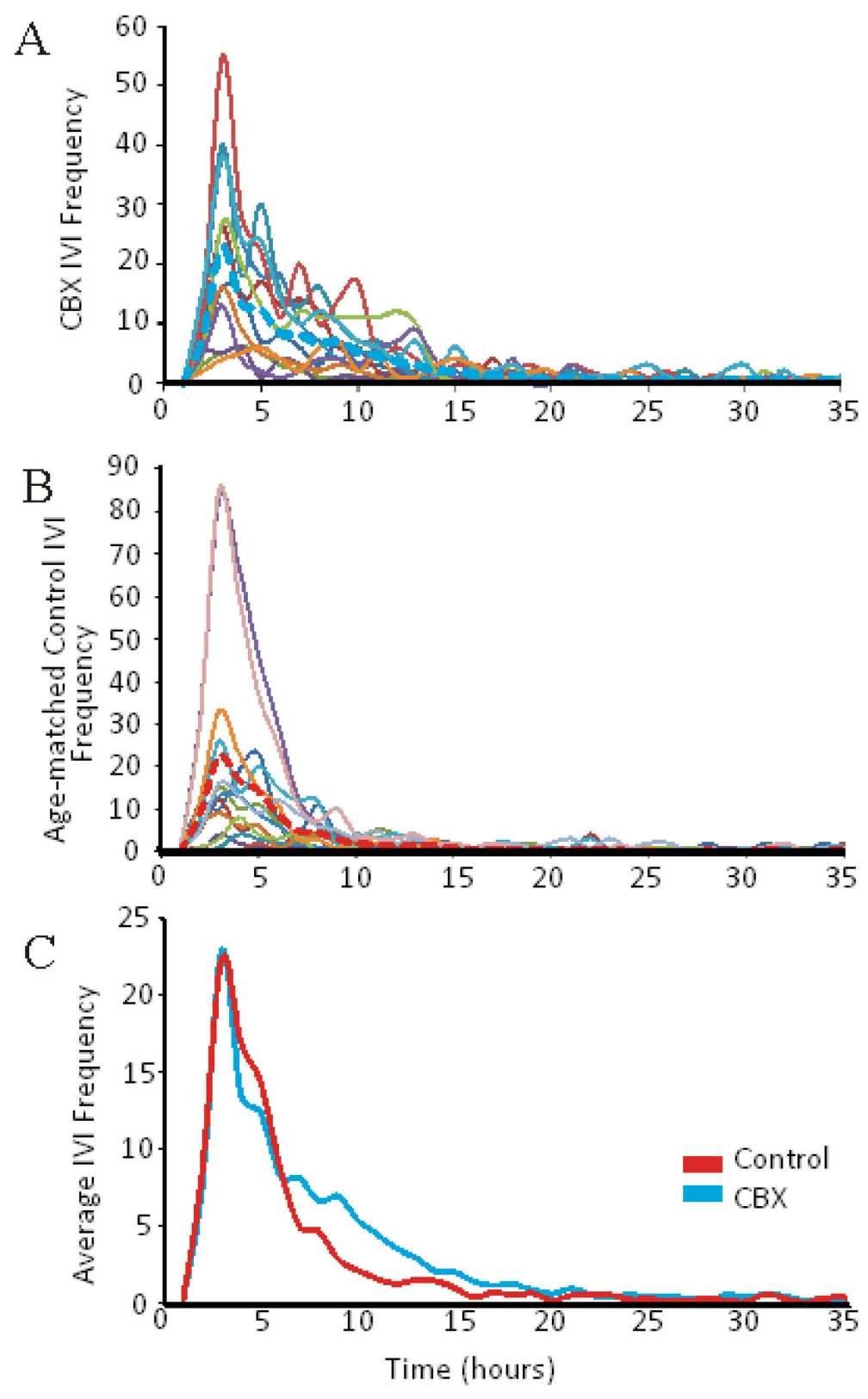

Figure 4.5 Intervisit intervals (IVI) distribution for cerebellectomized mice and agematched controls.

(A) The distributions of the control littermates are shown. Data from each mouse is shown in a different color and the average value from all the mice is shown in the reddotted line. Several IVIs did occur at periods longer than 35 hours and are not shown. (B) Cerebellectomized (CBX) mouse IVIs are shown with individual colors given to individual mice. Any IVIs above 35 hours are not shown and the average of all the mice is shown in the blue dotted line. (C)The distribution of the IVI averages of the littermates (red) and CBX (blue) are shown. 

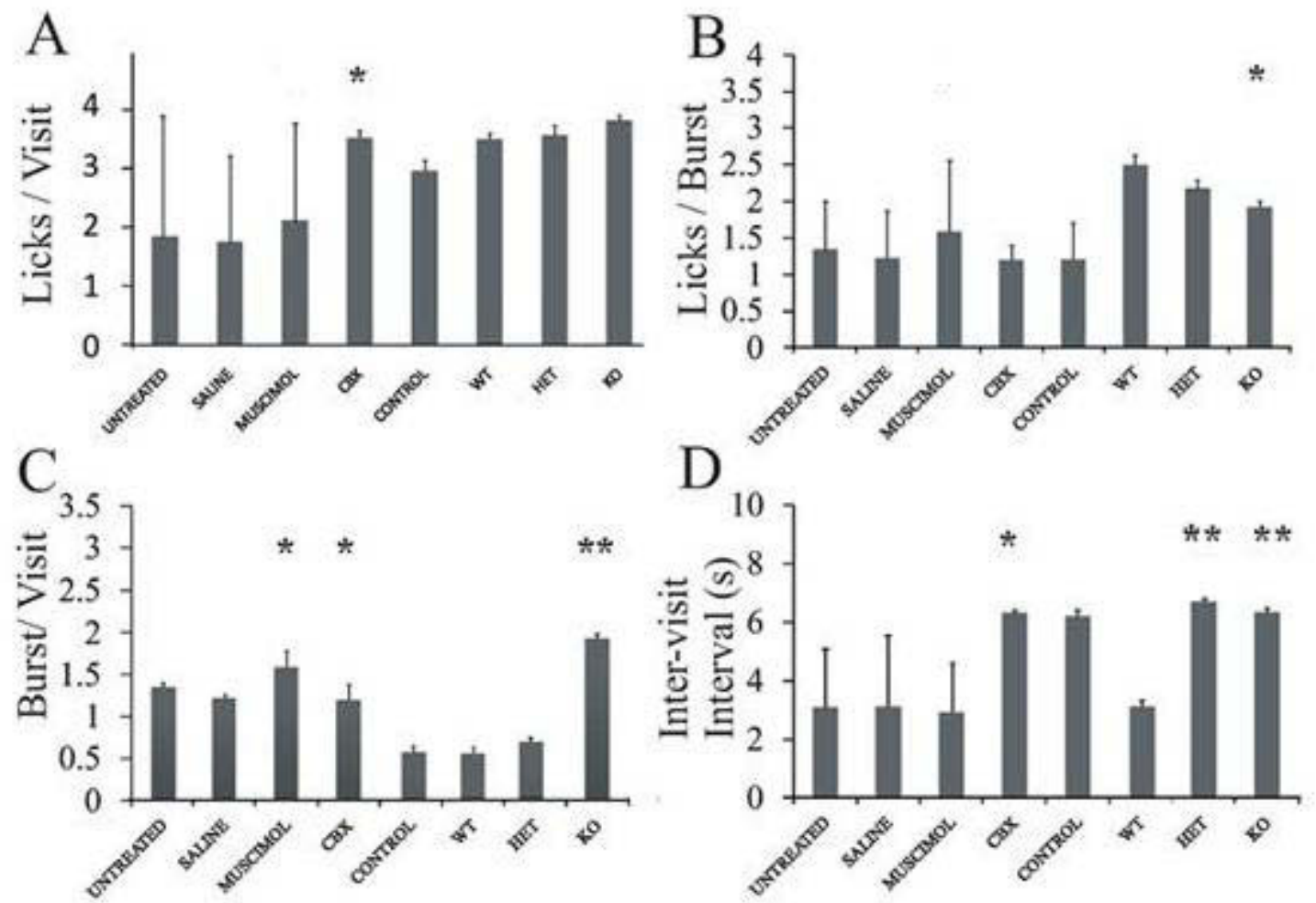

$\mathrm{D}$

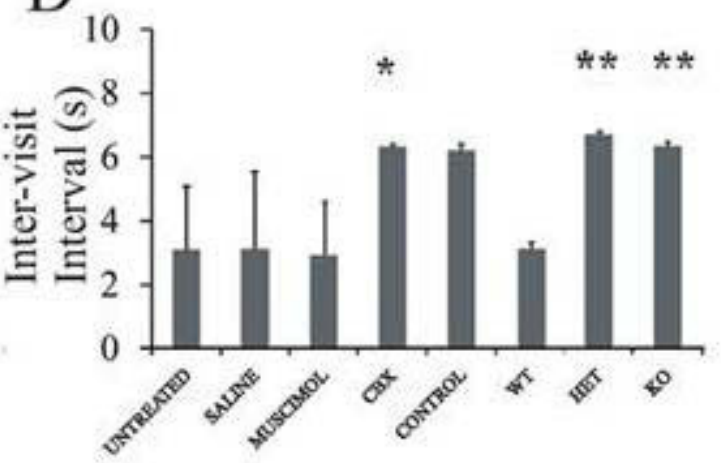

Figure 4.6 Microstructure of licking behavior in ataxic mice.

(A) The average ratio of licks/visit is shown for different experimental groups of mice with altered cerebellar function. (B) The average ratio of licks/bursts is shown for the different groups. (C) The bursts/visit ratio of the groups is shown. (D) The average intervisit interval of the groups is shown. All y-axis scales are logarithmic. Significance of experimental groups are compared to untreated (muscimol experiment), controls (CBX mice), and WT for Cbln1 Knockout (KO) and Heterozygous (HET) mice. * ${ }^{*} \mathrm{P}<0.05$ and $* *=\mathrm{P}<0.01$. The error bars display standard error values. 
10.4, compared to the wild type average of 3.52 . Thus, CBX mice had more individual licks per visit. The increase in individual licks is consistent with the fact that these animals consumed a similar amount of fluid in total during the course of the day despite having had less fluid per lick. In an effort to quantify the regularity of the interlick intervals, the average coefficients of variation for the CBX mice $(0.45 \pm 0.092)$ and the controls $(0.42 \pm 0.10)$ were compared and found to similar $(P=0.46)$. This finding shows that the regularity of the behavior, typical of movements originating from a central pattern generator, is not altered when the cerebellum is removed.

\section{Licking Behavior in Mice with a Genetic Origin to Cerebellar Ataxia}

The CBLN1 knockout mice $(\mathrm{N}=8)$ along with their heterozygous $(\mathrm{N}=6)$ and wild type $(\mathrm{N}=8)$ littermates were also observed in the long-term lick paradigm. The CBLN1 knockout and heterozygous mice licked at a faster rate than the wild type as seen in Fig. 4.7 with the mean of the heterozygous mice falling between the wild type and knockout values. In regards to licking microstructure, the heterozygous and knockout mice both differed from wild type only in that the groups had longer inter-visit intervals. The wild type and heterozygous groups displayed a similar number of overall licks/ visit thought the KO mice had more (see Fig. 4.6A). The KO animals also organized those licks differently by having a significantly lower average number of licks/burst (84.2) than wild type (241) or heterozygous (153) as shown in Fig. 4.6B. The KO mice also had many more bursts per visit with an average of 23.9 bursts per visit for the $\mathrm{KO}$ compared to averages of 4.92 for the heterozygous and 3.39 for the wild type (Fig. 4.6B then Fig. 4.6C respectively). Another aspect of the licking microstructure that was different in the $\mathrm{KO}$ and HET mice was the volume of fluid consumed per lick. Both groups had a lower volume consumed per lick with $0.5 \mu \mathrm{L} /$ lick in the HET mice and $0.62 \mu \mathrm{L} /$ lick for the KO mice (Fig. 4.4B). While both the HET and KO groups differed in the amount of fluid consumed per lick, neither group differed from the WT in the total amount of fluid consumed in a day. Wild type animals consumed an average of $4.40 \pm 1.09 \mathrm{~mL}$ of water in a day while the knockout mice consumed $3.62 \pm 0.90 \mathrm{~mL}(P=0.12)$. The heterozygous mice drank $3.16 \pm 2.2 \mathrm{~mL}$ per day which was not significantly lower than the wild type animals $(P=0.15$, t-test). None of these groups differed significantly in the coefficients of variation either. The mean $\pm \mathrm{SD}$ of the coefficient of variation for WT, HET, and KO were $0.35 \pm 0.10,0.33 \pm 0.10$, and $0.39 \pm 0.08$ respectively. Pair-wise Ttest analysis of the group coefficients of variation yielded $P=0.65$ for the heterozygous mice and $P=0.48$ for knockout compared to wild type.

A subset of these mice ( $\mathrm{N}=4$ for both knockout and wild type animals) also underwent electrophysiological recordings in a head-fixed preparation similar to the one described in Chapters 2 and 3. The results of these recordings in both the wild-type and CBLN1 knockout showed very similar response types to those collected from the C57BL/6J mice to address aim 1. All three response types were detected and when statistically compared by a Chi-square test (Fig. 4.8) but showed no difference in the proportion of response types represented. The average firing rates of Purkinje cells in the KO mice were not significantly different than the wild type Purkinje cells though it 


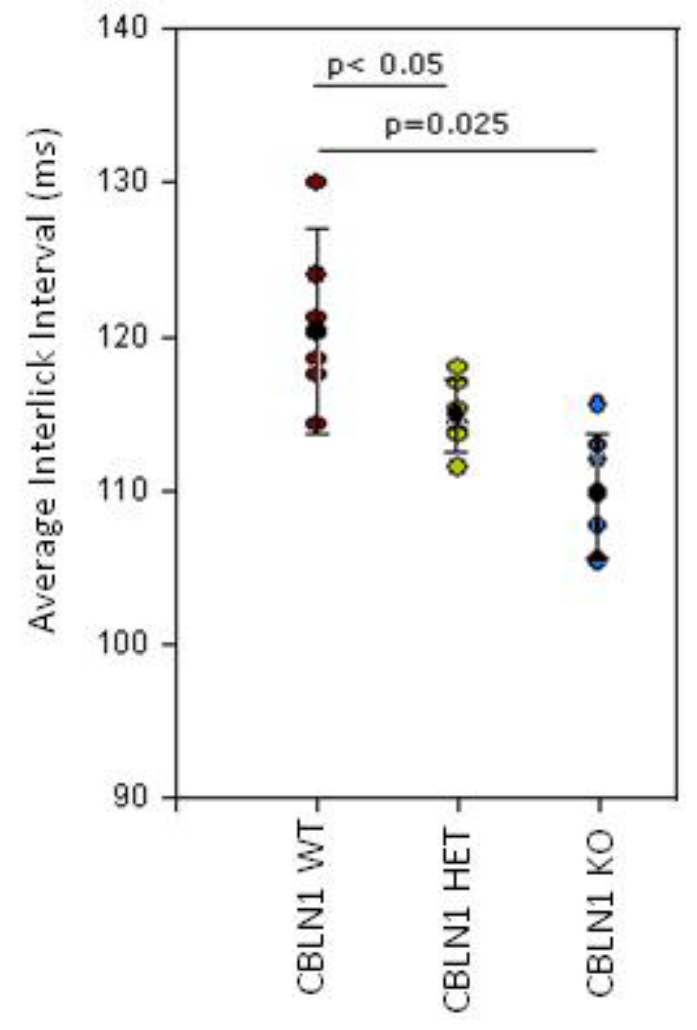

Figure 4.7 Average ILIs in the mouse model of ataxia in a genetically altered cerebellum.

The average ILI of the CBLN1 knockouts (KO), heterozygous (HET), and wild type (WT) mice are shown. The black dot with error bars in the center of each distribution show the average ILI and standard deviation. 


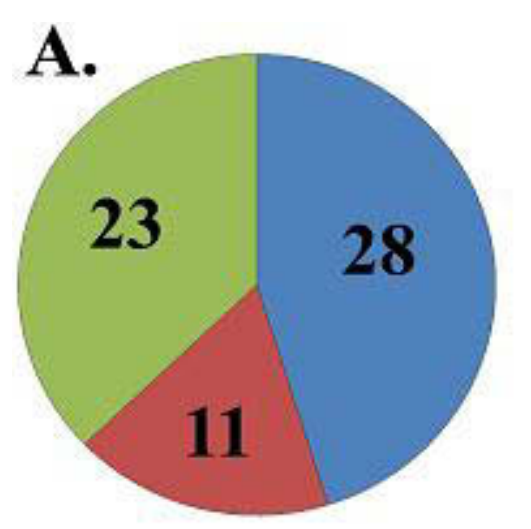

\section{C57BL/6J}

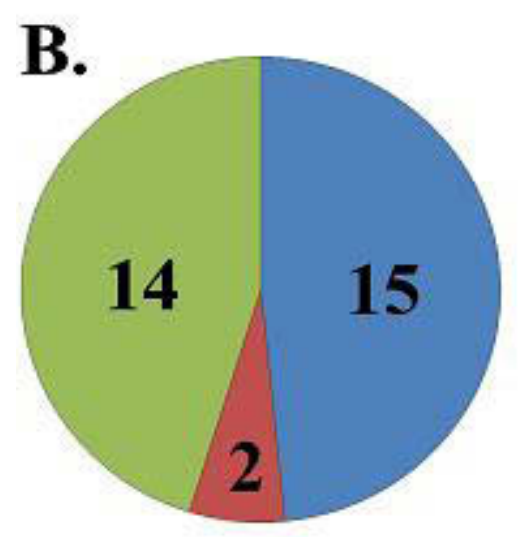

CBLN1 Wild Type

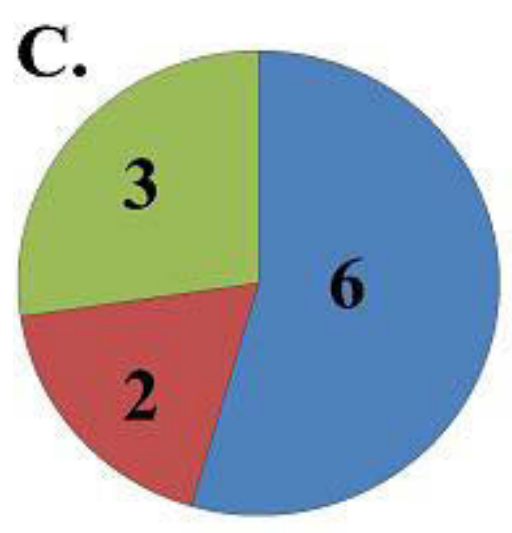

CBLN1 Knockout a Rhythmic

Task-related, nonrhythmic

Not task-related

Figure 4.8 Purkinje cell electrophysiological response types.

The cellular response categories are shown for (A) C57BL/6J mice used in Chapter 3, (B) Mice of the CBLN1 wild type genotype, and (C) CBLN1 knockout mice. 
should be noted that they tended to be lower (data not shown). There were not enough recordings from heterozygous mice to yield any viable statistical comparisons although within the 6 neurons recorded from 2 animals, all three response types were found ( 3 rhythmic; 1 task-related, nonrhythmic; and 2 nontask-related units). More Purkinje cells would be needed from the knockout animals to do correlation analysis of the task related neurons to ILIs of various durations.

\section{Licking Behavior in Mice with a Pharmacologically Altered Cerebellum}

The final experiment required making observations of licking behavior following the injection of the $\mathrm{GABA}_{\mathrm{A}}$ receptor agonist, muscimol, into the interposed nuclei of the deep cerebellar nuclei. Animals were weighed prior to microinjections and again after the completing measurements of licking behavior in their home cage. Untreated mice had an average weight $26.5 \pm 2.0 \mathrm{~g}$ while following injection of muscimol mice had an average weight of $24.9 \pm 1.9 \mathrm{~g}$. Saline-treated animals had an average weight of $26.1 \pm 1.8 \mathrm{~g}$. The injection provided a transient inactivation of the cerebellum. Mice $(\mathrm{N}=9)$ allowed to roam freely in a homecage modified to allow the monitoring of licking behavior had an average ILI duration of $105 \pm 7 \mathrm{~ms}$. Following an injection of muscimol into the cerebellar nuclei the average ILI duration increased significantly to $125 \pm 9 \mathrm{~ms}\left(t_{16}=5.3\right.$, $p=0.001$, paired Student's t-test). Mice injected with the vehicle (saline) had average post injection ILI durations of $106 \pm 13 \mathrm{~ms}$, which was not significantly different $\left(t_{16}=\right.$ $0.20, p=0.84$ ) from pre-treatment durations (Fig. 4.3A). The average volume of water consumed per individual lick was measured in 3 animals. Consistent with our findings in cerebellectomized mice (Fig. 4.4A) blocking cerebellar nuclei activity reduced fluid licking efficiency by reducing the fluid intake volume per lick. Muscimol treated animals consumed $0.94 \pm 0.1 \mu \mathrm{L}$ per lick whereas the same mice consumed $1.2 \pm 0.2 \mu \mathrm{L}$ per lick prior to microinjection $\left(t_{2}=5.0, p=0.038\right.$ with a paired t-test). When these mice were subjected to a saline microinjection, they consumed an average of $1.3 \pm 0.3 \mu \mathrm{L}$ per lick. The difference in volume per lick between saline injection and untreated conditions was not significant.

The licking microstructure of these mice was also analyzed although only the data from the 6 hour period following injections were used (Fig. 4.9) and this showed an initial increase in ILI followed by a return to the untreated condition after 3 hours. The mice injected with saline did not differ from the wild type in any of the measurements when the average ILI of the first 3 hours was used, though the second hour showed a significant decrease in the mean interlick interval for mice treated with the vehicle. At the fourth hour, the mean \pm SD for the untreated group $118 \pm 13 \mathrm{~ms}$, the mean ILI for saline-injected animals was $109 \pm 21 \mathrm{~ms}(p=0.29$ versus control in T-test), and the mean ILI for muscimol-injected animals was $122 \pm 10 \mathrm{~ms}(p=0.48$ versus the untreated control condition with a T-test). However, mice injected with muscimol did show changes to the number of licks (125) per visit when compared to the untreated condition (85 licks per visit) and the saline-injected condition (81 licks per visit) as shown in Fig. 4.6A.

Muscimol-injected mice also saw an increase in licks per burst with 32 LPB compared to 23 LPB in the untreated animals and 20 in the saline-injected animals (Fig. 4.6B). 


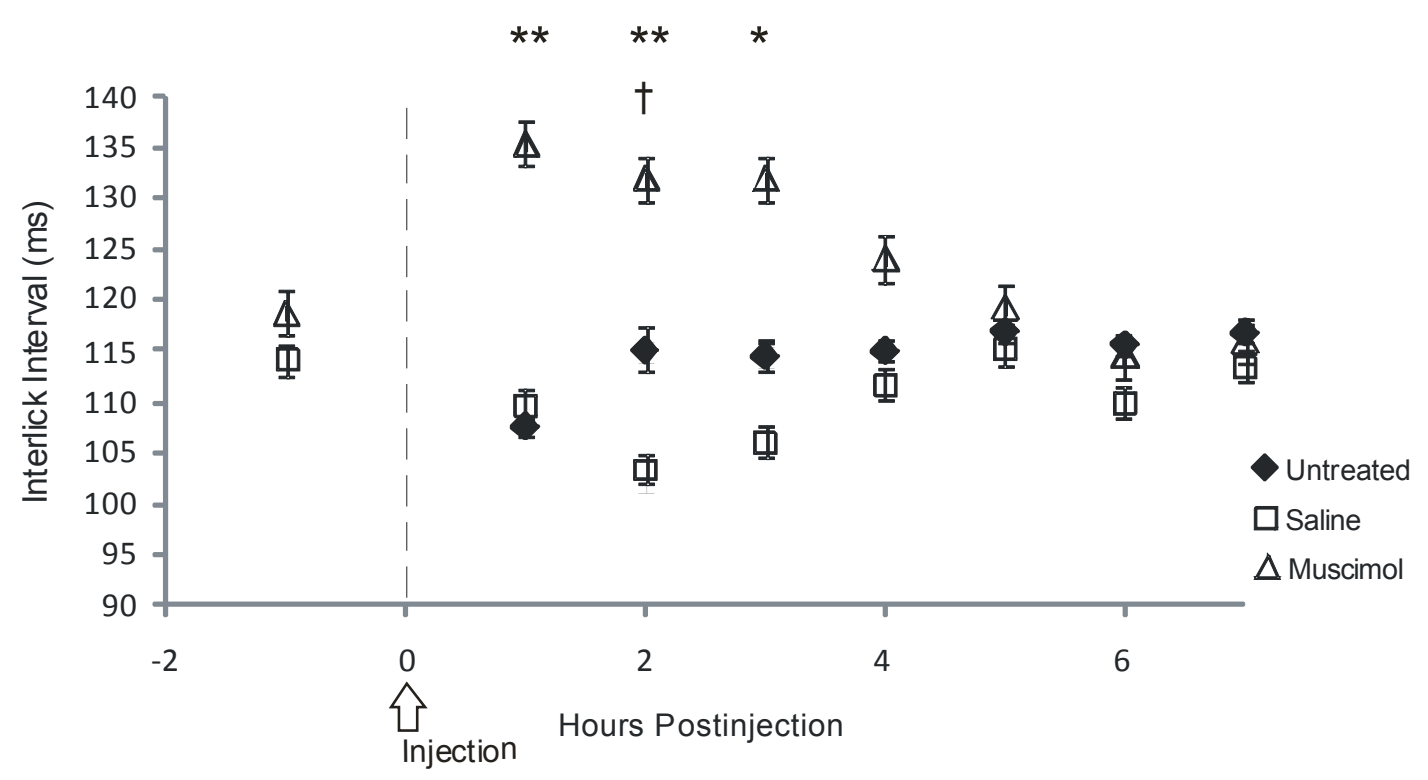

Figure 4.9 Change in average ILI following microinjection.

The average interlick intervals of the mice are shown for the untreated (diamonds), saline injected (squares), and muscimol-injected (triangles) sessions. Untreated data was collected from mice started 24 hours before injection, so time zero for that data set begins from the time that the animal is placed in its home cage with the grid and modified water spout. For the treated groups, the time frame is in reference to the microinjection of saline or muscimol. The animals randomly received saline or muscimol injections first. Error bars display standard error. ${ }^{*}=p<0.05$ (muscimol), $\dagger=p<0.05$ (saline), $* *=p<0.01$ (muscimol) T-test comparisons were made between treatment groups for the ILI for all mice at each hour. 
Neither of the treated groups differed significantly or the number of bursts per visit, with an average of $25 \mathrm{BPV}$ for untreated animals, nor did the treated groups differ for the average inter-visit interval with 323s for the muscimol -treated animals, $630 \mathrm{~s}$ for the saline treated animals, and $601 \mathrm{~s}$ for the untreated animals (Fig. 4.6D). Similarly to the cerebellectomized mice, the coefficients of variation did not differ significantly between the groups. When untreated, animals had an average $\mathrm{CV}$ of $0.38 \pm 0.10$. The muscimoltreated group $\mathrm{CV}$ was $0.59 \pm 0.10(P=0.10$ when compared to untreated with a Student's T-test) and the saline-treated group had a CV of $0.36 \pm 0.12(P=0.19$, Student's T-test). For a very small subset of these animals, $N=3$, we also measured the volume of water consumed per lick. Consistent with our findings in cerebellectomized mice, blocking cerebellar nuclei activity reduced fluid licking efficiency by decreasing the fluid intake per lick. Muscimol-treated animals consumed $0.94 \pm 0.1 \mu \mathrm{L}$ per lick whereas the same mice consumed $1.2 \pm 0.2 \mu \mathrm{L}$ per lick prior to the injection $\left(\mathrm{t}_{2}=5.0, P=\right.$ 0.038 with a paired t-test). Saline-treated mice consumed $1.3 \pm 0.3 \mu \mathrm{L}$ per lick $\left(\mathrm{t}_{2}=0.48\right.$, $P=0.66)$. Following the final injection of saline or muscimol in these mice, stereotaxic microinjections of methylene blue or nontoxic India ink were used to verify that the microinjections of pharmacological agents were in the deep cerebellar nuclei.

\section{Discussion}

Complete removal of the cerebellum revealed that, in contrast to limb and body movements, the gross licking motor pattern is not under the control of the cerebellum. Thus, the pattern of a jaw dropping, followed by a tongue protrusion, tongue contact with the waterspout and water, and the ultimate retraction of the tongue was present in all models of ataxic mice and their control. This is consistent with the notion that the licking movement is controlled by a central pattern generator. The disruption of the cerebellar cortical circuitry or the transient inactivation of deep cerebellar nuclei did not affect the ability of the animals to perform the gross licking movement. However, the efficiency of the movement was considerably altered if one considers that volume of water consumed per lick. Both the cerebellectomized and the CBLN1 mutant mice saw a decrease in this measure. Other macro- and microstructure aspects of the behavior changed as well. The temporal aspect of the behavior was significantly altered, as the lick rhythm was significantly slower in cerebellectomized mice compared to healthy controls. It is very likely that more than one neuronal mechanism is in place to provide such vital motor functions as the protection of the airways. The increase in inter-lick interval duration observed after loss of cerebellar function may thus reflect a less effective and thus more time consuming coordination of licking with swallowing and respiration by compensatory neuronal mechanisms. The faster and more efficient coordination of brain stem pattern generators by the cerebellum provides an evolutionary advantage as it reduces the vulnerable times spent drinking and improves the protection of the airways from asphyxiation. Even small improvements in these vital functions may provide significant advantages over the course of evolution. The lack of detectable differences between the genders could have multiple interpretations. Larger numbers of animals might reveal a gender difference like that found by (Boughter et al., 2007) for a study observing 37 mice of C57BL/J but not for another commonly studied strain DBA/2J 
(Boughter et al., 2007) with the use of a general linear model factoring the treatment group and mouse gender. Alternatively, the removal of the cerebellum and its function in coordinating the motor output necessary to perform the multiple rhythmic behaviors associated with fluid consumption may have removed part of the pathway that resulted in discernable differences between the genders. The licking macrostructure of the animals lacking a cerebellum also showed pronounced changes including an increase in the time between visits to the water spout although the gross motor motions required to consume fluids remained intact. Perhaps the ataxic gait in the animals impaired the ability to move about the home cage to get chow and fluids. The increases in bursts/visit could also be reasonably explained as a necessary compensation for these less frequent visits in order to obtain similar amounts of water. The increases in bursts could also compensate for the lower efficiency licking in the cerebellectomized mice.

The genetic model of altering the cerebellum yielded an insightful change to fluid-licking behavior in that this model of cerebellar dysfunction significantly altered the licking rhythm, but in a direction opposing what was seen for animals completely lacking a cerebellum. Mice lacking the Precerebellin gene licked faster and had fewer licks per burst but many more bursts per visit. The increase in burst again seems like a compensatory change in fluid licking microstructure capable of counteracting the decreased efficiency volume of water consumed per lick and a significant increase in the time between visits. These animals have what could be considered an intact cerebellum save the synaptic protein known to stabilize inputs from the granule cell layer. The heterozygous mice also showed significant changes to ILI and IVI, suggesting that even the partial removal of the functional CBLN1 gene results in a phenotype regarding rhythmic oromotor behavior. Electrophysiological recordings in the cerebella of KO mice also displayed normal response types in the cell suggesting that the ataxia in these mice may not be due to dysfunctional network activity in the cerebellar cortex. Unfortunately the CBLN1 knockout is a complicated model of genetic ataxia as the gene affects many other tissues and is not completely understood for its role in phenotypic responses. This study is one of the first to show a discernable phenotype in the heterozygous mouse. Even with the limitations to the interpretations of the results for these mice, strong evidence is shown supporting the argument that a present, yet dysfunctional cerebellum can also influence fluid-licking rhythm and microstructure of the behavior.

Mice that were subjected to transient inactivation of cerebellar function also showed changes that were consisted with the other models of altered cerebellar function. Like the CBX mice, muscimol-injected mice had increased interlick intervals. Both of these groups also saw an increase in licks per visit, which is a viable change to licking microstructure to ensure that similar amounts of fluid is being consumed since these animals maintained body weights. There was some evidence that the group treated with the vehicle, saline, actually exhibited a temporary shortening of the ILI during the second hour following an injection. If saline could indeed have an antagonist affect to the muscimol, than those results imply that the effects of the muscimol were possibly reduced, but still yield significant changes consistent with the CBX model of cerebellar dysfunction. The recovery of cerebellar function over time as the muscimol was metabolized aligned with the return of the average ILI to the value obtained before the 
mice were subjected to injections. Thus, this series of experiments show that the functional cerebellum is contributing to the microstructure of fluid-licking behavior as observed in the untreated mouse. Without devising a better means of maintaining the effects of muscimol over an extended period of time, like the 72 hour period in which CBX and CBLN1 mice were observed, I hesitate to make generalized conclusions about other changes to macrostructure, such as inter-visit interval measurements.

The studies presented in this chapter were designed to complement the goals of the first specific aim while addressing the objective of the second aim. I hypothesized that the disruption of cerebellar circuitry would significantly alter the observed temporal pattern of fluid licking the mouse. All of the techniques used to alter the normal function of the cerebellum resulted in changes to the behavior of interest. In the case of transient inactivation and the cerebellectomies, the two methods of functional ablation yielded similar results in the lengthening of the interlick interval and the corresponding increase in licks per visit. The genetic model of ataxia showed that changing the normal functions of the cerebellum could also result in changes to licking microstructure that were in the opposite direction of the functional ablation models in that the CBLN1 knockout mice licked at a faster rate. These observations importantly show that, even though ataxia generally slows down movements of affected mice, the effect on licking can be a decrease or an increase in the speed of licking rhythm, depending on the causes of ataxia. The changes in microstructure for the CBX and muscimol treated animals all are explainable when analysis of volume of water per lick or intervals between visits are analyzed because they provide viable means for these ataxic animals to maintain their fluid intake and nutritional needs. These micro- and macrostructural characteristics of fluid licking behavior could ultimately be considered components of an animal's fluid homeostasis along with other behaviors such as mictrurition or panting. 


\section{CHAPTER 5: SUMMARY}

\section{Review of Aims}

In the rodent, fluid licking involves the coordination of rhythmic opposing movements of orofacial muscle groups. Protrusion and retraction of the tongue, swallowing, respiration, and mastication are all motions with intrinsic rhythms thought to originate in the rudimentary portions of the CNS. Within the brainstem are known central pattern generators with activity correlated to these behaviors. The hypoglossal nucleus, in particular, has been shown to fire in conjunction with rhythmic tongue movements (Travers \& Jackson, 1992); though evidence also suggests a major role for other regions of the brainstem such as the reticular formation (Travers \& Jackson, 1992; Travers, DiNardo, \& Karimnamazi, 1997; Travers, DiNardo, \& Karimnamazi, 2000). Licking, along with several other movements of a rhythmic nature such as the swimming of a dogfish (Paul \& Roberts, 1984), can be evoked in decerebrate animals which provide evidence of movement origin from central pattern generators in the brainstem (Berntson $\&$ Micco, 1976). These behavioral outputs of these central pattern generators are subject to supramedullary controls in the intact animals and the data reported within this dissertation supports a cerebellar role in the regulation or coordination of these rhythmic movements. I divided the final discussion of the work presented in this dissertation based on the manner in which the specific aims were addressed.

\section{Specific Aim 1}

The first aim of this endeavor was to test the hypothesis that the cerebellum modulates the rhythm observed during fluid licking and therefore will have a neuronal representation of the behavior. This led to a primary goal of characterizing the Purkinje cell activity during the rhythmic behavior of fluid-licking to determine if neuronal activity reflected the ongoing behavior observed. The experiments designed to test this hypothesis required a means to measure the neuronal activity of an awake, behaving mouse during an innate, rhythmic oromotor behavior. First, it was necessary to be able to monitor the behavior in a manner that contributed to electrophysiological studies. Few labs have attempted to perform electrophysiological studies in a behaving mouse and the few that did lacked detailed descriptions of the technique. By referring to previous studies in awake rodents (Heck, Kummell, Thach, \& Aertsen, 2002; Bryant, Roy, \& Heck, 2009), I was able to adapt multiple techniques to a head-fixed preparation for electrophysiology with a simple and efficient means of monitoring licking (Hayar et al., 2006). Through this technique, I was able to attain extracellular recordings of single and multi-unit recordings from the Purkinje cells of cerebellar cortex regions linked to orofacial sensations. The Purkinje cell activity I observed yields three patterns of activity. Purkinje cells typically fire at a high rate of continuous simple spikes $(10-200 \mathrm{~Hz})$ interspersed with some pauses in activity and some complex spikes at a rate of approximately 1-5 Hz. I was also able to monitor licking behavior in these mice, and determined that the C57BL/6J mice used in these tests licked at a rate of approximately $8 \mathrm{~Hz}$. Some research 
has implicated the olivocerebellar system modulation of the activity in the cerebellar cortex during behavior such as licking (Welsh, 1998; Lang, Sugihara, Welsh, \& Llinas, 1999; Groth \& Sahin, 2009). For this reason, I performed cross-correlation analysis of complex spike activity with fluid-licking but found no significant correlation. However, correlation analysis of simple spike activity to fluid-licking yielded evidence of two distinct types of Purkinje cell responses related to licking behavior. For some neurons, licking engaged a rhythmic change in the firing rates of the neuron that reflected the interlick interval of the mouse.

A closer examination of cells with this response pattern showed that the neurons were not necessarily firing at the same phase with the behavior as other neurons, even if recorded in the same animal at the same time. The electrolytic lesions set following the completion of electrophysiological recordings also made it possible to determine the area from which neurons were recorded. Analysis of spatial distribution of the recordings showed no regional specificity of the simple spike response types. There were also no changes to the mean spike rate recorded before and during licking behavior, suggesting that the observed responses were modulated around the mean firing rate of the neuron. In an effort to address if cerebellar responses were related motor commands, sensory feedback, or both; simple spike rate changes were then compared based on where they occurred in relation to lick onset. Presumably, the analysis would yield a preference for changes that occur after lick onset for a predominantly sensory response. This analysis revealed a normal distribution about the lick onset meaning that changes to rate occurred equally before and after licks. Correlations of the simple spike firing rates to interlick intervals of long and short durations showed that some cells changed rates very close to lick onset, as if reacting to a sensory stimulus such as the contact of the tongue with the waterspout; still other cells appeared to alter rates in relation to the duration of individual interlick intervals.

Evidence for sensory responses in frog cerebellum in response to electrical stimuli on the tongue (Hanamori \& Ishiko, 1987) and retrograde tracing studies showing sensory projection from the hypoglossal and trigeminal nerves in the amphibian system (Mandal $\&$ Anderson, 2009) readily support a role for the cerebellum's responses to relate to the sensory experience of fluid licking, however these experiments did not sufficiently addressed the hypothesis that the cerebellum influence the motor characteristics of the rhythmic oromotor behavior. Alternatively, evidence of zonal electrical stimulation of the fastigial and dentate nuclei in monkey resulted in changes of the tongue musculature (Bowman \& Aldes, 1980) and supports the argument than the cerebellum can influence the motor aspects of fluid licking. The experiments designed to address specific aim 2 do address cerebellar influence on the motor aspects of fluid-licking, but in an awake animal allowed to initiate the behavior in a more typical setting.

The electrophysiological recordings in the head-fixed mouse as described in this dissertation have yielded several advances to the field. The technique has been thoroughly documented and allows for the application of the method to other mouse models of central nervous system disorders. Mice offer an opportunity to study many genetic models of human disease in a mammalian system. The fact that the animal is 
conscious and capable of being subjected to multiple stimuli also provides more opportunities to observe neural networks function in a more natural manner than electrophysiological recordings in slices or cells can. Although the response types of the Purkinje cells of the murine cerebellar cortex were found to be similar to response types documented in monkey and dogfish, the findings add to the validity of rodent models of human disorders. The level of analysis of simple spike rate changes in relation to the behavior set the foundation for future studies to elucidate the specific aspects of the behavior with which the neuron is concerned. Fluid consumption is a more complex behavior than just the protrusion and retraction of the tongue although for simplicity, the analysis looks at just the licking. During the fluid-consumption the mouse must lick, swallow, and breathe. Future studies will hopefully do more to determine how much motor control the cerebellum exerts on coordinating the timing and occurrence of all of the actions that occur during fluid-consumption.

Much of the research on the network activity of the cerebellum takes place in organotypic slices or in anesthetized animals, which is not conducive to studying the system during behavior often thought to be heavily influenced by the cerebellum. Thach was one of the earlier researchers to observe neuronal behavior in an awake, behaving primate (Thach, 1968). His paradigm involved a behavior that resulted in an alternating movement of the limbs. His results yielded the discovery that Purkinje cells with multiple response patterns during this behavior. The first was those cells that were phasically firing with the alternating movements; the second group changed their pattern of activity during movement though not in a phasic manner, and lastly those cells that did not change firing patterns at all. Similar response patterns findings would later be reported in decerebrate dogfish that were stimulated to produce swimming motions (Paul \& Roberts, 1984). Thus, cerebellar Purkinje cell activity appears to have consistent patterns of activity in relation to behaviors of a rhythmic nature. While I am not the first to investigate activity in the cerebellar cortex as it relates to behavior, I am the first to examine the simple spike activity of the Purkinje cells as it relates to fluid licking. The previously investigated lick related complex spike activity is a rare event, believed to be related learning in the cerebellum. The high frequency simple spike output is involved in the modulation of ongoing behavior and thus the more relevant signal to understanding the cerebellar role in controlling behavior.

The techniques used provided an adequate temporal resolution of the spike correlated behavior allowing comparison of rhythmic changes in spike rate at the ms level. Additionally, the method offers some advantageous over possible other means of examining neuronal activity as it is correlated to behavior. Vast improvements are currently being made in the field of optical imaging but current methods are limited in the depth of recording in vivo (Grewe \& Helmchen, 2009) with rapid detection of voltage changes. While functional multineuron calcium imaging can have single cell resolution, it is recognized as particularly invasive to living biosystems (Takahashi, Sasaki, Usami, Matsuki, \& Ikegaya, 2007). Multiple electrode arrays could also be used during behavior to better investigate network activity during behavior. These studies could be viable next steps in understanding the interactions of neurons in the cerebellar cortex during fluid licking and are greatly improved by profiles of simple spike response categories and 
spatial arrangements of Purkinje cell response types elucidated within this dissertation.

\section{Specific Aim 2}

The second aim of this work was to test the hypothesis that disruption of the cerebellar circuitry will significantly alter the observed temporal pattern of fluid licking in the mouse. Following the characterization of Purkinje cell responses during fluidlicking, I gained insight into to behavior correlated activity in the network of the cerebellar cortex. The next set of experiments set about examining the effects on the behavior if the cerebellar network had altered function. The first set of experiments addressed fluid licking in a cerebellectomized mouse. Observation of fluid-licking behavior from these animals and their age-matched controls yielded several significant differences in the behavior. Observations of the mice over an extended period also proved advantageous to understanding the behavior of interest more in depth. Not only did I find that the rate or rhythm of licking slowed down, but I also discovered that the animals now altered the overall temporal strategy associated with fluid consumption.

Cerebellectomized mice demonstrated longer intervals between visits to the waterspout and in those visits they tended to have more bursts although the number of licks per burst did not differ from their littermates. Analysis of fluid consumption showed that like other experimental models of altered cerebellar function, the cerebellectomized mice consumed less fluid per lick. In order to consume similar amounts of water in the same time frame as their littermates but in reduced visit numbers, these mice had to lick more per visit. This is an interesting method of counteracting potential deficits in nutritional intake. Another reasonable method would have been to decrease the inter-visit interval though this may interrupt other behaviors related to fluid homeostasis in the mouse.

Interpretation of the cerebellectomized mouse data must also consider the possibility that compensatory processes alleviated the affects of a complete cerebellectomy at postnatal day 14. If adult survival rates were improved, observation of the behavior in a cerebellectomized but otherwise mature brain could prove useful.

Mice subjected to transient inactivation of the cerebellum underwent similar changes to licking microstructure such as increased inter lick intervals and a dramatic increase in inter-visit intervals. The benefit to the model involving transient inactivation was the ability to watch cerebellar function return and see that the $\mathrm{m}$ ice also returned to licking microstructure similar to the untreated state. The genetic model of ataxia offered an interesting means of testing the hypothesis in that heterozygous animals offered an opportunity to see if the genetic influence could be mitigated a heterozygous genotype. Indeed these animals displayed fluid-licking behavior phenotypes that fell in the range between wild type and knockout values for ILI. CBLN1 knockout mice and heterozygous mice also saw a decrease in licking efficiency by decreasing the average volume of fluid consumed per lick. One consideration in the interpretation of these results is that the Precerebellin gene and similar proteins have been discovered in the brainstem, adrenal gland, dorsal cochlear nuclei, and several other regions of the central nervous system. Modifying expression of that gene could affect multiple regions and confound interpretation of the results. While the CBLN1 genetic mutants provided useful insights 
into the cerebellar regulation of fluid licking behavior, a genetic model of cerebellar ataxia with effects confined to the cerebellum, such a mouse model of spinocerebellar ataxia 1 would be useful in that one would not have consider such confounding issues such as changes to other central nervous system structures or other body systems due to the deletion of the gene and the potential effect those changes would have on observed behavior. As noted earlier, CBLN1 is found in multiple areas of the body such as the adrenal glands, the dorsal cochlear nucleus, and the cerebellum though most notably it is found within the cerebellar cortex.

Overall, the three models of cerebellar ataxia were successful at demonstrating a definite role for the cerebellum in the regulation of fluid licking. This chapter conclusively shows that the cerebellum contributes to fluid homeostasis. It is also the first study to address the contribution of the cerebellum to supramedullary regulation of the macrostructure of fluid licking.

\section{Conclusions}

The cerebellum plays an important role in the defining the temporal characteristics of the ororhythmic behavior of fluid licking. Cerebellar regulation of fluid licking occurs both on the level of fluid homeostasis in macrostructure of fluid licking behavior and at the microstructure of fluid licking. The influence of the cerebellum on the macrostructure of fluid licking can be seen in the altered intervisit intervals for ataxic mice. While the underlying mechanisms of this influence have not been uncovered, one may speculate that the dysfunctional cerebellum may disrupt the integrity of the circuit responsible for nutritional homeostasis. Cerebellar-hypothalamic connections (Dietrichs, Wiklund, \& Haines, 1992) provide a possible pathway. Another possibility could be the direct influence of the cerebellum on thirst. This possibility is supported by case studies of abnormal thirst in patients with neurodegenerative diseases of the cerebellum (Fukazawa, Tsukishima, Sasaki, Hamada, \& Tashiro, 1995) and functional imaging (Egan et al., 2003) and neurophysiological (Zhu \& Wang, 2008) studies showing a cerebellar role in the consciousness of thirst. While more work is needed to define the exact neural mechanisms and pathways associated with cerebellar influence on fluid licking, this study provides evidence of a cerebellar representation of the activity of Purkinje cells and detectable alterations in the behavior in models of cerebellar dysfunction in support of the premise that the cerebellar cortex and deep cerebellar nuclei are neural substrates in the modulatory pathway responsible for rhythmic oromotor behavior.

The electrophysiological methods are easily adapted to other regions of the brain and amenable to adaptation for studying other orofacial movements such as whisking. The behavior-correlated neuron activity in an awake, behaving mouse presented in this work is preceded by somatosensory mapping experiments in anaesthetized rats, observed dysphagia in cerebellar patients, and other studies suggesting that the current findings are in accordance with the literature. The novel aspects of this work include the choice of model, the method of monitoring the behavior, and the application of the questions to the 
short term and long term behavior. The data presented within work show that the lick related cerebellar cortical activity is related to the observed fluid-licking behavior in the mouse. Altering the normal functioning or the structure of the cerebellum caused distinguishable changes to the behavior in the form of changes to the average interlick interval as well as changes to macrostructure by changing the intervals in which the mice visited the waterspout. In order to understand the role of the cerebellum in fluid licking we measured licking behavior in mice with permanent and temporary loss of cerebellar function. We compared mice with permanent and temporary ataxia to control for potential compensatory effects from long term adaptation of cerebellectomized mice to loss of cerebellar function. Both the permanent removal of the cerebellum and the temporary block of cerebellar spike output resulted in a significant slowing of the licking frequency as previously seen with functional ablation in the rat (Vajnerova et al., 2000) further supporting a cerebellar role in modulating the licking frequency. The effect was slightly more severe in acutely ataxic mice (19\% increase in ILI duration) compared to mice that were cerebellectomized at postnatal day 14 (15\% increase in ILI duration). This might be the result of compensatory mechanisms established over the lifetime of cerebellectomized mice which are not available to temporarily ataxic mice. The fact that the gross licking movement was not obviously altered in either form of ataxia is consistent with the notion that the licking movement is controlled by a brainstem central pattern generator (Nishijo \& Norgren, 1991; Brozek, Zhuravin, Megirian, \& Bures, 1996; Travers, DiNardo, \& Karimnamazi, 1997) which would be responsible for generating the muscle activity pattern underlying the gross licking movement. However, our finding of a decrease in the average volume of fluid consumed with each lick shows that the cerebellum is involved in fine motor coordination to increase the efficiency of the licking movement.

This dissertation attributes a novel role to the cerebellum in that it provides evidence of cerebellar regulation of fluid licking behavior on micro- and macrostructural level. Many methods have been used to study fluid licking in the rodent, several researchers have performed neurophysiological recordings in the awake mouse, but I am the first to combine methods in addition to applying in-depth analysis of an innate behavior in the mouse as it occurs during the animals extended pattern of behavior. While previous studies have shown complex spike correlation and population synchrony in relation to licking behaviors, none examined the simple spike changes. My work does show behavior-correlated spike activity from a dispersed population of Purkinje cells encoding the licking rhythm and some still unknown non-rhythmic aspect of licking behavior. Furthermore, I show that simple spike activity distinguished between short and long inter-lick intervals, consistent with a cerebellar role in temporal aspects of motor control, in this case though modulating brainstem pattern generator activity. The results of chapters 3 and 4 of this work suggests that both the temporal pattern of fluid licking at the level of individual licks and at the level of the visit are both affected by the cerebellum.

In clinical cases involving damage to the cerebellum, injuries to regions that are the developmental equivalent in human and rodents, such as Crus I and Crus II, produce devastating cognitive effects that disrupt language and memory recall (Schmahmann \& 
Sherman, 1998). While in rodents, this Crus I corresponds to sensorimotor processing of orofacial regions, a battery of behavioral tests in rodents does not currently exist which is capable of detecting the intricate disruption of the quality of life found for human patients. The use of a behavioral analysis presented within this study offers one means of investigating coordination deficits of orofacial movements and changes to basic behaviors that result from an alteration of normal cerebellar function. While this work provides some answers to scientific questions about the roles and the spheres of influence of the cerebellum, there is still much to be known. Further investigation on the sensory and motor components of the cerebellum's actions during fluid-licking can elucidate specific mechanisms of neuronal network activity. 


\section{LIST OF REFERENCES}

Accolla, R., Bathellier, B., Petersen, C. C., \& Carleton, A. (2007). Differential spatial representation of taste modalities in the rat gustatory cortex. J.Neurosci., 27, 1396-1404.

Albertin, G., Malendowicz, L. K., Macchi, C., Markowska, A., \& Nussdorfer, G. G. (2000). Cerebellin stimulates the secretory activity of the rat adrenal gland: in vitro and in vivo studies. Neuropeptides, 34, 7-11.

Albus, J. (1971). A theory of cerebellar function. Math Biosci,10, 25-61.

Aldes, L. D. \& Bowman, J. P. (1979). Representation of the tongue in the cerebellar nuclei of the monkey. Exp.Neurol., 64, 202-215.

Anderson, C. W. \& Nishikawa, K. C. (1997). The functional anatomy and evolution of hypoglossal afferents in the leopard frog, Rana pipiens. Brain Res., 771, 285-291.

Auvray, N., Caston, J., Reber, A., \& Stelz, T. (1989). Role of the cerebellum in the ontogenesis of the equilibrium behavior in the young rat: a behavioral study. Brain Res., 505, 291-301.

Ball, G. G., Micco, D. J., Jr., \& Berntson, G. G. (1974). Cerebellar stimulation in the rat: complex stimulation-bound oral behaviors and self-stimulation. Physiol Behav., 13, 123127.

Bao, D., Pang, Z., \& Morgan, J. I. (2005). The structure and proteolytic processing of Cbln1 complexes. J.Neurochem., 95, 618-629.

Bao, D., Pang, Z., Morgan, M. A., Parris, J., Rong, Y., Li, L. (2006). Cbln1 is essential for interaction-dependent secretion of Cbln3. Mol.Cell Biol., 26, 9327-9337.

Beales, M., Lorden, J. F., Walz, E., \& Oltmans, G. A. (1990). Quantitative autoradiography reveals selective changes in cerebellar GABA receptors of the rat mutant dystonic. J.Neurosci., 10, 1874-1885.

Belknap, J. K., Crabbe, J. C., \& Young, E. R. (1993). Voluntary consumption of ethanol in 15 inbred mouse strains. Psychopharmacology (Berl), 112, 503-510.

Berntson, G. G. \& Micco, D. J. (1976). Organization of brainstem behavioral systems. Brain Res.Bull., 1, 471-483.

Berrebi, A. S., Morgan, J. I., \& Mugnaini, E. (1990). The Purkinje cell class may extend beyond the cerebellum. J.Neurocytol., 19, 643-654. 
Berrebi, A. S., Oberdick, J., Sangameswaran, L., Christakos, S., Morgan, J. I., \& Mugnaini, E. (1991). Cerebellar Purkinje cell markers are expressed in retinal bipolar neurons. J.Comp Neurol., 308, 630-649.

Blomfield, S. \& Marr, D. (1970). How the cerebellum may be used. Nature, 227, 12241228.

Boughter, J. D., Jr., Baird, J. P., Bryant, J., St John, S. J., \& Heck, D. (2007). C57BL/6J and DBA/2J mice vary in lick rate and ingestive microstructure. Genes Brain Behav., 6, 619-627.

Bowman, J. P. \& Aldes, L. D. (1980). Organization of the cerebellar tongue representation in the monkey. Exp.Brain Res., 39, 249-259.

Bradley, R. M., King, M. S., Wang, L., \& Shu, X. (1996). Neurotransmitter and neuromodulator activity in the gustatory zone of the nucleus tractus solitarius.

Chem.Senses, 21, 377-385.

Breslin, P. A. \& Spector, A. C. (2008). Mammalian taste perception. Curr.Biol., 18, R148-R155.

Browning, R. A., Turner, F. J., Simonton, R. L., \& Bundman, M. C. (1981). Effect of midbrain and pontine tegmental lesions on the maximal electroshock seizure pattern in rats. Epilepsia, 22, 583-594.

Brozeki, G., Zhuravin, I. A., Megirian, D., \& Bures, J. (1996). Localization of the central rhythm generator involved in spontaneous consummatory licking in rats: functional ablation and electrical brain stimulation studies. Proc.Natl.Acad.Sci.U.S.A, 93, 33253329.

Bryant, J. L., Roy, S., \& Heck, D. H. (2009). A technique for stereotaxic recordings of neuronal activity in awake, head-restrained mice. J.Neurosci.Methods, 178, 75-79.

Caputi, F., Spaziante, R., de Divitiis, E., \& Nashold, B. (1995). Luigi Rolando and his pioneering efforts to relate structure to function in the nervous system. J.Neurosurg., 83, 933-937.

Case-Smith, J., Cooper, P., \& Scala, V. (1989). Feeding efficiency of premature neonates. Am.J.Occup.Ther., 43, 245-250.

Caston, J., Vasseur, F., Stelz, T., Chianale, C., Haye-Bouchaud, N., \& Mariani, J. (1995). Differential roles of cerebellar cortex and deep cerebellar nuclei in the learning of the equilibrium behavior: studies in intact and cerebellectomized lurcher mutant mice. Brain Res.Dev.Brain Res., 86, 311-316. 
Caston, J., Lalonde, R., Haye-Bouchaud, N., \& Mariani, J. (1998). The cerebellum and postural sensorimotor learning in mice and rats. Behav.Brain Res., 95, 17-22.

Cazin, L., Precht, W., \& Lannou, J. (1980). Pathways mediating optokinetic responses of vestibular nucleus neurons in the rat. Pflügers Arch., 384, 19-29.

Chan-Palay, V. (1978). Autoradiographic localization of gamma-aminobutyric acid receptors in the rat central nervous system by using $[3 \mathrm{H}]$ muscimol.

Proc.Natl.Acad.Sci.U.S.A., 75, 1024-1028.

Chandra, D., Halonen, L., Linden, A., Procaccini, C., Hellsten, K., Homanics, G. (2009). Prototypic GABAA receptor agonist muscimol acts preferentially through forebrain highaffinity binding sites. Neuropsychopharmacology, 1-9.

Chen, Z., Travers, S. P., \& Travers, J. B. (2001). Muscimol infusions in the brain stem reticular formation reversibly block ingestion in the awake rat.

Am.J.Physiol.Regul.Integr.Comp.Physiol., 280, R1085-R1094.

Chen, Z. \& Travers, J. B. (2003). Inactivation of amino acid receptors in medullary reticular formation modulates and suppresses ingestion and rejection responses in the awake rat. Am.J.Physiol.Regul.Integr.Comp.Physiol., 285, R68-R83.

Cheron, G., Gall, D., Servais, L., Dan, B., Maex, R., \& Schiffmann, S. N. (2004). Inactivation of calcium-binding protein genes induces $160 \mathrm{~Hz}$ oscillations in the cerebellar cortex of alert mice. J.Neurosci., 24, 434-441.

Clark, S. (1938). Responses following electrical stimulation of the cerebellar cortex in the normal cat. J.Neurophysiol., 2, 19-35.

D'Agata, V., Drago, F., Serapide, F., \& Cicirata, F. (1993). Effects of cerebellectomy on motivation-related behavior: a time-course study. Physiol.Behav., 53, 173-176.

Dahhaoui, M., Caston, J., Auvray, N., \& Reber, A. (1990). Role of the cerebellum in an avoidance conditioning task in the rat. Physiol.Behav., 47, 1175-1180.

Davis, B. J. (1991). The ascending gustatory pathway: a Golgi analysis of the medial and lateral parabrachial complex in the adult hamster. Brain Res.Bull., 27, 63-73.

de Blas, A. L., Vitorica, J., \& Friedrich, P. (1988). Localization of the GABAA receptor in the rat brain with a monoclonal antibody to the $57,000 \mathrm{Mr}$. peptide of the GABAA receptor/benzodiazepine receptor/Cl- channel complex. J.Neurosci., 8, 602-614.

de Zeeuw, C. I., Ruigrok, T. J., Schalekamp, M. P., Boesten, A. J., \& Voogd, J. (1990). Ultrastructural study of the cat hypertrophic inferior olive following anterograde tracing, immunocytochemistry, and intracellular labeling. Eur.J.Morphol., 28, 240-255. 
de Zeeuw, C. I., Lang, E. J., Sugihara, I., Ruigrok, T. J., Eisenman, L. M., Mugnaini, E. (1996). Morphological correlates of bilateral synchrony in the rat cerebellar cortex. J.Neurosci., 16, 3412-3426.

de Zeeuw, C. I., Hoebeek, F. E., \& Schonewille, M. (2008). Causes and consequences of oscillations in the cerebellar cortex. Neuron, 58, 655-658.

Di Lorenzo, P. M., Platt, D., \& Victor, J. D. (2009). Information processing in the parabrachial nucleus of the pons. Ann.N.Y.Acad.Sci., 1170, 365-371.

Di Domenico, C., Villani, G. R., Di Napoli, D., Nusco, E., Cali, G., Nitsch, L. (2009). Intracranial gene delivery of LV-NAGLU vector corrects neuropathology in murine MPS IIIB. Am.J.Med.Genet.A, 149A, 1209-1218.

Dinardo, L. A. \& Travers, J. B. (1994). Hypoglossal neural activity during ingestion and rejection in the awake rat. J.Neurophysiol., 72, 1181-1191.

Dotson, C. D. \& Spector, A. C. (2005). Drinking spout orifice size affects licking behavior in inbred mice. Physiol.Behav., 85, 655-661.

Dresel, C., Castrop, F., Haslinger, B., Wohlschlaeger, A. M., Hennenlotter, A., \& Ceballos-Baumann, A. O. (2005). The functional neuroanatomy of coordinated orofacial movements: sparse sampling fMRI of whistling. Neuroimage., 28, 588-597.

Eccles, J.C, Ito, M, \& Szentágothai, J. (1967). The Cerebellum As a Neuronal Machine. Springer. Berlin, Heidelberg, New York: Springer-Verlag. p. 335.

Egan, G., Silk, T., Zamarripa, F, Williams, J., Federico, P., Cunnington, R., Carabott, L., Blair-West, J., Shade, R., McKinley, M., Farreell, M., Lancaster, J., Jackson, G., Fox, P., and Denton, D. (2003). Neural correlates of the emergence of consciousness of thirst. Proc.Natl.Acad.Sci., 100: 15241-15246.

Estanol, B., Romero, R., \& Corvera, J. (1979). Effects of cerebellectomy on eye movements in man. Arch.Neurol., 36, 281-284.

Eylam, S., Garcea, M., \& Spector, A. C. (2000). Glossopharyngeal nerve transection does not alter taste reactivity to sucrose conditioned to be aversive. Chem.Senses, 25, 423-428.

Federico, F., Leggio, M. G., Mandolesi, L., \& Petrosini, L. (2006). The NMDA receptor antagonist CGS 19755 disrupts recovery following cerebellar lesions.

Restor.Neurol.Neurosci., 24, 1-7.

Federico, F., Leggio, M. G., Neri, P., Mandolesi, L., \& Petrosini, L. (2006). NMDA receptor activity in learning spatial procedural strategies II. The influence of cerebellar lesions. Brain Res.Bull., 70, 356-367. 
Ferezoui, I., Haiss, F., Gentet, L. J., Aronoff, R., Weber, B., \& Petersen, C. C. (2007). Spatiotemporal dynamics of cortical sensorimotor integration in behaving mice. Neuron, 56, 907-923.

Fornal, C. A., Metzler, C. W., Marrosu, F., Ribiero-do-Valle, L. E., \& Jacobs, B. L. (1996). A subgroup of dorsal raphe serotonergic neurons in the cat is strongly activated during oral-buccal movements. Brain Res., 716, 123-133.

Fukazawa, T., Tsukishima, E., Sasaki, H., Hamada, T., and Tashiro, K. (1995) ErdheimChester disease and slowly progressive cerebellar dysfunction. J.Neurol.Neurosurg. Psychiatry, 58, 238-240.

Furuya, S., Irie, F., Hashikawa, T., Nakazawa, K., Kozakai, A., Hasegawa, A. (1994). Ganglioside GD1 alpha in cerebellar Purkinje cells. Its specific absence in mouse mutants with Purkinje cell abnormality and altered immunoreactivity in response to conjunctive stimuli causing long-term desensitization. J.Biol.Chem., 269, 32418-32425.

Gaillard, D., Laugerette, F., Darcel, N., El-Yassimi, A., Passilly-Degrace, P., Hichami, A. (2008). The gustatory pathway is involved in CD36-mediated orosensory perception of long-chain fatty acids in the mouse. FASEB J., 22, 1458-1468.

Galiana, H. L. \& Outerbridge, J. S. (1984). A bilateral model for central neural pathways in vestibuloocular reflex. J.Neurophysiol., 51, 210-241.

Gambarian, L. G., Tarnecki, R., \& Konorski, J. (1965). Effects of cerebellectomy on cortical action potentials evoked by stimulation of muscular nerves in cat.

Bull.Acad.Pol.Sci.Biol., 13, 373-376.

Genn, R. F., Higgs, S., \& Cooper, S. J. (2003). The effects of 7-OH-DPAT, quinpirole and raclopride on licking for sucrose solutions in the non-deprived rat.

Behav.Pharmacol., 14, 609-617.

Gilbert, P. F. \& Thach, W. T. (1977). Purkinje cell activity during motor learning. Brain Res., 128, 309-328.

Glendinning, J. I., Gresack, J., \& Spector, A. C. (2002). A high-throughput screening procedure for identifying mice with aberrant taste and oromotor function. Chem.Senses, 27, 461-474.

Glickstein, M., Sultan, F., \& Voogd, J. (2009). Functional localization in the cerebellum. Cortex. Advance online publication. doi: 10.1016/j.cortex.2009.09.001. PubMed PMCID: 19833328

Glickstein, M., Strata, P., \& Voogd, J. (2009). Cerebellum: history. Neuroscience, 162, 549-559. 
Godaux, E. \& Vanderkelen, B. (1984). Vestibulo-ocular reflex, optokinetic response and their interactions in the cerebellectomized cat. J.Physiol., 346, 155-170.

Goodkin, H. P. \& Thach, W. T. (2003). Cerebellar control of constrained and unconstrained movements. I. Nuclear inactivation. J.Neurophysiol., 89, 884-895.

Goossens, H. H., Hoebeek, F. E., van Alphen, A. M., Van Der, S. J., Stahl, J. S., de Zeeuw, C. I. (2004). Simple spike and complex spike activity of floccular Purkinje cells during the optokinetic reflex in mice lacking cerebellar long-term depression. Eur.J.Neurosci., 19, 687-697.

Goto, N., Yamamoto, T., Kaneko, M., \& Tomita, H. (1983). Primary pontine hemorrhage and gustatory disturbance: clinicoanatomic study. Stroke, 14, 507-511.

Grewe, B. F. \& Helmchen, F. (2009). Optical probing of neuronal ensemble activity. Curr.Opin.Neurobiol., 19, 520-529.

Grigson, P. S., Spector, A. C., \& Norgren, R. (1993). Microstructural analysis of successive negative contrast in free-feeding and deprived rats. Physiol.Behav., 54, 909916.

Groth, J. D. \& Sahin, M. (2009). Signal characteristics of cerebellar activity recorded with 2D micro-electrode arrays. Conf.Proc.IEEE Eng Med.Biol.Soc., 1, 2937-2939.

Habas, C., Axelrad, H., \& Cabanis, E. A. (2004). The cerebellar second homunculus remains silent during passive bimanual movements. Neuroreport, 15, 1571-1574.

Hanamori, T. \& Ishiko, N. (1987). Response properties of cerebellar neurons to stimulation of the frog glossopharyngeal nerve and tongue. Brain Res.Bull., 18, 491-499.

Hashimoto, N., Katayama, T., Ishiwata, Y., \& Nakamura, Y. (1989). Induction of rhythmic jaw movements by stimulation of the mesencephalic reticular formation in the guinea pig. J.Neurosci., 9, 2887-2901.

Hayar, A., Bryant, J. L., Boughter, J. D., \& Heck, D. H. (2006). A low-cost solution to measure mouse licking in an electrophysiological setup with a standard analog-to-digital converter. J.Neurosci.Methods, 153, 203-207.

Heck, D. \& Sultan, F. (2002). Cerebellar structure and function: making sense of parallel fibers. Hum.Mov Sci., 21, 411-421.

Heck, D., Kummell, F., Thach, W. T., \& Aertsen, A. (2002). Dynamic correlation of neuronal activity in rat cerebellar cortex modulated by behavior. Ann.N.Y.Acad.Sci., 978, 156-163. 
Heck, D. H., Thach, W. T., \& Keating, J. G. (2007). On-beam synchrony in the cerebellum as the mechanism for the timing and coordination of movement.

Proc.Natl.Acad.Sci.U.S.A, 104, 7658-7663.

Heck, D. H., Roy, S., Xie, N., \& Waters, R. S. (2008). Prenatal alcohol exposure delays acquisition and use of skilled reaching movements in juvenile rats. Physiol.Behav., 94, $540-544$.

Heck, D. H., Zhao, Y., Roy, S., Ledoux, M. S., \& Reiter, L. T. (2008). Analysis of cerebellar function in Ube3a-deficient mice reveals novel genotype-specific behaviors. Hum.Mol.Genet., 17, 2181-2189.

Heckmann, J. G. \& Lang, C. J. (2006). Neurological causes of taste disorders. Adv.Otorhinolaryngol., 63, 255-264.

Higgins, D. C. (1987). The cerebellum and initiation of movement: the stretch reflex. Yale J.Biol.Med., 60, 123-131.

Hilber, P., Jouen, F., Haye-Bouchaud, N., Mariani, J., \& Caston, J. (1998). Differential roles of cerebellar cortex and deep cerebellar nuclei in learning and retention of a spatial task: studies in intact and cerebellectomized lurcher mutant mice. Behav.Genet., 28, 299308.

Hill, D. L. \& Almli, C. R. (1983). Parabrachial nuclei damage in infant rats produces residual deficits in gustatory preferences/aversions and sodium appetite. Dev.Psychobiol., 16, 519-533.

Hill, J. \& Stellar, E. (1951). An electronic drinkometer. Science, 114, 43-44.

Hirai, H., Pang, Z., Bao, D., Miyazaki, T., Li, L., Miura, E. (2005). Cbln1 is essential for synaptic integrity and plasticity in the cerebellum. Nat.Neurosci., 8, 1534-1541.

Horowitz, G. P., Whitney, G., Smith, J. C., \& Stephan, F. K. (1977). Morphine ingestion: genetic control in mice. Psychopharmacology (Berl), 52, 119-122.

Horowitz, G. P., Stephan, F. K., Smith, J. C., \& Whitney, G. (1977). Genetic and environmental variability in lick rates of mice. Physiol Behav., 19, 493-496.

Horowski, R. (1978). A new method for automatic registration of stereotyped behaviour in the rat. Arzneimittelforschung., 28, 2281-2286.

Hsiao, S. \& Spencer, R. (1983). Analysis of licking responses in rats: effects of cholecystokinin and bombesin. Behav.Neurosci., 97, 234-245. 
Iacovitti, L., Reis, D. J., \& Joh, T. H. (1981). Reactive proliferation of brain stem noradrenergic nerves following neonatal cerebellectomy in rats: role of target maturation on neuronal response to injury during development. Brain Res., 227, 3-24.

Ikeda, Y., Tanaka, H., \& Esaki, M. (2008). Effects of gestational diethylstilbestrol treatment on male and female gonads during early embryonic development. Endocrinology, 149, 3970-3979.

Ito, M. (1972). Neural design of the cerebellar motor control system. Brain Res., 40, 8184.

Ito, M. (2009). Functional roles of neuropeptides in cerebellar circuits. Neuroscience, $162,666-672$.

Kandel, E., Schwartz, J., \& Jessell, T. (2000a). Organization of Movement, In Principles of Neural Science (4th ed.). New York: McGraw-Hill. pp. 653-673.

Kandel, E., Schwartz, J., \& Jessell, T. (2000b). Smell and Taste: The Chemical Senses. In J.Butler \& H. Lebowitz (Eds.), In Principles of Neural Science (4th ed.) New York: McGraw-Hill. pp. 625-647.

Katakura, N., Jia, L., \& Nakamura, Y. (1995). NMDA-induced rhythmical activity in XII nerve of isolated CNS from newborn rats. Neuroreport, 6, 601-604.

Kavety, B., Jenkins, N. A., Fletcher, C. F., Copeland, N. G., \& Morgan, J. I. (1994). Genomic structure and mapping of precerebellin and a precerebellin-related gene. Brain Res.Mol.Brain Res., 27, 152-156.

Kavety, B. \& Morgan, J. I. (1998). Characterization of transcript processing of the gene encoding precerebellin-1. Brain Res.Mol.Brain Res., 63, 98-104.

Kelley, A. E., Lang, C. G., \& Gauthier, A. M. (1988). Induction of oral stereotypy following amphetamine microinjection into a discrete subregion of the striatum. Psychopharmacology (Berl), 95, 556-559.

Kelly, T. M., Zuo, C. C., \& Bloedel, J. R. (1990). Classical conditioning of the eyeblink reflex in the decerebrate-decerebellate rabbit. Behav.Brain Res., 38, 7-18.

Kobayashi, M., Masuda, Y., Fujimoto, Y., Matsuya, T., Yamamura, K., Yamada, Y. (2002). Electrophysiological analysis of rhythmic jaw movements in the freely moving mouse. Physiol Behav., 75, 377-385.

Lalonde, R. \& Strazielle, C. (2007). Spontaneous and induced mouse mutations with cerebellar dysfunctions: behavior and neurochemistry. Brain Res., 1140, 51-74. 
Lang, E. J., Sugihara, I., Welsh, J. P., \& Llinas, R. (1999). Patterns of spontaneous Purkinje cell complex spike activity in the awake rat. J.Neurosci., 19, 2728-2739.

Lazar, W. (2009). Anglo-American interest in cerebral physiology. J.Hist.Neurosci., 18, 304-311.

Ledoux, M. S., Lorden, J. F., \& Ervin, J. M. (1993). Cerebellectomy eliminates the motor syndrome of the genetically dystonic rat. Exp.Neurol., 120, 302-310.

Ledoux, M. S., Lorden, J. F., \& Meinzen-Derr, J. (1995). Selective elimination of cerebellar output in the genetically dystonic rat. Brain Res., 697, 91-103.

Ledoux, M. S., Hurst, D. C., \& Lorden, J. F. (1998). Single-unit activity of cerebellar nuclear cells in the awake genetically dystonic rat. Neuroscience, 86, 533-545.

Leergaard, T. B., Lyngstad, K. A., Thompson, J. H., Taeymans, S., Vos, B. P., De Schutter, E. (2000). Rat somatosensory cerebropontocerebellar pathways: spatial relationships of the somatotopic map of the primary somatosensory cortex are preserved in a three-dimensional clustered pontine map. J.Comp Neurol., 422, 246-266.

Lewis, S. R., Ahmed, S., Dym, C., Khaimova, E., Kest, B., \& Bodnar, R. J. (2005). Inbred mouse strain survey of sucrose intake. Physiol.Behav., 85, 546-556.

Leznik, E., Makarenko, V.; \& Llinas, R. (2002). Electrotonically mediated oscillatory patterns in neuronal ensembles: an in vitro voltage-dependent dye-imaging study in the inferior olive. J.Neurosci., 22, 2804-2815.

Lindsay, K. W. \& Rosenberg, J. R. (1977). The effect of cerebellectomy on tonic labyrinth reflexes in the forelimb of the decerebrate cat [proceedings]. J.Physiol., 273, 76-77.

Llinas, R. (2009). Inferior olive oscillation as the temporal basis for motricity and oscillatory reset as the basis for motor error correction. Neuroscience. 162, 797-804.

Llinas, R., Lang, E. J., Welsh, J. P., \& Makarenko, V. I. (1997). A new approach to the analysis of multidimensional neuronal activity: Markov random fields. Neural Netw., 10, 785-789.

Llinas, R., Lang, E. J., \& Welsh, J. P. (1997). The cerebellum, LTD, and memory: alternative views. Learn.Mem., 3, 445-455.

Logan, K. \& Robertson, L. T. (1986). Somatosensory representation of the cerebellar climbing fiber system in the rat. Brain Res., 372, 290-300.

Lovell, K. L., Bruner, C. A., \& Moore, K. E. (1982). Lack of effect of cerebellectomy on ascending dopaminergic neurons in the rat brain. Neurosci.Lett., 32, 187-192. 
Lutherer, L. O., Lutherer, B. C., Dormer, K. J., Janssen, H. F., \& Barnes, C. D. (1983). Bilateral lesions of the fastigial nucleus prevent the recovery of blood pressure following hypotension induced by hemorrhage or administration of endotoxin. Brain Res., 269, 251-257.

Mandal, R. \& Anderson, C. W. (2009). Anatomical organization of brainstem circuits mediating feeding motor programs in the marine toad, Bufo marinus. Brain Res., 1298, 99-110.

Manni, E. \& Dow, R.S. (1963). Some observations on the effects of cerebellectomy in the rat. J. Comp Neurol. 121, 189-194.

Marchetti, E., Gauthier, G. M., \& Pellet, J. (1983). Cerebellar control of eye movements studied with injection of harmaline in the trained baboon. Arch.Ital.Biol., 121, 1-17.

Marr, D. (1969). A theory of cerebellar cortex. J.Physiol., 202, 437-470.

Martin, J. H., Cooper, S. E., Hacking, A., \& Ghez, C. (2000). Differential effects of deep cerebellar nuclei inactivation on reaching and adaptive control. J.Neurophysiol., 83, 1886-1899.

Mazzocchi, G., Andreis, P. G., De Caro, R., Aragona, F., Gottardo, L., \& Nussdorfer, G. G. (1999). Cerebellin enhances in vitro secretory activity of human adrenal gland. J.Clin.Endocrinol.Metab, 84, 632-635.

Meinecke, D. L., Tallman, J., \& Rakic, P. (1989). GABAA/benzodiazepine receptor-like immunoreactivity in rat and monkey cerebellum. Brain Res., 493, 303-319.

Miura, E., Matsuda, K., Morgan, J. I., Yuzaki, M., \& Watanabe, M. (2009). Cbln1 accumulates and colocalizes with Cbln3 and GluRdelta2 at parallel fiber-Purkinje cell synapses in the mouse cerebellum. Eur.J.Neurosci., 29, 693-706.

Mizuno, Y., Takahashi, K., Totsune, K., Ohneda, M., Konno, H., Murakami, O. (1995). Decrease in cerebellin and corticotropin-releasing hormone in the cerebellum of olivopontocerebellar atrophy and Shy-Drager syndrome. Brain Res., 686, 115-118.

Montarolo, P. G., Palestini, M., \& Strata, P. (1982). The inhibitory effect of the olivocerebellar input on the cerebellar Purkinje cells in the rat. J.Physiol, 332, 187-202.

Morabito, C. (2000). Luigi Luciani and the localization of brain functions: Italian research within the context of European neurophysiology at the end of the nineteenth century. J.Hist.Neurosci., 9, 180-200.

Morgan, J. I., Slemmon, J. R., Danho, W., Hempstead, J., Berrebi, A. S., \& Mugnaini, E. (1988). Cerebellin and related postsynaptic peptides in the brain of normal and neurodevelopmentally mutant vertebrates. Synapse, 2, 117-124. 
Mouginot, D. \& Gahwiler, B. H. (1995). Characterization of synaptic connections between cortex and deep nuclei of the rat cerebellum in vitro. Neuroscience, 64, 699-712.

Mugnaini, E., Berrebi, A. S., Dahl, A. L., \& Morgan, J. I. (1987). The polypeptide PEP19 is a marker for Purkinje neurons in cerebellar cortex and cartwheel neurons in the dorsal cochlear nucleus. Arch.Ital.Biol., 126, 41-67.

Mugnaini, E. \& Morgan, J. I. (1987). The neuropeptide cerebellin is a marker for two similar neuronal circuits in rat brain. Proc.Natl.Acad.Sci.U.S.A, 84, 8692-8696.

Mugnaini, E., Dahl, A. L., \& Morgan, J. I. (1988). Cerebellin is a postsynaptic neuropeptide. Synapse, 2, 125-138.

Nakamura, Y. \& Katakura, N. (1995). Generation of masticatory rhythm in the brainstem. Neurosci.Res., 23, 1-19.

Nakamura, Y., Katakura, N., \& Nakajima, M. (1999). Generation of rhythmical ingestive activities of the trigeminal, facial, and hypoglossal motoneurons in in vitro CNS preparations isolated from rats and mice. J.Med.Dent.Sci., 46, 63-73.

Nakamura, Y., Katakura, N., Nakajima, M., \& Liu, J. (2004). Rhythm generation for food-ingestive movements. Prog.Brain Res., 143, 97-103.

National Research Council (1996). Guide for the Care and Use of Laboratory Animals. National Academies Press.

Nishizawa, O., Ebina, K., Sugaya, K., Noto, H., Satoh, K., Kohama, T. (1989). Effect of cerebellectomy on reflex mictrurition in the decerebrate dog as determined by urodynamic evaluation. Urol.Int., 44, 152-156.

Nistri, A., Ostroumov, K., Sharifullina, E., \& Taccola, G. (2006). Tuning and playing a motor rhythm: how metabotropic glutamate receptors orchestrate generation of motor patterns in the mammalian central nervous system. J.Physiol, 572, 323-334.

Ohishi, H., Ichikawa, J., Matsuzaki, R., Kyuhou, S., Matsuura-Nakao, K., Seki, T. (2003). Cortical field potentials preceding self-paced forelimb movements and influences of cerebellectomy upon them in rats. Neurosci.Lett., 352, 5-8.

Okayasu, I., Yamada, Y., Kohno, S., \& Yoshida, N. (2003). New animal model for studying mastication in oral motor disorders. J.Dent.Res., 82, 318-321.

Optican, L. M. \& Robinson, D. A. (1980). Cerebellar-dependent adaptive control of primate saccadic system. J.Neurophysiol., 44, 1058-1076.

Ott, J., Wheaton, P. S., \& Chilton, W. S. (1975). Fate of muscimol in the mouse. Physiol Chem.Phys., 7, 381-384. 
Pang, Z., Zuo, J., \& Morgan, J. I. (2000). Cbln3, a novel member of the precerebellin family that binds specifically to Cbln1. J.Neurosci., 20, 6333-6339.

Parker, K. L., Zbarska, S., Carrel, A. J., \& Bracha, V. (2009). Blocking GABAA neurotransmission in the interposed nuclei: effects on conditioned and unconditioned eyeblinks. Brain Res., 1292, 25-37.

Pastor, A. M., de la Cruz, R. R., \& Baker, R. (1994). Cerebellar role in adaptation of the goldfish vestibuloocular reflex. J.Neurophysiol., 72, 1383-1394.

Paul, D. H. \& Roberts, B. L. (1984). The activity of cerebellar neurones of the decerebrate dogfish Scyliorhinus during spontaneous swimming movements. J.Physiol, 352, 1-16.

Paz, C., Reygadas, E., \& Fernandez-Guardiola, A. (1982). Sleep alterations following total cerebellectomy in cats. Sleep, 5, 218-226.

Paz, C., Reygadas, E., \& Fernandez-Guardiola, A. (1985). Amygdala kindling in totally cerebellectomized cats. Exp.Neurol., 88, 418-424.

Precht, W. \& Anderson, J. H. (1979). Effects of cerebellectomy on the cat's vertical vestibuloocular reflex. Pflugers Arch., 382, 51-55.

Ramon y Cajal, S. (1989). Recollections of My Life. Cambridge: MIT Press.

Rasmussen, A., Jirenhed, D. A., \& Hesslow, G. (2008). Simple and complex spike firing patterns in Purkinje cells during classical conditioning. Cerebellum., 7, 563-566.

Rijntjes, M., Buechel, C., Kiebel, S., \& Weiller, C. (1999). Multiple somatotopic representations in the human cerebellum. Neuroreport, 10, 3653-3658.

Roberts, B. L., van Rossem, A., \& de Jager, S. (1992). The influence of cerebellar lesions on the swimming performance of the trout. J.Exp.Biol., 167, 171-178.

Robertson, L. T. (1985). Somatosensory representation of the climbing fiber system in the rostral intermediate cerebellum. Exp.Brain Res., 61, 73-86.

Rotter, A. \& Frostholm, A. (1986). Cerebellar benzodiazepine receptor distribution: an autoradiographic study of the normal C57BL/6J and Purkinje cell degeneration mutant mouse. Neurosci.Lett., 71, 66-71.

Rotter, A. \& Frostholm, A. (1988). Cerebellar benzodiazepine receptors: cellular localization and consequences of neurological mutations in mice. Brain Res., 444, 133 146. 
Rotter, A., Gorenstein, C., \& Frostholm, A. (1988). The localization of GABAA receptors in mice with mutations affecting the structure and connectivity of the cerebellum. Brain Res., 439, 236-248.

Rowland, N. C. \& Jaeger, D. (2005). Coding of tactile response properties in the rat deep cerebellar nuclei. J.Neurophysiol., 94, 1236-1251.

Rucinski, M., Albertin, G., Spinazzi, R., Ziolkowska, A., Nussdorfer, G. G., \& Malendowicz, L. K. (2005). Cerebellin in the rat adrenal gland: gene expression and effects of CER and [des-Ser1]CER on the secretion and growth of cultured adrenocortical cells. Int.J.Mol.Med., 15, 411-415.

Rucinski, M., Zok, A., Guidolin, D., De Caro, R., \& Malendowicz, L. K. (2008). Expression of precerebellins in cultured rat calvaria osteoblast-like cells. Int.J.Mol.Med., 22, 553-558.

Rucinski, M. \& Malendowicz, L. K. (2009). Precerebellin-related genes and precerebellin 1 peptide in endocrine glands of the rat - pattern of their expression. Int.J.Mol.Med., 23, 113-119.

Rucinski, M., Ziolkowska, A., Szyszka, M., \& Malendowicz, L. K. (2009). Cerebellin and des-cerebellin exert ACTH-like effects on corticosterone secretion and the intracellular signaling pathway gene expression in cultured rat adrenocortical cells--DNA microarray and QPCR studies. Int.J.Mol.Med., 23, 539-546.

Rucinski, M., Ziolkowska, A., Szyszka, M., \& Malendowicz, L. K. (2009). Precerebellinrelated genes and precerebellin 1 peptide in the adrenal gland of the rat: expression pattern, localization, developmental regulation and effects on corticosteroidogenesis. Int.J.Mol.Med., 23, 363-371.

Saito, K., Barber, R., Wu, J., Matsuda, T., Roberts, E., \& Vaughn, J. E. (1974). Immunohistochemical localization of glutamate decarboxylase in rat cerebellum. Proc.Natl.Acad.Sci.U.S.A, 71, 269-273.

Sakamoto, T. \& Endo, S. (2008). GABAA receptors in deep cerebellar nuclei play important roles in mouse eyeblink conditioning. Brain Res., 1230, 125-137.

Sasaki, K., Kawaguchi, S., Oka, H., Sakai, M., \& Mizuno, N. (1976).

Electrophysiological studies on the cerebellocerebral projections in monkeys. Exp.Brain Res., 24, 495-507.

Satoh, F., Takahashi, K., Murakami, O., Totsune, K., Ohneda, M., Mizuno, Y. (1997). Cerebellin and cerebellin mRNA in the human brain, adrenal glands and the tumour tissues of adrenal tumour, ganglioneuroblastoma and neuroblastoma. J.Endocrinol., 154, 27-34. 
Satora, L., Pach, D., Ciszowski, K., \& Winnik, L. (2006). Panther cap Amanita pantherina poisoning case report and review. Toxicon, 47, 605-607.

Sawczuk, A. \& Mosier, K. M. (2001). Neural control of tongue movement with respect to respiration and swallowing. Crit Rev.Oral Biol.Med., 12, 18-37.

Schieppati, M. \& Ducati, A. (1981). Effects of stimulus intensity, cervical cord tractotomies and cerebellectomy on somatosensory evoked potentials from skin and muscle afferents of cat hind limb. Electroencephalogr.Clin.Neurophysiol., 51, 363-372.

Schmahmann, J. D. \& Sherman, J. C. (1997). Cerebellar cognitive affective syndrome. Int.Rev.Neurobiol., 41, 433-440.

Schmahmann, J. D. \& Sherman, J. C. (1998). The cerebellar cognitive affective syndrome. Brain, 121 ( Pt 4), 561-579.

Schmahmann, J. D., Weilburg, J. B., \& Sherman, J. C. (2007). The neuropsychiatry of the cerebellum - insights from the clinic. Cerebellum., 6, 254-267.

Schonewille, M., Khosrovani, S., Winkelman, B. H., Hoebeek, F. E., De Jeu, M. T., Larsen, I. M. (2006). Purkinje cells in awake behaving animals operate at the upstate membrane potential. Nat.Neurosci., 9, 459-461.

Schonewille, M., Luo, C., Ruigrok, T. J., Voogd, J., Schmolesky, M. T., Rutteman, M. (2006). Zonal organization of the mouse flocculus: physiology, input, and output. J.Comp Neurol., 497, 670-682.

Segal, J. P., Stallings, N. R., Lee, C. E., Zhao, L., Socci, N., Viale, A. (2005). Use of laser-capture microdissection for the identification of marker genes for the ventromedial hypothalamic nucleus. J.Neurosci., 25, 4181-4188.

Seiger, A., Sorensen, S. M., \& Palmer, M. R. (1983). Cerebellar role in the differential ethanol sensitivity of long sleep and short sleep mice. Pharmacol.Biochem.Behav., 18 Suppl 1, 495-499.

Semba, K. \& Komisaruk, B. R. (1984). Neural substrates of two different rhythmical vibrissal movements in the rat. Neuroscience, 12, 761-774.

Slemmon, J. R., Blacher, R., Danho, W., Hempstead, J. L., \& Morgan, J. I. (1984). Isolation and sequencing of two cerebellum-specific peptides. Proc.Natl.Acad.Sci.U.S.A, 81, 6866-6870.

Slemmon, J. R., Danho, W., Hempstead, J. L., \& Morgan, J. I. (1985). Cerebellin: a quantifiable marker for Purkinje cell maturation. Proc.Natl.Acad.Sci.U.S.A, 82, 71457148. 
Slemmon, J. R., Goldowitz, D., Blacher, R., \& Morgan, J. I. (1988). Evidence for the transneuronal regulation of cerebellin biosynthesis in developing Purkinje cells.

J.Neurosci., 8, 4603-4611.

Small, D. M. (2006). Central gustatory processing in humans. Adv.Otorhinolaryngol., 63, 191-220.

Smith, B. K., Volaufova, J., \& West, D. B. (2001). Increased flavor preference and lick activity for sucrose and corn oil in SWR/J vs. AKR/J mice. Am.J.Physiol Regul.Integr.Comp Physiol, 281, R596-R606.

Smith, G. P. (2000). The controls of eating: a shift from nutritional homeostasis to behavioral neuroscience. Nutrition, 16, 814-820.

Somogyi, P., Takagi, H., Richards, J. G., \& Mohler, H. (1989). Subcellular localization of benzodiazepine/GABAA receptors in the cerebellum of rat, cat, and monkey using monoclonal antibodies. J.Neurosci., 9, 2197-2209.

Speck, D. F. \& Webber, C. L., Jr. (1982). Cerebellar influence on the termination of inspiration by intercostal nerve stimulation. Respir.Physiol, 47, 231-238.

Spector, A. C. (1995). Gustatory parabrachial lesions disrupt taste-guided quinine responsiveness in rats. Behav.Neurosci., 109, 79-90.

Spector, A. C. (1995). Gustatory function in the parabrachial nuclei: implications from lesion studies in rats. Rev.Neurosci., 6, 143-175.

Spector, A. C., Scalera, G., Grill, H. J., \& Norgren, R. (1995). Gustatory detection thresholds after parabrachial nuclei lesions in rats. Behav.Neurosci., 109, 939-954.

Spector, A. C. \& St John, S. J. (1998). Role of taste in the microstructure of quinine ingestion by rats. Am.J.Physiol, 274, R1687-R1703.

Spector, A. C. (2000). Linking gustatory neurobiology to behavior in vertebrates. Neurosci.Biobehav.Rev., 24, 391-416.

Spector, A. C. \& Travers, S. P. (2005). The representation of taste quality in the mammalian nervous system. Behav.Cogn Neurosci.Rev., 4, 143-191.

Spector, A. C. \& Glendinning, J. I. (2009). Linking peripheral taste processes to behavior. Curr.Opin.Neurobiol., 19, 370-377.

Spencer, R. L., Deupree, D., Hsiao, S., Mosberg, H. I., Hruby, V., Burks, T. F. (1986). Centrally-administered opioid selective agonists inhibit drinking in the rat.

Pharmacol.Biochem.Behav., 25, 77-82. 
Stasi, K., Mitsacos, A., Triarhou, L. C., \& Kouvelas, E. D. (1997). Cerebellar grafts partially reverse amino acid receptor changes observed in the cerebellum of mice with hereditary ataxia: quantitative autoradiographic studies. Cell Transplant., 6, 347-359.

Straube, A., Helmchen, C., Robinson, F., Fuchs, A., \& Buttner, U. (1994). Saccadic dysmetria is similar in patients with a lateral medullary lesion and in monkeys with a lesion of the deep cerebellar nucleus. J.Vestib.Res., 4, 327-333.

Strazielle, C. \& Lalonde, R. (1998). Grooming in Lurcher mutant mice. Physiol Behav., 64, 57-61.

Szentágothai, J. \& Rajkovits, K. (1955). Effect of specific neural function on structure of neural elements. Acta Morphol.Acad.Sci.Hung., 5, 253-274.

Szentágothai, J. \& Rajkovits, K. (1958). The cerebral nervous portion of the pyramidal tract \& the pre-motor apparatus of the brain nerve motor nuclei.

Arch.Psychiatr.Nervenkr.Z.Gesamte Neurol.Psychiatr., 197, 335-354.

Takahashi, N., Sasaki, T., Usami, A., Matsuki, N., \& Ikegaya, Y. (2007). Watching neuronal circuit dynamics through functional multineuron calcium imaging (fMCI). Neurosci.Res., 58, 219-225.

Tang, C., Mittler, T., Duke, D. C., Zhu, Y., Pawlak, A. P., \& West, M. O. (2008). Doseand rate-dependent effects of cocaine on striatal firing related to licking. J.Pharmacol.Exp.Ther., 324, 701-713.

Ten-Donkelaar, H. J. \& De Boer-Van, H. R. (1981). Ascending projections of the brain stem reticular formation in a nonmammalian vertebrate (the lizard Varanus exanthematicus), with notes on the afferent connections of the forebrain. J.Comp Neurol., 200, 501-528.

Thach, W. T. (1967). Somatosensory receptive fields of single units in cat cerebellar cortex. J.Neurophysiol., 30, 675-696.

Thach, W. T. (1968). Discharge of Purkinje and cerebellar nuclear neurons during rapidly alternating arm movements in the monkey. J.Neurophysiol., 31, 785-797.

Thach, W. T. (1970). Discharge of cerebellar neurons related to two maintained postures and two prompt movements. II. Purkinje cell output and input. J.Neurophysiol., 33, 537547.

Thach, W. T. (1972). Cerebellar output: properties, synthesis and uses. Brain Res., 40, 89-102.

Thach, W. T. (1975). Timing of activity in cerebellar dentate nucleus and cerebral motor cortex during prompt volitional movement. Brain Res., 88, 233-241. 
Thach, W. T. (1978). Correlation of neural discharge with pattern and force of muscular activity, joint position, and direction of intended next movement in motor cortex and cerebellum. J.Neurophysiol., 41, 654-676.

Thach, W. T. \& Jones, E. G. (1979). The cerebellar dentatothalamic connection: terminal field, lamellae, rods and somatotopy. Brain Res., 169, 168-172.

Thach, W. T., Schieber, M. H., Mink, J., Kane, S., \& Horne, M. (1986). Cerebellar relation to muscle spindles in hand tracking. Prog.Brain Res., 64, 217-224.

Thach, W. T. (1987). Cerebellar inputs to motor cortex. Ciba Found.Symp., 132, 201220.

Thach, W. T., Goodkin, H. P., \& Keating, J. G. (1992). The cerebellum and the adaptive coordination of movement. Annu.Rev.Neurosci., 15, 403-442.

Thach, W. T., Perry, J. G., Kane, S. A., \& Goodkin, H. P. (1993). Cerebellar nuclei: rapid alternating movement, motor somatotopy, and a mechanism for the control of muscle synergy. Rev.Neurol.(Paris), 149, 607-628.

Thach, W. T. (1998). A role for the cerebellum in learning movement coordination. Neurobiol.Learn.Mem., 70, 177-188.

Thach, W. T. \& Bastian, A. J. (2004). Role of the cerebellum in the control and adaptation of gait in health and disease. Prog.Brain Res., 143, 353-366.

Thach, W. T. (2007). On the mechanism of cerebellar contributions to cognition. Cerebellum, 6, 163-167.

Tocris Bioscience. (7-1-2009). Muscimol hydrate 98+\% Material Safety Data Sheet. [0289]. Ellisville, MO, Tocris Bioscience. Ref Type: Catalog

Tolbert, D. L. (1989). Somatotopically organized transient projections from the primary somatosensory cortex to the cerebellar cortex. Brain Res.Dev.Brain Res., 45, 113-127.

Tomiyama, K., Makihara, Y., Inoue, M., Oka, J. I., Waddington, J., \& Koshikawa, N. (2004). A comparative study of D1-like dopamine receptor agonists and transduction mechanisms on orofacial movements of mice. Journal of Pharmacological Sciences, 94, $294 \mathrm{P}$.

Travers, J. B. \& Jackson, L. M. (1992). Hypoglossal neural activity during licking and swallowing in the awake rat. J.Neurophysiol., 67, 1171-1184.

Travers, J. B., Dinardo, L. A., \& Karimnamazi, H. (1997). Motor and premotor mechanisms of licking. Neurosci.Biobehav.Rev., 21, 631-647. 
Travers, J. B., Dinardo, L. A., \& Karimnamazi, H. (2000). Medullary reticular formation activity during ingestion and rejection in the awake rat. Exp.Brain Res., 130, 78-92.

Travers, J. B. \& Rinaman, L. (2002). Identification of lingual motor control circuits using two strains of pseudorabies virus. Neuroscience, 115, 1139-1151.

Travers, J. B. (2006). Organization and expression of reward in the rodent orbitofrontal cortex. Focus on "orbitofrontal ensemble activity monitors licking and distinguishes among natural rewards". J.Neurophysiol., 95, 14-15.

Upton, A. R. \& Cooper, I. S. (1976). Some neurophysiological effects of cerebellar stimulation in man. Can.J.Neurol.Sci., 3, 237-254.

Uusisaari, M. \& Knopfel, T. (2008). GABAergic synaptic communication in the GABAergic and non-GABAergic cells in the deep cerebellar nuclei. Neuroscience, 156, 537-549.

Vajnerova, O., Zhuravin, I. A., \& Brozek, G. (2000). Functional ablation of deep cerebellar nuclei temporarily impairs learned coordination of forepaw and tongue movements. Behav.Brain Res., 108, 189-195.

Vajnerova, O., Bielavska, E., Jiruska, P., \& Brozek, G. (2003). Level of vigilance influences licking frequency in rats. Physiol Res., 52, 243-249.

Venugopal, S., Travers, J. B., \& Terman, D. H. (2007). A computational model for motor pattern switching between taste-induced ingestion and rejection oromotor behaviors. J.Comput.Neurosci., 22, 223-238.

Wei, P., Smeyne, R. J., Bao, D., Parris, J., \& Morgan, J. I. (2007). Mapping of Cbln1-like immunoreactivity in adult and developing mouse brain and its localization to the endolysosomal compartment of neurons. Eur.J.Neurosci., 26, 2962-2978.

Wei, P., Rong, Y., Li, L., Bao, D., \& Morgan, J. I. (2009). Characterization of transneuronal trafficking of Cbln1. Mol.Cell Neurosci., 41, 258-273.

Weijnen, J. A. (1998). Licking behavior in the rat: measurement and situational control of licking frequency. Neurosci.Biobehav.Rev., 22, 751-760.

Welsh, J. P., Lang, E. J., Sugihara, I., \& Llinas, R. (1995). Dynamic organization of motor control within the olivocerebellar system. Nature, 374, 453-457.

Welsh, J. P. (1998). Systemic harmaline blocks associative and motor learning by the actions of the inferior olive. Eur.J.Neurosci., 10, 3307-3320.

Williams, J. L., Robinson, P. J., \& Lutherer, L. O. (1986). Inhibitory effects of cerebellar lesions on respiration in the spontaneously breathing, anesthetized cat. Brain Res., 399, 224-231. 
Wong, R. O. (1998). Calcium imaging and multielectrode recordings of global patterns of activity in the developing nervous system. Histochem.J., 30, 217-229.

Xerri, C., Manzoni, D., \& Pompeiano, O. (1981). Effects of cerebellectomy on responses of lateral reticular neurons to sinusoidal tilt after ipsilateral labyrinthectomy. Arch.Ital.Biol., 119, 255-277.

Yeo, C. H., Lobo, D. H., \& Baum, A. (1997). Acquisition of a new-latency conditioned nictitating membrane response--major, but not complete, dependence on the ipsilateral cerebellum. Learn.Mem., 3, 557-577.

Yildrim, F. \& Sarikcioglu, L. (2007). Marie Jean Pierre Flourens (1794-1867): an extraordinary scientist of his time. J.Neurol.Neurosurg.Psychiatr., 78, 852.

Zhang, H. \& Stanford, J. A. (2008). Acute and rebound effects of lorazepam on orolingual motor function in young versus aged Fischer 344/Brown Norway rats. Behav.Pharmacol., 19, 161-165.

Zhuravin, I. A., Brozek, G., \& Bures, J. (1994). Differential contribution of motor cortex and caudate nucleus to instrumental tongue-forelimb synchronization in rats: a functional ablation study. Neuroscience, 58, 193-200.

Zion, C., Auvray, N., Caston, J., Reber, A., \& Stelz, T. (1990). Effects of cerebellectomy at day 15 on the ontogenesis of the equilibrium behavior in the rat. Brain Res., 515, 104110. 


\section{VITA}

Ms. Jerí Bryant was born on October 20, 1982 in Greenville, SC. In 1996, she matriculated to the Greenville County Magnate School for International Studies, Southside High School. She graduated as valedictorian and as a recipient of an International Baccalaureate diploma in June 2000. In August 2000, she began her undergraduate education at Wake Forest University in Winston-Salem, NC. Upon completing her bachelors of Science degree in biology with a minor in neuroscience in May 2004, she moved to Memphis, Tennessee to pursue a doctorate of philosophy as a member of the inaugural class of the Integrated Program in Biomedical Science and as the initial recipient of the University of Tennessee Alumni scholarship in honor of Edsel T. Bucovasz, Ph.D. 